\title{
Solid Phase Epitaxial Regrowth of alkali ion irradiated $\alpha$-quartz
}

\author{
Dissertation \\ zur Erlangung des Doktorgrades \\ der Mathematisch-Naturwissenschaftlichen Fakultäten \\ der Georg-August-Universität zu Göttingen
}

vorgelegt von

Stanisława Ga̧siorek

aus Krakau/Polen

Göttingen 2003 
D7

Referent:

Prof. Dr. K. P. Lieb

Korreferent:

Prof Dr. J. Styczeń

Tag der mündlichen Prüfung: 19.01.2004 


\section{Contents}

1 Summary 5

2 Introduction 7

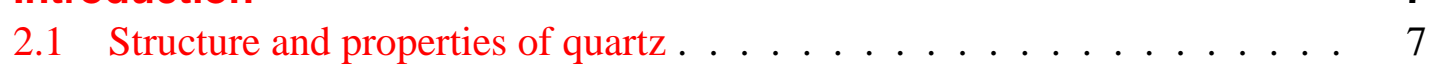

2.1 .1 Point defects in $\mathrm{SiO}_{2} \ldots \ldots \ldots \ldots \ldots$

2.2 Amorphization and solid phase epitaxy . . . . . . . . . . . . 10

2.2 .1 Amorphization and epitaxy in quartz . . . . . . . . . . . . . 10

2.2.2 Solid phase epitaxy . . . . . . . . . . . . . . . . 11

2.3 Technological application . . . . . . . . . . . . . . . . 15

2.4 Scheme of this thesis $\ldots \ldots \ldots \ldots \ldots \ldots \ldots \ldots$

3 Experiment 17

3.1 Sample preparation . . . . . . . . . . . . . . . . . . . 17

3.1 .1 Ion implantation . . . . . . . . . . . . . . . . 17

3.1.2 Thermal annealing in air or ${ }^{18} \mathrm{O}_{2} \ldots \ldots \ldots \ldots \ldots$

3.2 Analysis techniques . . . . . . . . . . . . . . . 20

3.2.1 Rutherford Backscattering Spectrometry (RBS) and Channeling . 20

3.2.2 Elastic Recoil Detection Analysis (ERDA) _ . . . . . . . . . 27

3.2 .3 Atomic Force Microscopy (AFM) . . . . . . . . . . . 30

3.2.4 Cathodoluminescence (CL) . . . . . . . . . . . . . . 32

3.2.5 Mechanical surface profilometry . . . . . . . . . . . 34

4 SPEG after Rb implantation $\quad 37$

4.1 Influence of annealing temperature . . . . . . . . . . . . 37

4.1 .1 Epitaxy in air . . . . . . . . . . . . . . . . . . . . . 37

4.1 .2 Epitaxy in ${ }^{18} \mathrm{O}_{2}$-gas . . . . . . . . . . . . . . . 42

4.2 Influence of $\mathrm{Rb}$ ion-fluence . . . . . . . . . . . . . 46

4.2 .1 Epitaxy in air . . . . . . . . . . . . . . . . 46

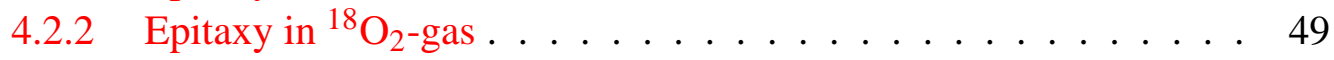

4.3 Influence of ${ }^{18} \mathrm{O}_{2}$ pressure $\ldots \ldots \ldots \ldots \ldots \ldots \ldots \ldots$

$4.4 \mathrm{Rb}$ out-diffusion . . . . . . . . . . . . . . . . . . 52

4.5 Oxygen migration during thermal annealing $\ldots \ldots \ldots \ldots$ 
4.6 Surface topography . . . . . . . . . . . . . . . . . 64

5 SPEG after Na-implantation $\quad \mathbf{7 1}$

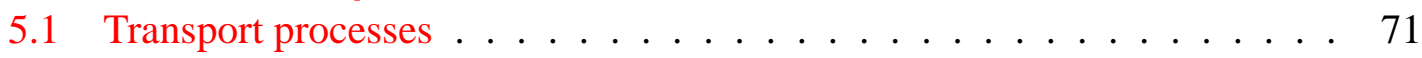

5.2 Surface topography . . . . . . . . . . . . . . . 78

6 Discussion $\quad \mathbf{8 3}$

6.1 Topology of silica network . . . . . . . . . . . . . 83

6.2 Alkali diffusion in silica . . . . . . . . . . . . . . . 87

6.3 The SPEG mechanism . . . . . . . . . . . . . . . . . . 89

7 Outlook $\quad 95$

7.1 Epitaxy after alkali ion implantation ... . . . . . . . . . . . 95

7.2 Cathodoluminescence after $\mathrm{Rb}$ ion irradiation . . . . . . . . . . . . . . 97

7.3 Laser-induced epitaxy . . . . . . . . . . . . . . . . . . . 101

$\begin{array}{ll}\text { References } & 102\end{array}$ 


\section{Summary}

Solid Phase Epitaxial Regrowth (SPEG) of the amorphized layer in synthetic $\alpha$-quartz induced by $\mathrm{Na}$ and $\mathrm{Rb}$-ion implantations was studied by thermal annealing in air and ${ }^{18} \mathrm{O}_{2}$ atmosphere.

The present detailed study of chemically guided epitaxy proves full epitaxy after properly chosen implantation and annealing conditions. Complete or partial SPEG was observed to depend on many parameters in ion-irradiated $\alpha$-quartz (ion fluence, annealing atmosphere, annealing temperature, oxygen pressure, and annealing time). After the irradiation a continuous amorphous layer grew, which during epitaxy decreased in thickness by a planar movement of the $\mathrm{a} / \mathrm{c}$ interface to the surface. The damage profiles and $\mathrm{Rb}$ concentration were monitored by means of Rutherford Backscattering Channeling Spectrometry. The out-diffusion of the implanted $\mathrm{Na}$ and the ${ }^{18} \mathrm{O} \Leftrightarrow{ }^{16} \mathrm{O}$ exchange between the sample and the annealing gas were investigated using Time-of-Flight Elastic Recoil Detection analysis. By depth profiling the implanted alkali-ions and the oxygen exchange in the near-surface layers it was possible to monitor the transport of all-important partners involved in this process and to relate them to the epitaxy of the matrix.

In the case of $\mathrm{Rb}$ implantation at a typical fluence of $2.5 \times 10^{16} \mathrm{ions} / \mathrm{cm}^{2}$, full epitaxy was achieved at very similar temperatures in air $(1170 \mathrm{~K})$ and ${ }^{18} \mathrm{O}_{2}$ gas $(1130 \mathrm{~K})$. The recrystallization rate in air follows a two-step Arrhenius process with activation energies of $E_{a x}^{L}$ $=0.6 \pm 0.2 \mathrm{eV}$ and $E_{a x}^{H}=2.7 \pm 0.4 \mathrm{eV}$ above and below an annealing temperature of 1070 $\mathrm{K}$, respectively.

It was demonstrated that the recrystallization rate increases with increasing ion fluence and temperature, but depends little on the ${ }^{18} \mathrm{O}_{2}$ pressure. The annealing temperature had the dominant role and epitaxial recrystallization occurred only above critical temperature and alkali ion fluences.

The three processes, namely planar recrystallization of the amorphized a-SiO${ }_{2}$ layer, alkali ion out-diffusion, and ${ }^{18} \mathrm{O} \Leftrightarrow{ }^{16} \mathrm{O}$ exchange, are highly correlated. This correlation was discussed by considering the topological structures and network connectivity of $\mathrm{SiO}_{2}$ in analogy to previous results obtained after $\mathrm{Li}$ and $\mathrm{Cs}$ implantation. The epitaxy is thought to be a consequence of the dissolution of alkali-oxides (network modifiers), which increase the structural freedom of the network due to the formation of non-conneted $\left[\mathrm{SiO}_{4}\right]$-tetrahedron corners, stabilized by a nearby alkali ion. The observed correlation between the migration of alkali ions and oxygen was used to explain the rearrangement 
process of the $\mathrm{SiO}_{2}$ network.

For the first time the surface morphology of samples was measured before irradiation and during the full process of chemically guided epitaxy. The AFM results confirmed the swelling during implantation and compaction during epitaxy. AFM also showed the presence of a regular "open web" at the surface after recrystallization.

Finally, a cathodoluminescence (CL) study was performed to identify different defect centers in the $\mathrm{SiO}_{2}$ matrix after $\mathrm{Rb}$ irradiation and its evolution during thermal annealing in air as well as in ${ }^{18} \mathrm{O}_{2}$. The room temperature CL spectra showed six bands: red $-2.0 \mathrm{eV}$, green - $2.4 \mathrm{eV}$, blue - $2.8 \mathrm{eV}$, violet $1-3.25 \mathrm{eV}$, violet 2 - $3.4 \mathrm{eV}$, and $\mathrm{UV}-4.3 \mathrm{eV}$. The violet bands are probably associated with Rb-related defects. All the other bands are connected to different defect centers in the $\mathrm{SiO}_{2}$ matrix created either by ion-implantation or by electron irradiation during the CL measurements. 


\section{Introduction}

\subsection{Structure and properties of quartz}

Silicon dioxide or silica is one of the most common compounds in the Earth's Crust. $\mathrm{SiO}_{2}$ has an extremely rich phase diagram (see fig.2.1) with a wide variety of crystal structures (polymorphs): $\alpha$-quartz, $\beta$-quartz, cristobalite, tridymite, coesite, and stishovite $[1,2,3,4]$. A common feature of crystalline and amorphous $\mathrm{SiO}_{2}$ at ordinary pressure are the $\left[\mathrm{SiO}_{4}\right]$ tetrahedron building units, where a central silicon atom is surrounded by four oxygen atoms. Each $\left[\mathrm{SiO}_{4}\right]$ tetrahedron is bridged via $\mathrm{Si}-\mathrm{O}-\mathrm{Si}$ bonds to neighboring tetrahedrons to form a three-dimensional fully connected network. Transitions between the polymorphs can occur upon change of ambient temperature or pressure.

The most common and stable phase at atmospheric temperature and pressure of all known crystalline forms of $\mathrm{SiO}_{2}$ is $\alpha$-quartz (low-quartz). $\alpha$-quartz has a hexagonal space-group symmetry which is defined by the lattice constants: $a=4.913 \AA$ And $c=5.405 \AA$. S The unit cell contains three $\mathrm{SiO}_{2}$ molecules [5]. The $\mathrm{Si}-\mathrm{O}-\mathrm{Si}$ bond length is 1.61 Ånd the $\mathrm{Si}$ $\mathrm{O}-\mathrm{Si}$ bond angle varies between $108.8^{\circ}$ and $110.5^{\circ}$. The angle between two corner-sharing tetrahedral $\left[\mathrm{SiO}_{4}\right]$ units is $143.6^{\circ}$. The adjacent tetrahedra form a threefold spiral around the $\mathrm{z}$ axis [6]. When $\alpha$-quartz is heated to $573^{\circ} \mathrm{C}$, it changes to another stable crystalline structure known as high-quartz or $\beta$-quartz. $\alpha$-quartz has a density of $2.65 \mathrm{~g} / \mathrm{cm}^{3}$ and is denser than the high-temperature forms tridymite $\left(2.26 \mathrm{~g} / \mathrm{cm}^{3}\right)$ and crystobalite $(2.32$ $\left.\mathrm{g} / \mathrm{cm}^{3}\right)$, but less dense than the high pressure forms coesite $\left(3.01 \mathrm{~g} / \mathrm{cm}^{3}\right)$ and stishovite $\left(4.28 \mathrm{~g} / \mathrm{cm}^{3}\right)$ [3, 7]. It was found [8] that after ion-beam induced amorphization of $\mathrm{SiO}_{2}$ the density decreased by about $19 \%$ as compared to the density of $\alpha$-quartz. Due to the high Si-O bond energy $(4.57 \mathrm{eV}[9,10])$, quartz is resistant to chemical weathering (it is only soluble in hydrofluoric acid and in hot alkalis) and corrosion. It is hard (Mohs' hardness 7$)$, brittle, and has a very high melting point $\left(1710^{\circ} \mathrm{C}[10]\right)$. Due to its wide band gap of about $9 \mathrm{eV}[11,12]$, it is optically transparent and shows low electrical conductivity. 


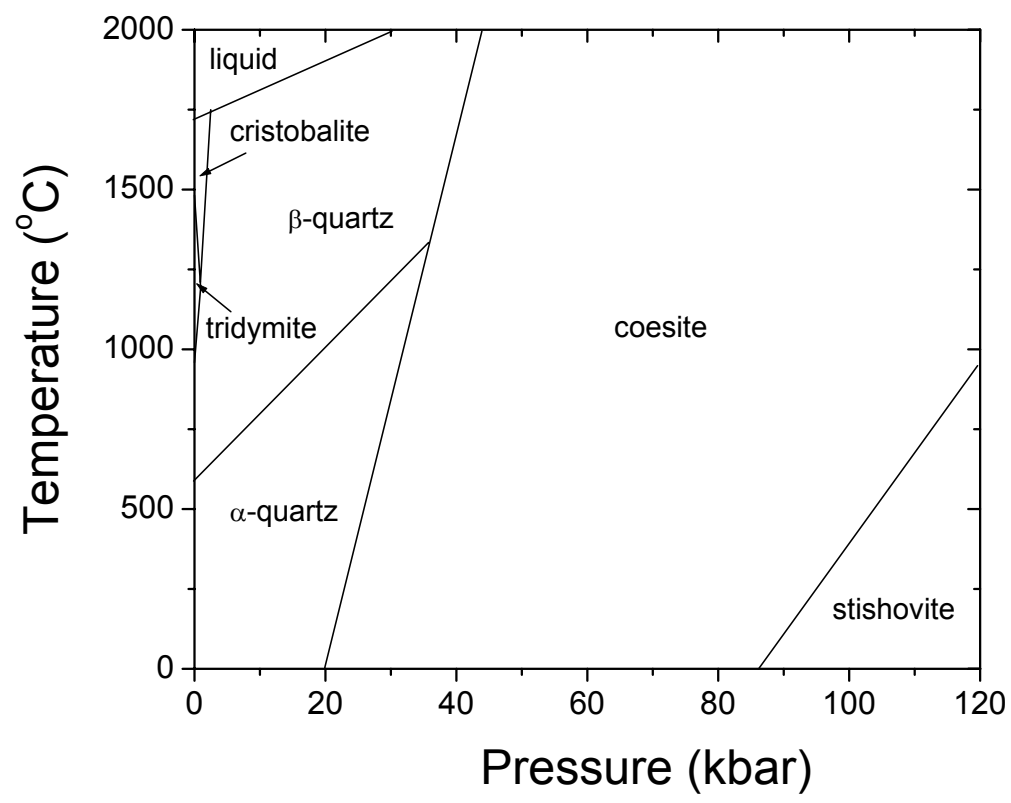

Figure 2.1: Phase diagram of the crystalline polymorphs of $\mathrm{SiO}_{2}$ [10].

\subsubsection{Point defects in $\mathrm{SiO}_{2}$}

The presence of defects in the matrix can dramatically modify its structural, electrical, and optical properties. Many parameters, such as manufacturing process, irradiation, mechanical stress, change of temperature, and the presence of impurities may cause the formation of defects and/or lead to the transformation of the existing defects into another type of defect [13]. Generally, the lattice defects can be grouped according to their structure and size as follows: point defects, dislocations (linear defects), and plane defects [14].

A variety of defect structures are known to exist in silica materials and were one of the major subjects of extensive experimental and theoretical studies $[15,16,17,18,19,20$, $21,22]$, due to practical applications of silica. Many aspects regarding the nature of the defects and their correlated properties are still controversial and not yet completely understood.

If the imperfection in the crystalline network is at the lattice site or in its immediate vicinity, this imperfection is called a point defect [14]. The following types of point defects can be considered: intrinsic and extrinsic. Intrinsic point defects involve atoms of the host matrix only, for example: vacancies (the host atoms are missing, Schottky defect or Frenkel pair) and selfinterstitials (additional host atoms at an interstitial position). Extrinsic point defects involve atoms chemically different from the host crystal, such as those used for electrical doping.

The defects and impurities in silicon dioxide have been studied by several techniques: 
electron spin resonance (ESR) $[12,15,17,23]$, electron paramagnetic resonance (ESP/EPR) [13], photoluminescence (PL) and cathodolumescence (CL) [13, 24, 25, 26], thermally stimulated luminescence [27], optical absorption [28, 29], Auger spectroscopy [12, 30], electric force microscopy (EFM) [24], and positron lifetime spectroscopy [16].

The impurity and lattice defects created during recrystallization have generally been interpreted as charge compensated (diamagnetic defect centers). Electron irradiation during measurements and natural radioactivity result in the transformation of the diamagnetic precursor centers into paramagnetic centers. The irradiation forms defects either by traping an electron or by forming a hole at the site of the precursor defect [13].

Electron spin resonance (ESR) spectroscopy is a powerful and widely used technique for the detection and identification of the paramagnetic centers, which have a net magnetic moment. About 20 different paramagnetic defect centers were found in silica [31]. The following fundamental paramagnetic centers were identified in silicon dioxide: the E' center ( $\equiv \mathrm{Si} \cdot)$, the peroxy radical ( $\equiv \mathrm{Si}-\mathrm{O}-\mathrm{O} \cdot$ ), and the non-bridging oxygen hole center $\mathrm{NBOHC}(\equiv \mathrm{Si}-\mathrm{O} \cdot)$. In each case, the symbol $\equiv \mathrm{Si}$ represents a silicon atom bonded to three oxygen atoms in the $\mathrm{SiO}_{2}$ network, and the dot refers to an unpaired electron.

Several properties of silicon dioxide are dominated by a single point defect known as the E' center [13]. $\equiv \mathrm{Si}$. is the oxygen vacancy which possesses the unpaired electron in a dangling $\mathrm{sp}^{3}$ orbital of the silicon atom which is pyramidally bonded to the three oxygen atoms in the $\mathrm{SiO}_{2}$ network. A variety of $\mathrm{E}$ '-like centers have been identified in silica and these are conventionally differentiated by appending the subscripts, for example 1, 2, 4, $\mathrm{s}, \alpha, \beta, \gamma, \delta$. Details of the proposed defect models can be found in Ref. [13, 17]. These point defects have been observed in $\alpha$-quartz, fused $\mathrm{SiO}_{2}$, and in $\mathrm{a}-\mathrm{SiO}_{2}[5,16]$.

The most important oxygen-associated hole centers (OHC's) stable at room temperature are the peroxy radical and the non-bridging oxygen hole center [32]. The peroxy radical is an oxygen associated hole center [31] consisting of a trapped hole on a singly coordinated $\mathrm{O}_{2}{ }^{-2}$ molecule ion [22]. An alternative configuration called the "small peroxy radical" has been predicted to exist by Edwards and Flower [22]. However, no experimental results confirm this speculation to date [13]. The non-bridging oxygen hole center (NBOHC) is a trapped hole on a singly coordinated $\mathrm{O}^{2-}$ [22].

PL and CL spectroscopy provide information about non-paramagnetic precursors of the paramagnetic centers. The non-paramagnetic oxygen vacancy ( $\equiv \mathrm{Si}$-Si $\equiv$ ) can appear in the network as a member of a Frenkel defect pair or it can originate from irradiation [33]. The $\equiv \mathrm{Si}-\mathrm{Si} \equiv$ has been proposed as a possible precursor of the E' center and has been explained by the asymmetric relaxation model proposed by Feigl, Flower, and Yip [34, 35]. The peroxy linkages ( $\equiv \mathrm{Si}-\mathrm{O}-\mathrm{O}-\mathrm{Si} \equiv$ ) $[22]$ are probably precursors of the peroxy radical and/or the NBOHC. Another way of forming the peroxy radical has been proposed to result from the reaction of the interstitional molecular oxygen with the E' center [22]:

$\equiv \mathrm{Si} \cdot+\mathrm{O}_{2} \longrightarrow \equiv$ Si-O-O .

In natural and synthetic quartz, impurity ions can be incorporated either into interstatial or substitutional positions in the lattice, depending on ion radius and charge. Be- 
cause of the small ionic radius of $\mathrm{Si}^{4+}(0.42 \AA)$ and its high valence, the probability of the substitution of a silicon atom is rather low. The most common substitutes are: $\mathrm{Al}^{3+}(0.51 \AA), \mathrm{Ga}^{3+}(0.62 \AA), \mathrm{Fe}^{3+}(0.64 \AA), \mathrm{Ge}^{4+}(0.53 \AA), \mathrm{Ti}^{4+}(0.64 \AA)$, and $\mathrm{P}^{5+}$ $(0.35 \AA)$. The interstitional charge compensators are $\mathrm{H}^{+}, \mathrm{Li}^{+}, \mathrm{Na}^{+}, \mathrm{K}^{+}, \mathrm{Cu}^{+}, \mathrm{Ag}^{+}$. The paramagnetic impurity center $\mathrm{X}$ (typically $\mathrm{Ge}^{4+}$ or $\mathrm{Ti}^{4+}$ ) can result in the development of the non-paramagnetic center $\left[\mathrm{XO}_{4}\right]^{0}$, which can be the precursor of the paramagnetic center $\left[\mathrm{XO}_{4}\right]^{-}$(this transformation takes place during ionization irradiation). The $\left[\mathrm{XO}_{4}\right]^{0}$ can catch diffusing cations $\mathrm{M}^{+}\left(\mathrm{H}^{+}, \mathrm{Li}^{+}, \mathrm{Na}^{+}\right)$and create the paramagnetic centre $\left[\mathrm{XO}_{4} / \mathrm{M}^{+}\right]^{0}[31]$.

One of the most common impurities is water, which can be bonded in the network in the form of $\mathrm{H}^{+}, \mathrm{OH}^{-}$or $\mathrm{H}_{2} \mathrm{O}$. For example, hydrogen can be incorporated as hydroxyl groups which tend to cluster in pairs in $\mathrm{SiO}_{2}$ : $\equiv \mathrm{Si}-\mathrm{OH} \mathrm{HO}-\mathrm{Si} \equiv[33,36]$. Atomic and molecular hydrogen occurred in interstitial positions. Irradiation of the hydroxy group below $100 \mathrm{~K}$ results in the formation of reactive atomic hydrogen $\mathrm{H}^{0}$, which thermally migrates and is dimerized above $130 \mathrm{~K} . \mathrm{H}_{2}$ diffusion becomes significant in the temperature range of 170 - $200 \mathrm{~K}$ [13]. Above $230 \mathrm{~K}$ the NBOHC's and $\mathrm{H}_{2}$ molecules can combine to reform a nonbridging hydroxyl group ( $\equiv \mathrm{Si}-\mathrm{OH})[33]$.

\subsection{Amorphization and solid phase epitaxy}

\subsubsection{Amorphization and epitaxy in quartz}

The formation of radiation damage and amorphization of quartz by ion implantation has been of considerable interest in the last decades, both experimentally and theoretically $[8,12,37,38,39,40,41,42,43,44]$.

The effects of heavy-ion damage in quartz produced by implantation with $\mathrm{He}$ to $\mathrm{Bi}$ ions in the energy range of $15-200 \mathrm{keV}$ was investigated by Macaulay-Newcombe et al. [39]. Fischer et al. [45, 46] studied the mechanism of damage production and the annealing behaviour up to $1370 \mathrm{~K}$ in quartz after $35 \mathrm{keV} \mathrm{He}, 70 \mathrm{keV} \mathrm{B}$, and $150 \mathrm{keV}$ Ar ions implantation. Recently, Harbsmeier and Bolse [8] carried out detailed analyses of the accumulation of damage and determined the critical condition for full amorphization of $\alpha$-quartz. The three-dimensional nucleation and growth model based on the Avrami-Johnson-Mehl function was found to work best for low and medium mass ions $(\mathrm{H}, \mathrm{N}, \mathrm{Ne}, \mathrm{Na})$ in the 10 - $100 \mathrm{keV}$ energy and $10^{13}-10^{17}$ ions $/ \mathrm{cm}^{2}$ fluence range. In the present work with rather heavy $\mathrm{Rb}$ ions, quartz was fully amorphized even for fluences as low as $10^{13}$ ions $/ \mathrm{cm}^{2}$. Although many attempts were made to obtain the epitaxial recovery of the radiation damage in $\alpha$-quartz, it was only successfully achieved quite recently and under rather peculiar conditions. Devaud et al. [47] observed partial solid phase epitaxial growth (SPEG) of natural Brazilian quartz after "self-ion" implantation $\left(180 \mathrm{keV}\right.$ Si with a fluence of $5 \times 10^{13}$ 
ions $/ \mathrm{cm}^{2}$ and $75 \mathrm{keV} \mathrm{O}$ with a fluence of $1 \times 10^{14}$ ions $/ \mathrm{cm}^{2}$ ) and post annealing in air at $1323 \mathrm{~K}$. This study concluded that impurity $\mathrm{OH}$-groups were responsible for recrystallization. Already in 1980, Arnold and Peercy [48] on the basis of experimental results, after quartz had been irradiated by $\mathrm{Li}$-ions and $\mathrm{Li}_{2} \mathrm{O} \cdot 2 \mathrm{SiO}_{2}$ by noble gas ions, found evidence of the special role of alkali ions during epitaxy in silicates. Crystalline $\mathrm{Li}_{2} \mathrm{O} \cdot 2 \mathrm{SiO}_{2}$ was achieved after annealing the irradiated sample at $773 \mathrm{~K}$ and recrystallization of Lidoped $\mathrm{SiO}_{2}$ was achieved at 973 - $1073 \mathrm{~K}$. More recently, Harbsmeier et al. [49] carried out similar experiments on pure $\alpha$-quartz after $50-\mathrm{keV}$ carbon ion implantation and annealing in vacuum up to $1673 \mathrm{~K}$. In these experiments, SPEG was found to set in at 1473 K. However, no full recrystallization was achieved up to $1673 \mathrm{~K}$, the highest annealing temperature used in this experiment. Besides these chemically guided SPEG studies, in which implanted or resident impurities play an important role, Dhar, Bolse and Lieb have studied dynamic SPEG after Ne [50] or Ba [51] implantation in hot quartz samples and achieved complete epitaxy.

Recently, Roccaforte and collaborators [52, 53, 54, 55, 56, 57, 58, 59, 60] extensively and successfully developed chemically guided SPEG by implanting $\mathrm{Cs}$ and $\mathrm{Na}$ ions into $\alpha$-quartz and subsequently annealing them in air or in an ${ }^{18} \mathrm{O}_{2}$ atmosphere. A similar study after Li implantation was carried out by Gustafsson et al. [58]. These studies presented full or partial SPEG of alkali-implanted $\alpha-\mathrm{SiO}_{2}$ occurring up to temperatures of about $1150 \mathrm{~K}$. These authors also found that the chemically guided technique using alkali ions led to epitaxy when the amorphous layer was produced via Si or O ion irradiation or $\mathrm{SiO}_{2}$ evaporation [59]. The temperature at which the alkali atoms become mobile and the recrystallization process starts was found to correlate with the fluence of the implanted alkali ions, as does the quality of the regrown crystalline layer.

\subsubsection{Solid phase epitaxy}

In the year 1928 Royer [61] defined the term epitaxy (or "ordered on" from the Greek words $\varepsilon \pi \imath$ - on and $\tau \alpha \xi 1 \sigma$ - in order) for the oriented growth process of a crystalline material on a single crystal surface. Epitaxy depends on the nucleation and growth relationship between two crystalline phases in such a way that an amorphous material (guest atoms) can grow with the same crystal structure on the host crystal of the same material. Generally, chemical and/or structural inhomogeneities develop at the guest/host interface. In the completed epitaxial reaction there exists a two-phase system, consisting of two adjacent heterochemical (different chemical species - heteroepitaxy) or isochemical (identical chemical species - homoepitaxy) epitaxial partners: the host and guest substrate [62]. The layer grown on the host matrix can be formed from amorphous solid deposits, a liquid phase (i.e. a solution or a melt), a vapor or gas, or from atomic or molecular beams. The following techniques are used for growing thin epitaxial structures: Solid Phase Epitaxy (SPE), Liquid Phase Epitaxy (LPE), Vapor Phase Epitaxy (VPE), with a special modifica- 


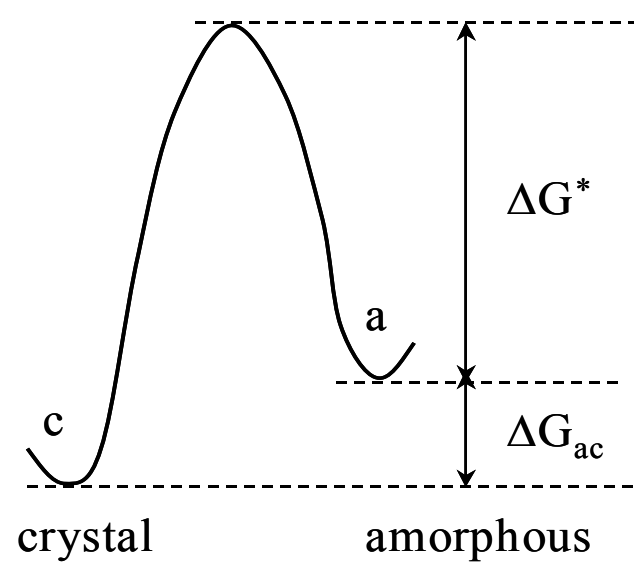

Figure 2.2: Schematic variation of the energy levels for thermally activated transfer between the crystal (c) and amorphous (a) phase. For the transition from the amorphous to the crystalline phase the energetic barrier of the activated complex must be overcome.

tion called Metalorganic Chemical Vapor Phase Epitaxy (MO VPE) or Organo-Metallic VPE (OM VPE), and Molecular Beam Epitaxy (MBE) [63].

According to thermodynamic considerations, growth is energetically favoured when the Gibbs free energy, $G$, of the system is lowered by the transformation of an interface atom from amorphous to crystalline phase. The free energy of the amorphous phase is higher by an amount of $\Delta G_{a c}$ with respect to the crystal, and the crystallization process is assumed to have an activation barrier $\Delta G^{*}$. This situation is schematically represented in fig.2.2. In the case of $\mathrm{Si}$, the following values were found: $\Delta G_{a c}=0.14 \mathrm{eV} /$ atom and $\Delta G^{*}=2.7$ eV/atom [64]. The higher stability of the crystalline phase is determined by the lower Gibbs free energy compared to the amorphous phase. $G$ is the driving force in rearranging the bond angles and distances in the amorphous material and in recovering the short range order by means of the disordered - ordered phase transition. This process is called recrystallization and is thermodynamically possible $(\Delta \mathrm{G}<0)$, but it is too slow to be observed at room temperature. The amorphous-to-crystal (a-c) transformation is difficult to be induced thermally, since $\Delta G_{a c}$ " $\Delta G^{*}$, but may be induced either under the influence of a chemical partner or by ion beam bombardment [63].

The heating treatment induces thermal vibration and leads to reordering of the atoms at the $\mathrm{a} / \mathrm{c}$ interface. This results in the propagation of the interface towards the surface and to the most energetically favourable state (the crystalline phase). The frequency of the amorphous-to-crystal transition $\left(v_{a c}\right)$ can be expressed as:

$$
\mathrm{v}_{a c}=\mathrm{v}_{f} e^{\left(\Delta G^{*} / k_{B} T\right)}
$$


where $v_{f}$ is the attempt frequency, $T$ the temperature, and $k_{B}$ the Boltzmann constant. On the other hand, the crystal-to-amorphous transition rate $\left(v_{c a}\right)$ is defined by:

$$
\mathrm{v}_{c a}=\mathrm{v}_{g} e^{\left(-\left(\Delta G^{*}+\Delta G_{a c}\right) / k_{B} T\right)} .
$$

The velocity $v_{S P E}$, at which the recrystallizing interface moves is given by the difference between these two rates multiplied by the distance across the a/c interface $\delta: v=\delta\left(v_{a c}-\right.$ $v_{c a}$ ). Assuming that the attempt frequencies $v_{f}$ and $v_{g}$ are identical, the net SPE interface velocity can be written as:

$$
v_{S P E}=v \delta e^{\left(\Delta G^{*} / k_{B} T\right)}\left[1-e^{\left(-\Delta G_{a c} / k_{B} T\right)}\right] .
$$

$\Delta G_{a c}$ and $\Delta G^{*}$ can be expressed as $\Delta H_{a c}-T \Delta S_{a c}$ and $\Delta H^{*}-T \Delta S^{*}$ respectively, where $\Delta H$ and $\Delta S$ represent the enthalpy and entropy difference. According to this definition, the upper equation can be given by the expression:

$$
v_{S P E}=v \delta e^{\left(\Delta S^{*} / k_{B} T\right)} e^{\left(-\Delta H^{*} / k_{B} T\right)}\left[1-e^{\left(\Delta S_{a c} / k_{B} T\right)} e^{\left(-\Delta H_{a c} / k_{B} T\right)}\right]
$$

and rewritten as:

$$
v_{S P E}=v_{o} e^{\left(-E_{a} / k_{B} T\right)}\left[1-e^{\left(\Delta S_{a c} / k_{B} T\right)} e^{\left(-\Delta H_{a c} / k_{B} T\right)}\right]
$$

where $E_{a}$ is the activation energy and has been substituted for $\Delta H^{*}$ and the pre-exponential factor, $v_{o}$, is defined by $v_{o}=v \delta e^{\left(\Delta S^{*} / k_{B} T\right)}$ [65]. Generally, if $E_{a} \gg \mathrm{k}_{B} \mathrm{~T}$ and $\Delta G_{a c} \gg$ $\mathrm{k}_{B} \mathrm{~T}$, the velocity of the moving $\mathrm{a} / \mathrm{c}$ interface (the regrowth rate) exhibits an Arrhenius temperature dependence:

$$
v=v_{o} e^{\left(-E_{a} / k_{B} T\right)}
$$

Two kinds of crystallization modes of the amorphous layer can be distinguished: Solid Phase Epitaxial Growth (SPEG) and Random Nucleation Growth (RNG), which are schematically illustrated in fig.2.3 and will now be discussed.

The most common configuration of the SPE growth system is shown in fig.2.3 (a). The basic sample configuration is a continuous amorphous layer in direct contact with an underlying single crystal substrate. The amorphous layer may be the result of ion-irradiation of the crystalline matrix. The thickness of the amorphous film may be up to several $\mu \mathrm{m}$, depending on the energy, mass and fluence of the implanted ions. Solid Phase Epitaxial Growth occurs at the amorphous-crystal interface, where the amorphous phase is consumed to produce the stable crystalline phase. The amorphous phase can regrow layerby-layer with the same crystalline structure as the host matrix. The regrowth rate is based on the measurement of the thickness of the amorphous layer as a function of annealing time at a fixed temperature. Lietoila et al. [66] found that the regrowth rate strongly depends on the crystal orientation.

Random Nucleation and Growth (see fig.2.3 (b)) occurs when the thermal fluctuations result in the occasional formation of crystalline nuclei of various sizes and thus short-range 
a) Solid Phase Epitaxial Growth (SPEG)

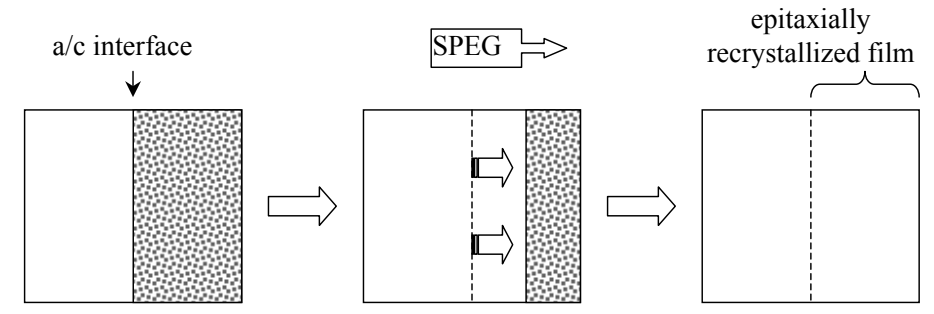

b) Random Nucleation and Growth (RNG)

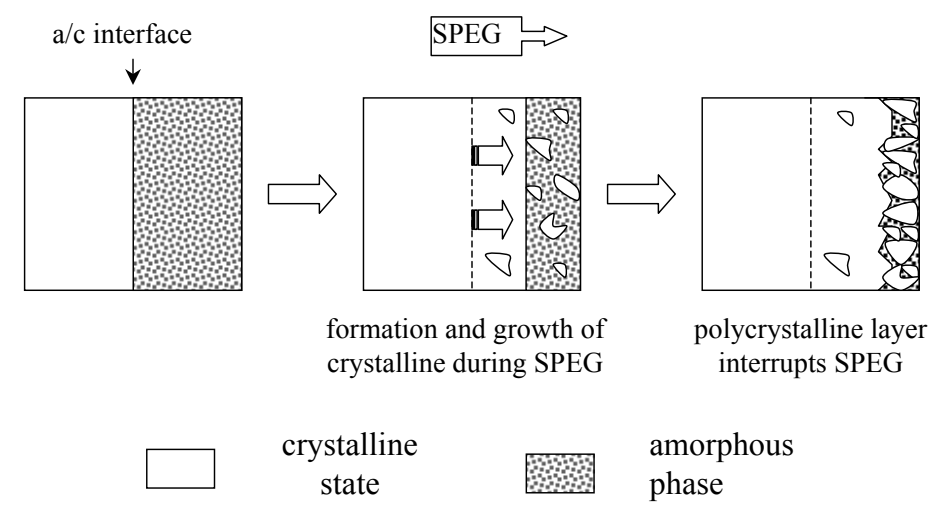

Figure 2.3: (a) Solid Phase Epitaxial Growth of a thin amorphous layer on a crystalline substrate. (b) Random Nucleation and Growth of crystallites in the amorphous phase can interfere with SPE at high temperature.

order recovery takes place within the amorphous matrix. Through random fluctuation, some of these crystallites, which exceed a certain radius, can expand and grow in size by the addition of furter atoms from the disordered state at the a/c interface. This part of the crystalline growth (on a microscopic scale) can be described as SPE on a small scale. The regrowth expands without any preferential direction and, as a result, the amorphous layer becomes a polycrystalline material.

From a technological point of view, the epitaxial recrystallization is more important than Random Nucleation and Growth. SPEG offers the possibility of removing radiation damage induced during the ion-doping process.

Two methods have been developed to achieve SPEG of $\alpha$-quartz during or after ion implantation:

- dynamic SPEG (the ions are implanted in vacuum into heated $\alpha$-quartz samples in such a fashion that the radiation-induced damage is removed during the implantation process itself) [50] 
- chemically guided SPEG (the implantation of alkali ions and their subsequent postannealing) [52, 53, 54, 55, 56, 57, 58, 59, 60].

This thesis will discuss the results of chemically guided SPEG due to $\mathrm{Na}$ and $\mathrm{Rb}$ ions.

\subsection{Technological application}

As electronic and optoelectronic devices become smaller and faster, ion implantation is a key tool in their fabrication, for doping control, impurity introduction, or electrical insulation. Due to its unique characteristics, silica in its crystalline and amorphous forms is the most important insulator in integrated optics and microelectronic technology. $\alpha$-quartz has been used in the fabrication of optical waveguides [67, 68, 69, 70]. A fundamental requirement from this type of device is the production of a region of high refractive index inside a lower index matrix. Ion beam techniques offer the possibility of changing the local refractive index due to ion-beam-induced damage or by implanting chemical dopants and producing a narrow "optical barrier" in the crystal. Chandler et al. [68] found a change in the refractive index of $\alpha$-quartz of about $5 \%$ after the crystalline-amorphous transition.

Due to its unique features, amorphous $\mathrm{SiO}_{2}\left(\mathrm{SiO}_{2}\right.$ glass $)$ has applications as an optical material for excimer laser photolithography systems, using $\mathrm{KrF}(5.0 \mathrm{eV}, 248 \mathrm{~nm}), \mathrm{ArF}$ $(6.4 \mathrm{eV}, 193 \mathrm{~nm})$, and $\mathrm{F}_{2}(7.9 \mathrm{eV}, 157 \mathrm{~nm})[71,72,73]$ lasers. Light sources with short wavelengths are designed to be used in the fabrication of optical semiconductor devices. Silica, besides its excellent transparency from infrared to vacuum-ultraviolet (VUV) regions, is resistant to laser damage. The absorption edge of synthetic $\mathrm{SiO}_{2}$ is located at about $9 \mathrm{eV}$, which is the largest band gap energy among known glassy oxides.

The piezoelectric properties of $\alpha$-quartz are widely employed to produce electronic devices such as bulk acoustic wave (BAW) and surface acoustic wave (SAW) devices. It exhibits vibration modes with zero linear temperature coefficients and excellent physical and chemical stability [74]. For example, synthetic quartz crystals were mass produced for use as autoclaves.

\subsection{Scheme of this thesis}

A multidisciplinary research program was applied to develop the understanding of the processes and mechanisms controlling the chemically guided epitaxy after $\mathrm{Na}^{+}$and $\mathrm{Rb}^{+}$ ion implantation in synthetic $\alpha$-quartz.

This thesis is organized in the following way. The present introduction addressed the structure and properties of quartz and gives a short review of ion-induced amorphization and Solid Phase Epitaxy. 
The first part of Chapter 3 briefly summarizes the sample preparation, including ion implantation and thermal annealing, and the second part discusses the basic features of the experimental methods used in this study. The amorphization of $\alpha$-quartz due to ion irradiation and epitaxial recrystallization during thermal annealing was monitored by means of Channeling (RBS-C). The migration of the implanted Rb was measured by Rutherford Backscattering Spectrometry (RBS). The role of the oxygen exchange between the annealing gas and the $\mathrm{SiO}_{2}$ matrix was highligthed by measuring the ${ }^{16} \mathrm{O}$ and ${ }^{18} \mathrm{O}$ profiles by Time-of-Flight Elastic Recoil Detection Analysis (TOF-ERDA). The Atomic Force Microscopy (AFM) was a useful tool for resolving the microscale surface topography. The optical properties were studied by Cathodoluminescence (CL).

In Chapter 4, the experimental results concerning the recrystallization of the Rb-beam induced damage in $\alpha$-quartz after thermal annealing are presented. In the first three sections the dependence of the epitaxy on the ion fluence and the parameters of the annealing gas (type: air or ${ }^{18} \mathrm{O}_{2}$, temperature, time, pressure) will be described in detail. The migration of the implanted $\mathrm{Rb}$-ions during the recovery process is discussed in more detail in Section 4.4. The next section of this chapter reports on the role of the oxygen in the SPEG process. In the last section the study of surface topography will be presented.

In Chapter 5, the experiments presented after $\mathrm{Rb}$ irradiation will be compared with the results obtained after Na-implantation.

The detailed study of chemically guided epitaxy after $\mathrm{Na}$ and $\mathrm{Rb}$ ion implantation show that SPEG occurs only if the following two conditions are fulfilled: presence of alkali ions in the amorphous layer and annealing in an oxygen atmosphere. These results will be discussed in Chapter 6 according to the topology of the silica network and scenario for epitaxy. The strong correlation between the three processes, namely planar recrystallization of the amorphized layer, alkali out-diffusion, and the ${ }^{16} \mathrm{O} \Leftrightarrow{ }^{18} \mathrm{O}$ exchange will be explained with the help of the concept of the $\mathrm{SiO}_{2}$ network topology.

Finally, in the outlook first results on the optical properties will be described briefly, which appear to lead to important future experiments. 


\section{Experiment}

\subsection{Sample preparation}

\subsubsection{Ion implantation}

In order to study the epitaxial recrystallization during thermal annealing, high quality synthetic single-crystalline $\mathrm{SiO}_{2}$ ( $\alpha$-quartz), (0001) oriented, 10x10x1 mm 3 in size, with one side polished, was used. The quartz samples were procured from Crystal GmbH, Berlin. The alkali ion implantations were performed by means of the ion implanter IONAS [75] at Göttingen. Stainless steel rods containing the alkali chloride salts were used for implanting alkali ions $(\mathrm{NaCl}, \mathrm{RbCl})$. The salt was dissolved in distilled water and dried using a lamp before being filled into the stainless steel rod. This rod was introduced into the Sidenius oven-source (So-55) of the ion implanter. The samples were irradiated with different ion species and fluences. The ion energy was chosen to obtain approximately the same projected ion range $\mathrm{R}_{p} \approx 100 \mathrm{~nm}$ as in the previously studied cases of $20-\mathrm{keV}$ $\mathrm{H}^{+}[50,59], 15-\mathrm{keV} \mathrm{Li}^{+}[58,59]$, and 250-keV Cs ${ }^{+}[52,53,59]$ implantations. The ion energy profiles, along with the full collision cascade due to the alkali-ion irradiation, were obtained by the SRIM 2000 code [78] and are summarized in table 3.1.

\begin{tabular}{|c|c|c|c|}
\hline Ion & Energy (keV) & Fluence (ions/cm ${ }^{2}$ ) & $\mathrm{Rp}(\mathrm{nm})$ \\
\hline $\mathrm{Na}^{+}$ & 50 & $1 \times 10^{14}-1 \times 10^{17}$ & 110 \\
\hline $\mathrm{Rb}^{+}$ & 175 & $5 \times 10^{15}-6 \times 10^{16}$ & 100 \\
\hline
\end{tabular}

Table 3.1: Parameters of alkali-ion irradiations of $\alpha$-quartz, with corresponding ion range $\mathrm{R}_{p}$, calculated by the computer code SRIM 2000 using an atomic density of $6.45 \times 10^{22}$ at. $/ \mathrm{cm}^{3}$ of amorphous $\mathrm{SiO}_{2}[8]$.

The samples were mounted on a copper target holder kept in thermal contact with a liquid nitrogen reservoir. Implantation was performed at liquid nitrogen temperature (about 80 $\mathrm{K})$ to prevent possible dynamic annealing effects, which may occur in quartz at higher irradiation temperatures [50]. During each irradiation, one half of the surface area of each sample was masked with an aluminum foil. This preserved a virgin part, required 
for the orientation of the crystal during channeling analysis or as a reference level for $\mathrm{AFM}$ /profilometer surface profiling. The ion beam current was kept below $1.5 \mu \mathrm{A}$ in order to minimize sample heating. Homogeneous implantation over an area of $10 \times 10 \mathrm{~mm}^{2}$ was achieved via an electrostatic X-Y sweeping system.

In insulators (i.e. $\alpha$-quartz), ion-beam analysis may be considerably influenced by the charging effect through the accumulation of charge on the sample surface. For example, in the case of the RBS measurement, the energy edges in the spectra are shifted towards higher energy values [76]. To prevent this effect during RBS analyses (at a typical $\alpha$ particle current of $15 \mathrm{nA}$ ), the edges of the samples were covered with conducting $\mathrm{Ag}$ paste (procured from Plano $\mathrm{GmbH}$ ). This ensured sufficient electrical contact between the sample and the copper target holder.

\subsubsection{Thermal annealing in air or ${ }^{18} \mathrm{O}_{2}$}

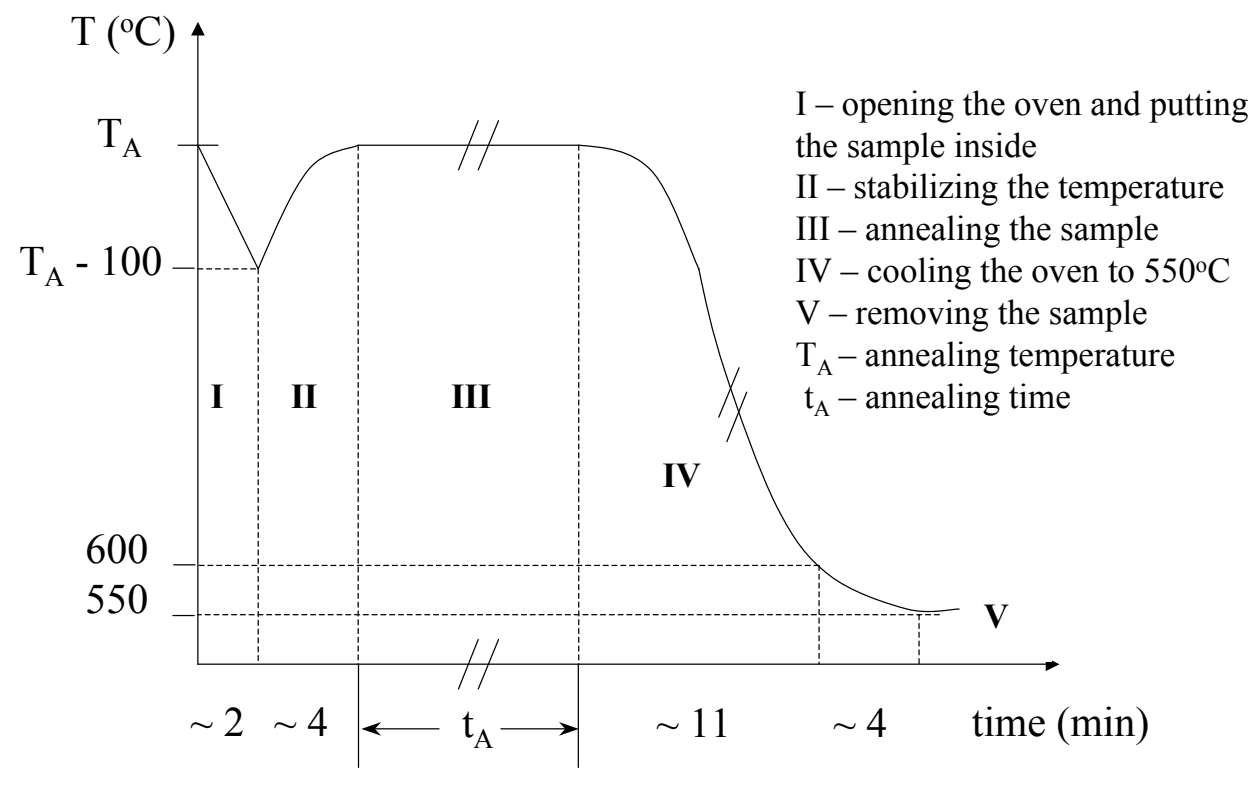

Figure 3.1: A schematic diagram of the annealing treatments.

Isochronal thermal annealings of 1 or $2 \mathrm{~h}$ between 673 and $1173 \mathrm{~K}$ were performed to study the amorphous network and its epitaxial regrowth. Annealing treatments of the implanted sample were carried out either in air or in an enriched oxygen atmosphere in a conventional air furnace from Nabatherm. Some of the annealings were done in vacuum by means of a Strohlein oven, which was evacuated to a pressure of about $5 \times 10^{-6}$ mbar. In all cases the temperature was controlled with a Pt-Rd thermocouple, with a precision of 
about $3^{\circ} \mathrm{C}$ [77]. Separate samples were used at each annealing temperature. In addition, a set of samples implanted with various fluences were annealed in air at a fixed temperature of $1123 \mathrm{~K}$, first for $1 \mathrm{~h}$ and then for another $1 \mathrm{~h}$.

A typical annealing treatment is schematically presented in fig.3.1. The sample was put into the oven after the oven temperature was stabilized at $\mathrm{T}_{A}$. Opening the oven and placing the sample in position caused the oven temperature to decrease by approximately 100 degrees. After 4 min., the heating temperature was reached again and the annealing could take place. Cooling the sample down had to be done very slowly. Quartz, as an insulator, has a very poor thermal conductivity and is very susceptible to temperature variations. If the sample is cooled down too fast, thermal stress can be provoke, which breaks the sample or causes cracks on its surface. For that reason, the first 30 degrees are cooled down very slowly, at a cooling rate of about $10^{\circ} \mathrm{C} / \mathrm{min}$. After this critical cooling time, the next cooling step can be accelerated $\left(25-30^{\circ} \mathrm{C} / \mathrm{min}\right)$. At $573^{\circ} \mathrm{C}$ the $\alpha \leftrightarrow \beta$-quartz phase transition occurs. This temperature is the second condition where cracks are likely to occur. In this sensitive region the cooling down was again carried out very slowly. After this procedure the sample was taken out of the oven.

For annealing in ${ }^{18} \mathrm{O}_{2}$, each sample was enclosed inside a quartz ampoule. After evacuating the ampoule to about $5 \times 10^{-5}$ mbar, it was filled with enriched $(95 \%){ }^{18} \mathrm{O}_{2}$ gas and then sealed. This part of the sample preparation was performed in the radiochemistry laboratory of the II. Physikalisches Institut in collaboration with Dr. L. Ziegler. The ${ }^{18} \mathrm{O}_{2}$

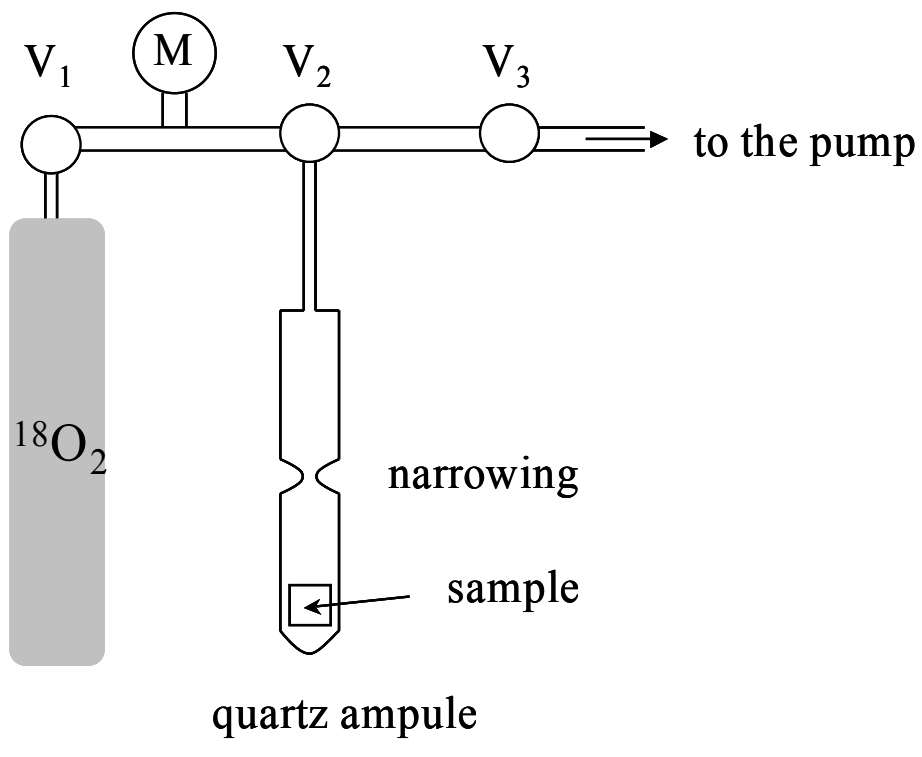

Figure 3.2: Set up for the encapsulation of the sample used for the ${ }^{18} \mathrm{O}_{2}$ annealing.

gas bottle was procured from Chemotrade Chemiehandelsgesellschaft $\mathrm{mbH}$. The set up used for the encapsulation of the samples for thermal annealing in an ${ }^{18} \mathrm{O}_{2}$ atmosphere is sketched in fig.3.2. The sample was put into an approximately $40 \mathrm{~cm}$ long quartz am- 
poule, $1.2 \mathrm{~cm}$ in diameter. The glass-blower created the same narrowing $12 \mathrm{~cm}$ from the ampoule's top. Later this narrowing can be successively sealed by melting it. Such an ampoule was mounted into the vacuum set up. First of all, the system was evacuated by opening valves $\mathrm{V}_{2}$ and $\mathrm{V}_{3}$. Then the ampoule was warmed up to remove the impurities (i.e. $\mathrm{Na}, \mathrm{H}_{2} \mathrm{O}$ ) contained in the quartz. This was performed to avoid the diffusion of impurities inside the sample during annealing. After reaching a vacuum of about $5 \times 10^{-5}$ mbar, $\mathrm{V}_{2}$ was closed and $\mathrm{V}_{1}$ slowly opened so that the ${ }^{18} \mathrm{O}_{2}$ gas could enter the ampoule. A manometer, $\mathrm{M}$, monitored the ${ }^{18} \mathrm{O}_{2}$ pressure. After reaching the required pressure, the valve $\mathrm{V}_{2}$ was closed, the ampoule was isolated from the rest of the system and the sealed ampoule was thermally annealed in the conventional Nabatherm air-furnace.

The ${ }^{18} \mathrm{O}_{2}$ gas pressure, $p_{A}$, at a particular annealing temperature, $T_{A}$, was equivalent to the partial gas pressure of oxygen in air, $p_{R}$, at room temperature, $T_{R}$, and is given by the ratio:

$$
\frac{p_{R}}{T_{R}}=\frac{p_{A}}{T_{A}} .
$$

\subsection{Analysis techniques}

\subsubsection{Rutherford Backscattering Spectrometry (RBS) and Channeling}

RBS is a well-established technique suitable for depth analysis of thin films and/or for quantitative determination of the concentration of trace elements heavier than the major constituents of the substrate [79, 80]. All RBS measurements were performed by means of 0.9-MeV $\alpha$-particles at the Göttingen implanter IONAS [75]. A silicon surface barrier detector having $\alpha$-particle energy resolution of $12.5 \mathrm{keV}$ Full Width at Half Maximum (FWHM) placed at a scattering angle, $\theta$, of $165^{\circ}$ was used for these analyses. The $15 \mathrm{nA}$ $\alpha$-particle beam was focused to a $2 \mathrm{~mm}^{2}$ spot.

The principle of RBS is sketched in fig.3.3. Rutherford Backscattering is based on the elastic collisions between an ion beam (typically $\alpha$-particles with $1-2 \mathrm{MeV}$ energy) and nuclei of the target material. This process leads to a change in direction and energy of these $\alpha$-particles. The energy $\mathrm{E}_{o}$ of the incident particle of mass $\mathrm{M}_{1}$ is reduced after collision with the target nucleus of mass $\mathrm{M}_{2}$ at the sample surface to the value:

$$
E=k\left(M_{2}, \theta\right) E_{o}=\left(\frac{M_{1} \cos \theta+\sqrt{M_{2}^{2}-M_{1}^{2} \sin ^{2} \theta}}{M_{1}+M_{2}}\right)^{2} E_{o}
$$

where $k$ is the kinematic factor for the elastic scattering process.

When the probing particles penetrate to a depth $x$ from the surface of the sample, the projectile energy dissipates due to interactions with electrons (electronic stopping) and nuclei 


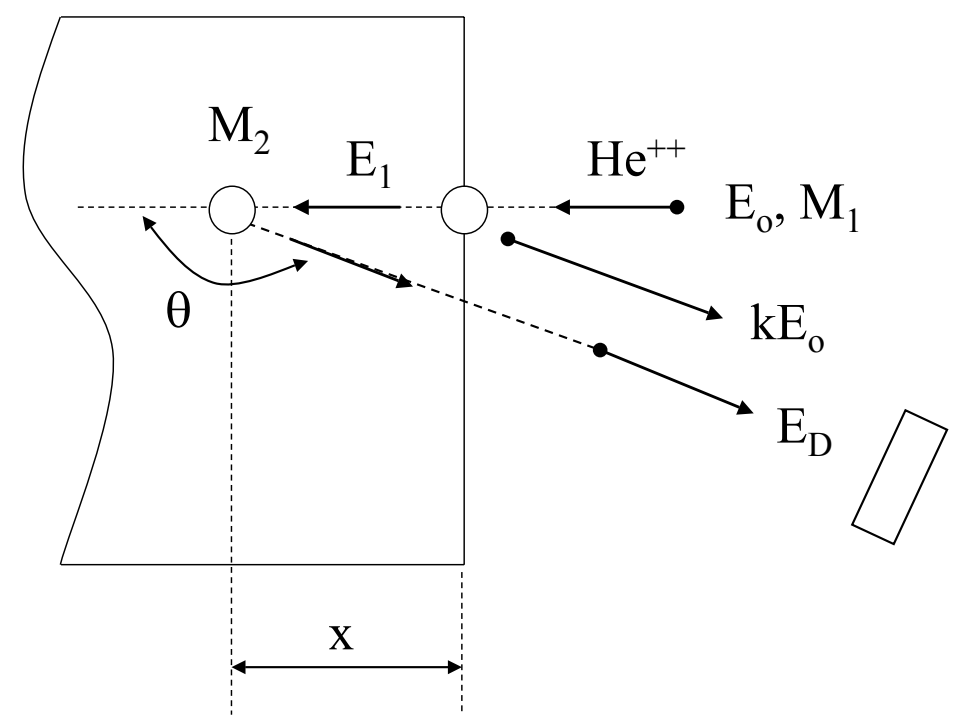

Figure 3.3: Scattering geometry in RBS.

of the target atoms (nuclear stopping). This indicates that a particle which backscatters from an element at some depth $x$ in a sample will have measurably less energy than a particle which backscatters from the same element on the sample surface. The final detected energy, $E_{D}$, of the impinging projectiles after scattering at depth $x$ is given by:

$$
E_{D}=k\left(E_{o}-\int_{0}^{x} \frac{d E}{d x} d x\right)-\int_{0}^{\frac{x}{\cos \theta}} \frac{d E}{d x} d x
$$

where the quantity $\frac{d E}{d x}$ is the energy loss by the projectile per unit distance travelled in the target given in $[\mathrm{eV} / \AA]$ and normally called the stopping power. It depends on the ion and the target material as well as on the ion energy. For practical analysis of RBS data, extensive stopping power tables were collected by Ziegler et al. [81]. The stopping cross section $\left[\mathrm{eV} /\left(\right.\right.$ atoms $\left.\left./ \mathrm{cm}^{2}\right)\right]$ assumes the energy loss per atom per atomic density $N$ of the target:

$$
S(E)=-\frac{d E}{d x} \frac{1}{N}
$$

Bragg's rule [82] was used to calculate the stopping power in the compound $\mathrm{A}_{x} \mathrm{~B}_{y}$. This approximation in the case of $\mathrm{SiO}_{2}$, reads as follows:

$$
S(E)=0.33 S_{S i}(E)+0.67 S_{O}(E) .
$$

The stopping power can be derived from equation 3.3:

$$
\left(\frac{d E}{d x}\right)_{A_{x} B_{y}}=N_{A_{x} B_{y}}\left(x_{1} S_{1}+x_{2} S_{2}\right)
$$


where $N_{A_{x} B_{y}}$ is the atomic density of the compound material.

Equation 3.3 implies that the difference in energy depends on the scattering depth $x$ and the atomic density. The depth resolution $\Delta x$ is proportional to the energy resolution, $\Delta x \approx \Delta E(d E / d x)^{-1}$ [83]. The total energy resolution is determined by the beam's energy uncertainties, $\Delta E_{b}$, the detection system's resolution, $\Delta E_{d},(12-15 \mathrm{keV})$, and the energy loss straggling in the material $\Delta E_{s}$ :

$$
\Delta E_{t o t}^{2}=\Delta E_{b}^{2}+\Delta E_{d}^{2}+\Delta E_{s}^{2}
$$

The beam energy spread $\Delta E_{b}$ depends on the energy and the charge of the accelerated particle $\left(\Delta E_{b}(500 \mathrm{keV})=105 \mathrm{eV}\right.$ for a proton beam at IONAS [75]) and can be neglected, because it is much smaller than the energy resolution of the silicon detector. The energy straggling, $\Delta E_{S}$, is a statistical process which accounts for the large number of interactions of the projectile with atoms along its trajectory. This limits the energy resolution that can be achieved for projectiles backscattered from larger sample depths. Bohr [84] formulated the beam straggling:

$$
\Delta E_{\text {Bohr }}^{2}=4 \pi Z_{1}^{2} Z_{2} N e^{4} x .
$$

Bohr's equation offers a good approximation of the straggling and predicts that Bohr straggling does not depend on the ion energy.

The yields of detecting a backscattered $\alpha$-particle at a depth $x$ with energy $E_{D}$ can be expressed as:

$$
Y=Y_{o} \frac{d \sigma}{d \Omega} N \Omega
$$

where $Y_{o}$ is the number of primary ions in the beam time integrated over the current of charged particles incident on the target, $N$ is the atomic density, and $\Omega$ is the solid angle of the detector.

The quantity $\frac{d \sigma}{d \Omega}$ is described as differential Rutherford scattering cross-section and in a lab system given as follows:

$$
\frac{d \sigma}{d \Omega}=\left(\frac{Z_{1} Z_{2} e^{2}}{4 E_{o}}\right)^{2} \frac{4}{\sin ^{4} \theta} \frac{\left[\cos \theta+\sqrt{1-\left(M_{1} / M_{2}\right)^{2} \sin ^{2} \theta}\right]^{2}}{\sqrt{1-\left(M_{1} / M_{2}\right)^{2} \sin ^{2} \theta}}
$$

$Z_{1}$ and $Z_{2}$ being the atomic numbers of the incident particle and target material, respectively. Typically, $M_{1} \ll M_{2}$ and the previous equation can be simplified:

$$
\frac{d \sigma}{d \Omega}=\left(\frac{Z_{1} Z_{2} e^{2}}{4 E_{o}}\right)^{2} \frac{1}{\sin ^{4}(\theta / 2)}
$$

Two important consequences can be seen from this formula. Firstly, $\frac{d \sigma}{d \Omega}$ is proportional to $Z_{2}^{2}$, meaning that the heavy elements have a higher RBS efficiency than the lighter ones. Secondly, the $E_{o}^{-2}$ dependence of the cross section leads to increasing scattering yield at 


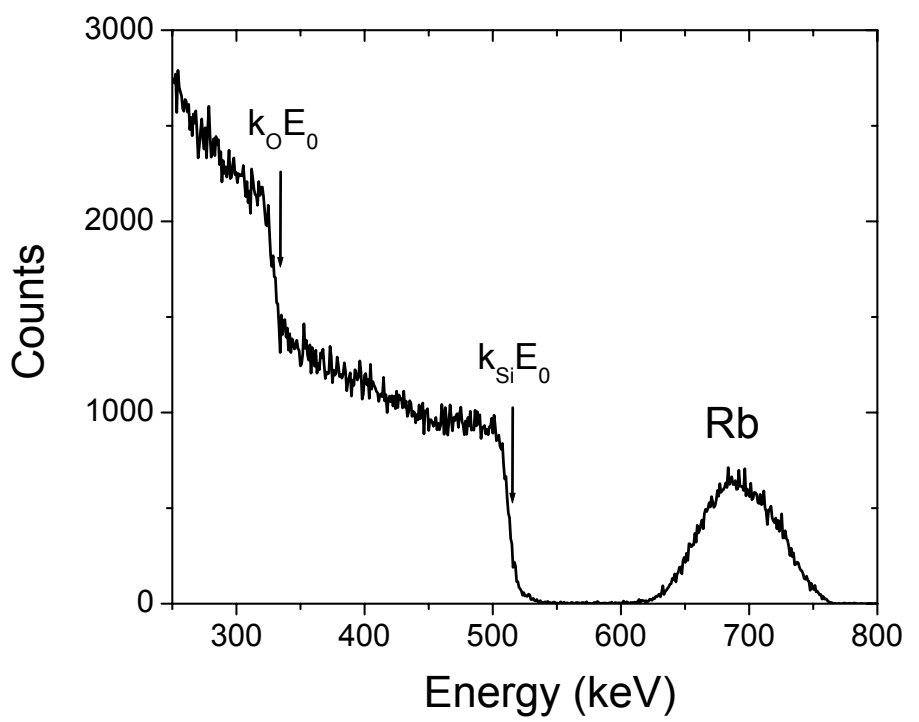

Figure 3.4: A typical RBS spectrum of $175 \mathrm{keV} \mathrm{Rb}$-ion irradiated $\alpha$-quartz at a fluence of $2.5 \times 10^{16} \mathrm{Rb} / \mathrm{cm}^{2}$ measured by $0.9-\mathrm{MeV} \alpha$-particles. The arrows indicate the energy positions of the $\mathrm{Si}$ and the $\mathrm{O}$ surfaces. The $\mathrm{Rb}$ distribution resembles a Gaussian profile.

low energies.

In figure 3.4 a typical RBS spectrum of $\mathrm{Rb}$-irradiated $\alpha$-quartz is presented, measured with $0.9-\mathrm{MeV} \alpha$-particles. On the high energy side there is a gaussian-shaped peak due the implanted $\mathrm{Rb}$-ions. The other two edges at lower energies originate from scattering of $\mathrm{Si}$ and $\mathrm{O}$ atoms at the $\mathrm{SiO}_{2}$ surface. No change in $\mathrm{Si}$ and $\mathrm{O}$ concentrations at the site of the $\mathrm{Rb}$ was observed at a fluence of $2.5 \times 10^{16} \mathrm{Rb} / \mathrm{cm}^{2}$. These two edges correspond to the values of $k_{S i} E_{o}$ and $k_{O} E_{o}, k_{S i}$ and $k_{O}$ being the kinematic factors for silicon and oxygen, and $E_{o}$ the beam energy. In an RBS analysis the atomic density of the substrate must be known in order to convert the energy scale of the RBS spectra into a depth scale. If the density is not known, the number of atoms in the examined layer is taken as abscissa and the depth scale in $10^{15}$ at. $/ \mathrm{cm}^{2}$ is used. This scale can be converted simply into a depth scale by dividing it by the atomic density, $\mathrm{N}$, of the material. In the case of this study, an amorphized layer of $1 \times 10^{15}$ at. $/ \mathrm{cm}^{2}$ corresponds to about $0.15 \mathrm{~nm}$ using $\mathrm{N}=6.45 \times 10^{22}$ at./cm $\mathrm{cm}^{3}$ of amorphous $\mathrm{SiO}_{2}$ [8]. Figure 3.5 shows a typical concentration profile of $\mathrm{Rb}$ ions implanted into $\mathrm{SiO}_{2}$ at a fluence of $2.5 \times 10^{16} \mathrm{Rb} / \mathrm{cm}^{2}$, as determined from the RBS data shown in fig.3.4.

The software package RUMP [85] was used to analyze the RBS data and to extract the $\mathrm{Rb}$ concentration profiles . 


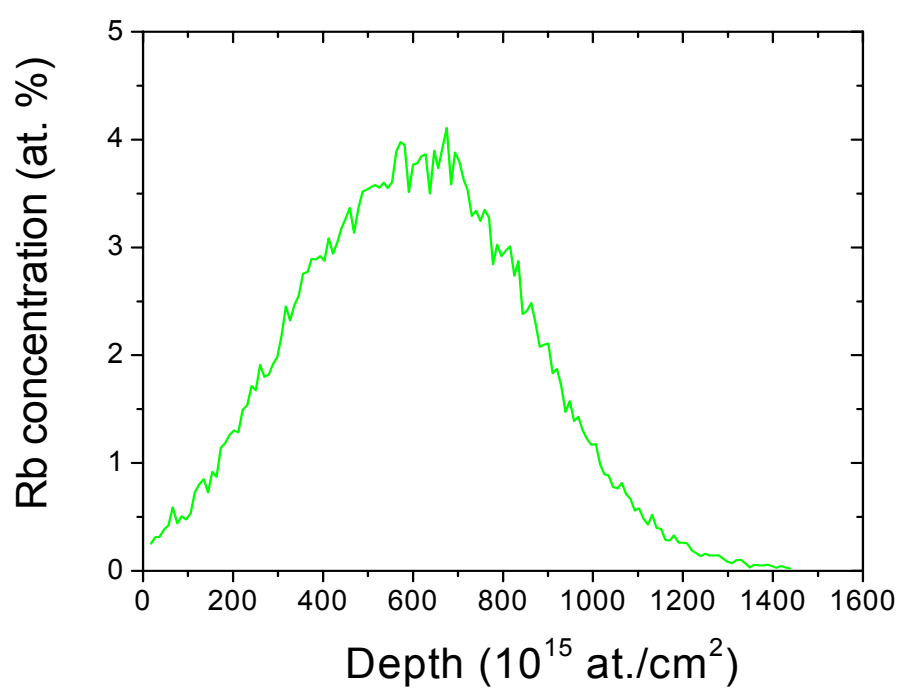

Figure 3.5: $\mathrm{Rb}$ concentration profile as a function of the depth for $\alpha-\mathrm{SiO}_{2}$ implanted at $80 \mathrm{~K}$ with $175 \mathrm{keV} \mathrm{Rb}$-ions at fluence of $2.5 \times 10^{16} \mathrm{Rb} / \mathrm{cm}^{2}$.

\section{RBS-Channeling (RBS-C)}

In addition to elemental compositional information, RBS under channeling conditions can also be used to study the crystallinity of the sample [79]. In this thesis, RBS-Channeling analysis was used to monitor the recovery of the damaged layer in alkali-ion amorphized $\alpha$-quartz before and after each annealing. The channeling spectra were taken along the $<0001>$ axis by means of a two-axis goniometer. A detailed description of an RBS chamber equipped with a two-axis goniometer is presented by Conrad [86]. Channeling can be defined as a phenomenon in which the rows or planes of atoms in the lattice are aligned parallel to the projectile direction. In this regime, the incident beam penetrates the crystal governed by motion due to correlated small-angle screened Coulomb collisions with the atoms bordering the channels. In the case of planar channeling the scattering yield decreases (5 - 30\% of the random yield) as the crystal is tilted so that the beam direction is parallel to the plane. When the beam is aligned to the axis of the crystal (axial channeling), the backscattering yield decreases (typically by 2 - 5\% for good crystals in low-index channels). Figure 3.6 presents three typical examples of the effects of the impinging beam on a crystalline substrate: (a) along a crystallographic axis, (b) in random direction, (c) corresponds to the situation, where the top layer of the crystalline substrate was amorphised. By measuring the reduction in the backscattering yield in various channeling directions, the crystal structure can be deduced and defect locations as well as defect concentrations can be measured. The histogram of this reduced yield is called channeling spectrum. However, if the defects consist of self atoms, this kind of 


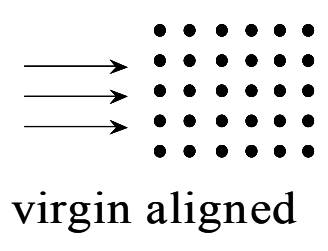

(a)

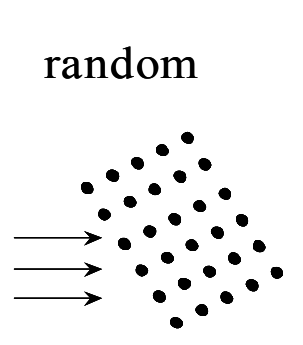

(b)

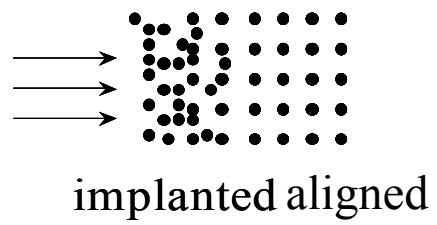

(c)

Figure 3.6: Schematic illustration of the crystalline sample oriented in various directions with respect to the beam: (a) virgin aligned - the beam enters a single crystal along a row of atoms in channeling conditions, (b) random - the beam hits the crystal in random condition, (c) implanted aligned - the channeling application in surface science (amorphized layer on the top of crystalline substrate).

measurement is impossible. In order to avoid channeling effects in single crystal layers when compositional analysis is being performed (the channeling can result in erroneously low concentrations for elements in these layers), the sample rotated or tilted 7 degrees off of the channeling axis is required (fig.3.6 (b)). Spectra achieved in this manner are called random spectra.

RBS-Channeling data for quartz irradiated with $50 \mathrm{keV} \mathrm{Na}$ ions at liquid nitrogen temperature are presented in fig.3.7 and compared with the spectra measured in random and inchannel direction in a non-irradiated crystalline quartz sample. This figure corresponds to the three situations schematically presented above. In the RBS-C random spectrum, two edges can be seen, which correspond to the energies of those $\alpha$-particles backscattered from $\mathrm{Si}$ and $\mathrm{O}$ surface atoms. The low minimum yield of about $5 \%$ for the virgin channeling spectrum proves the good quality of the quartz sample. After irradiation, the yield of the RBS-C spectra does not decrease from the random level above $410 \mathrm{keV} \alpha$-energy, indicating the formation of an amorphous layer. From the value of this energy, the thickness of the amorphous/crystalline $(\mathrm{a} / \mathrm{c})$ interface can be calculated. Below this energy, the observed channeling yield decreases and thus reveals the presence of the crystalline substrate underneath the amorphous layer, but the backscattering yield is by almost one 


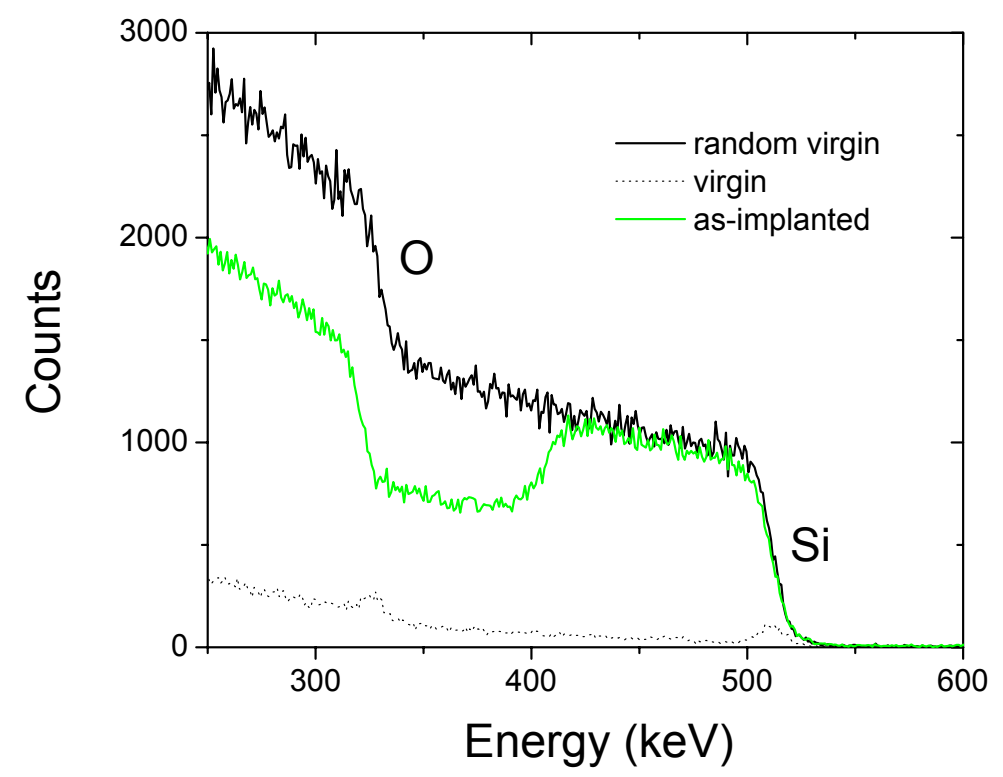

Figure 3.7: RBS-C spectra of virgin and $50 \mathrm{keV} \mathrm{Na-ion} \mathrm{irradiated} \mathrm{quartz} \mathrm{at} \mathrm{a} \mathrm{fluence}$ $1 \times 10^{16} \mathrm{Na} / \mathrm{cm}^{2}$.

order of magnitude higher than the virgin aligned spectrum. This effect appears through dechanneling. Some of the $\alpha$-particles passing through the damaged layer are deflected out of the channel and scattered at angles greater than the critical angle for channeling due to collisions with the defects in the structure. The dechanneled ions can then interact with the lattice atoms, resulting in an increase in the backscattering yield. Evidently, decreasing the thickness of the amorphous layer would lead to a decrease in the dechanneling. Generally, the value of damage, $\chi$, at the depth $x$ (corresponding to the channel number $i$ ) can be determined by comparing the yield of the implanted aligned spectrum $Y_{I A}(i)$ with the random one $Y_{R}(i)$ :

$$
\chi(i)=\frac{Y_{I A}(i)-Y_{D e c h}(i)}{Y_{R}(i)-Y_{D e c h}(i)}
$$

where $Y_{\text {Dech }}(i)$ is the dechanneling contribution. Fig.3.8 shows the Si damage profile, $\chi$, deduced from the RBS-C spectra presented in fig.3.7 using the computer code DAMAGE [86], which accounts for the dechanneling yield by employing a procedure proposed by Walker and Thompson [87]:

$$
Y_{\text {Dech }}(i)=Y_{V}(i)+C\left(\frac{1}{2} d(i)+\sum_{j=i+1}^{k} d(j)\right)
$$

where $Y_{V}(i)$ is the backscattering yield of the virgin aligned spectrum, $C$ is a constant which can be estimated by means of an iterative loop, $d(i)$ is the number of dechanneled 


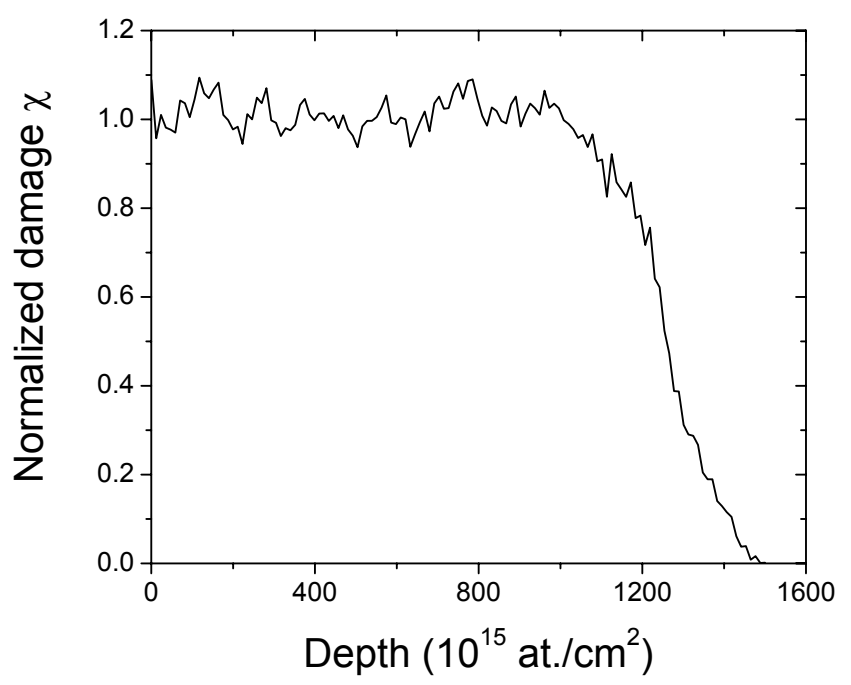

Figure 3.8: Depth distribution of the Si radiation damage extracted from the RBS-C spectra (see fig.3.7).

particles at channel $i$, and the sum gives the dechanneling due to the amorphized layer. The channeling and random spectra have the same yield up to $410 \mathrm{keV}$ (see fig.3.7), meaning that $\chi=1$ and a damaged layer has been formed. The crystalline substrate was amorphized up to a mean depth of $1260 \times 10^{15}$ at. $/ \mathrm{cm}^{2}$ (where $\chi=0.5$ ). By combining this value with an atomic density of amorphous $\mathrm{SiO}_{2}$, the calculated amorphous layer corresponded to $195 \mathrm{~nm}$, about twice the mean $\mathrm{Rb}$ range.

From the evolution of the amorphous layer thickness as a function of the annealing temperature and time, one may extract the regrowth velocity of the a/c interface.

\subsubsection{Elastic Recoil Detection Analysis (ERDA)}

As shown in the previous section, Rutherford Backscattering Spectrometry is not useful for detecting light elements. One of the most suitable ion-beam techniques for the depth profiling of light elements in thin-films is Elastic Recoil Detection Analysis (ERDA) [80, 88]. The concepts of RBS and ERDA are very similar. The main difference is that in the case of RBS the backscattered incident particles (usually $\alpha$-particle) are detected, whereas in the case of ERDA the recoiled target atoms are detected after being hit by a heavier projectile.

Figure 3.9 shows the principle of ERDA in glancing geometry. An energetic ion with energy $E_{o}$, mass $M_{1}$, and atomic number $Z_{1}$ is incident on a target at an angle $\theta_{1}$ to the target normal. After an elastic scattering collision between the ion and the target atom with mass $M_{2}$ and element number $Z_{2}$ at an angle of $\phi=\pi-\left(\theta_{1}-\theta_{2}\right)$, the energy $E_{R}$ of 


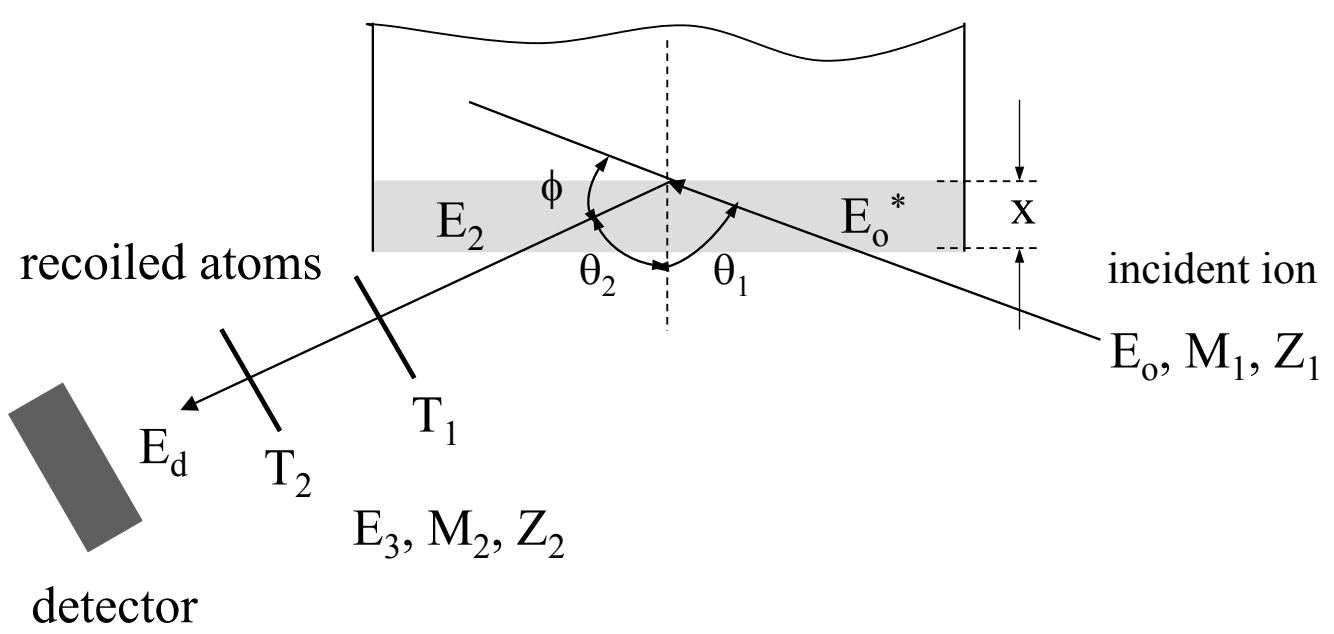

Figure 3.9: Schematic principle of the Elastic Recoil Detection Analysis (ERDA).

the recoiled atom is given by [80]:

$$
E_{R}=\Lambda E_{o}=\frac{4 M_{1} M_{2} E_{o}}{\left(M_{1}+M_{2}\right)^{2}} \cos ^{2} \phi
$$

By traversing the sample, the projectile has an energy $E_{o}^{*}$ (before being scattered out of the sample atom). If the collision takes place at a certain depth, $x$, inside the target, the recoil atoms lose further energy and emerge with energy $E_{3}(x)$, which can be expressed as:

$$
E_{3}(x)=\Lambda E_{o}-\left(\frac{\Lambda S_{P}}{\cos \theta_{1}}+\frac{S_{R}}{\cos \theta_{2}}\right) x
$$

where $S_{P}$ and $S_{R}$ are the average stopping powers of the incident projectile and the recoiled atom, respectively. Polymer or metallic films can be placed in the front of the detector to absorb the backscattered projectiles and to separate the different recoil elements (different atoms have a different stopping power and kinematic factor). The yield of detected recoiled particles at an energy, $E_{d}$, in the detector solid angle, $d \Omega$, is given by the equation:

$$
Y_{R}\left(E_{d}\right)=Y_{o} d \Omega d x \frac{d \sigma}{d \Omega}
$$

where $Y_{o}$ is the total number of incident ions, $d x$ the ion path length in the sample and $d \sigma / d \Omega$ the differential recoil cross section. In the laboratory coordinates the differen- 


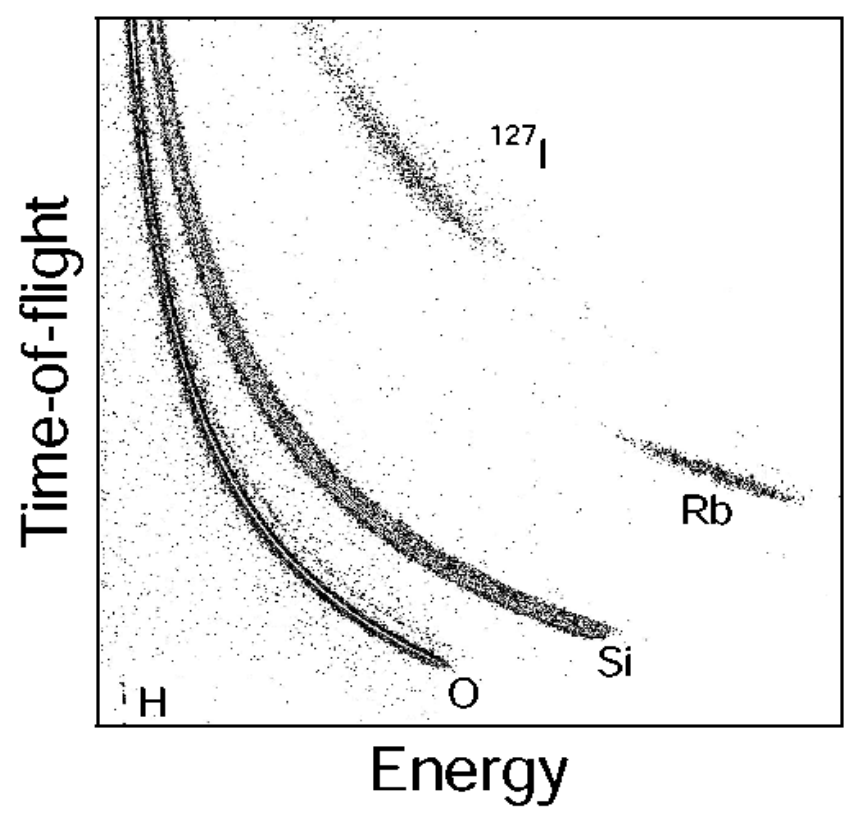

Figure 3.10: TOF-ERDA spectrum taken for an $\alpha$-quartz sample irradiated with $175 \mathrm{keV}$ $\mathrm{Rb}$-ions at the fluence $2 \times 10^{16} \mathrm{Rb} / \mathrm{cm}^{2}$. The banana curves present the signals coming from the substrate $\left({ }^{28} \mathrm{Si}\right.$ and $\left.{ }^{16} \mathrm{O}\right)$ and the ${ }^{85} \mathrm{Rb}$ signal.

tial cross-section for recoil atoms can be calculated assuming Rutherford scattering as follows:

$$
\frac{d \sigma}{d \Omega}=\left(\frac{Z_{1} Z_{2} e^{2}}{2 M_{2} E_{o}^{*}}\right)^{2} \frac{\left(M_{1}+M_{2}\right)^{2}}{\cos ^{3} \phi}
$$

In this work, Time of Flight (TOF) ERDA measurements were performed. In the TOFERDA technique the measured spectrum contains information about the energy and the velocity of the recoiled atoms. The Time-of-Flight is measured over a known flight distance ( $L$ up to $1 \mathrm{~m}$ ) between two timing gates $T_{1}$ and $T_{2}$ (typically, thin carbon foils same $\mu \mathrm{g} / \mathrm{cm}^{2}$ ). Recoiled atoms passing through the foil cause the emission of secondary electrons, which are accelerated and guided by means of an electrostatic mirror onto microchannel plates, where passage time signals are created. The correlation between the detected recoiled atom energy, $E_{3}$, its mass, $M_{2}$, and the time of flight, $t$, can be presented as:

$$
E_{3}=\frac{M_{2} v_{2}^{2}}{2}=\frac{M_{2} L^{2}}{2 t^{2}}
$$

where $v_{2}$ is the velocity of the recoiled atom. This technique solves the general problem of the mass-energy ambiguity incurred by Elastic Recoil Detection, and allows the mass and energy of the recoils atoms to be measured simultaneously, by the measurement of the energy and the time of flight. 
Time-of-flight isotope separation of an $\alpha$-quartz sample implanted with $175 \mathrm{keV} \mathrm{Rb}$-ions was obtained using a 53-MeV ${ }^{127} \mathrm{I}^{10+}$ beam and is shown in fig.3.10. Such typical TOFERDA spectra are called banana curves. The X-axis shows the recoil energy as function of the time of flight on the y-axis. On each banana, the different recoil energies correspond to a recoiled atom along the projectile path. The $\mathrm{Rb}$ was detected only near the surface, in the first $280 \mathrm{~nm}$ of the sample. The mass of the detected recoil atoms increases along the horizontal energy scale. The concentration profiles are converted by the deconvolution of the banana curves.

Time-of-Flight ERD analyses for depth profiling of the ${ }^{16} \mathrm{O},{ }^{18} \mathrm{O},{ }^{28} \mathrm{Si}$, and ${ }^{85} \mathrm{Rb}$ contents were performed by Dr. T. Sajavaara at the 5-MV EPG-10-II tandem accelerator of the University of Helsinki [88]. The 53-MeV ${ }^{127} \mathrm{I}^{10+}$ beam was directed at $70^{\circ}$ relative to the sample surface and the ejectives at $70^{\circ}$ relative to the sample surface, thus forming a scattering angle of $40^{\circ}$ to the incoming beam. The flight path $L$ between the time-marking detectors was $68.4 \mathrm{~cm}$ and an ion-implanted silicon detector was located behind the second timing gate at a distance of $124.3 \mathrm{~cm}$ from the target surface. The beam current was kept at about $0.5 \mathrm{pnA}$ and the spot size was $1 \mathrm{x} 2 \mathrm{~mm}^{2}$. Pure quartz was measured for background reduction. Ziegler-Biersack-Littmack (ZBL) stopping powers [78] and an amorphous density of $2.15 \mathrm{~g} / \mathrm{cm}^{2}\left(6.45 \times 10^{22}\right.$ at. $\left./ \mathrm{cm}^{3}\right)$ were used for determining the depth distributions. Details of the TOF-ERDA equipment and numerical procedure to derive the depth distributions are given in Ref. [88].

\subsubsection{Atomic Force Microscopy (AFM)}

The Atomic Force Microscope (AFM) was invented in 1986 by Binnig, Quate, and Gerber [93]. The objective of AFM studies was to observe surface topographies with the sub-atomic resolution. The surface roughness and topography investigated with AFM is based on the forces between a "sharp" tip, which is mounted to a cantilever spring and the sample surface.

Diagram 3.11 illustrates a schematic AFM setup. The laser beam is focused on the reverse side of the cantilever holding the tip and is reflected to a photodiode sensor. A feedback loop controls the movement of the tip (and therefore of the cantilever) and the bounced laser beam is ajusted to the same position with z-piezo movements. Generally, from these movements, the images of the surface topography can be achieved.

AFM can be operated by measuring attractive or repulsive forces between the tip and the sample [93]. Figure 3.12 presents the variation with separation, $r$, of the interatomic potential energy of two atoms. The interaction is repulsive at separations less than $r_{o}$. The force is attractive at separations greater than $r_{o} . r_{o}$ corresponds to the transition between the contact and non-contact mode. In repulsive (contact) mode, the tip and the sample remain in close contact. As the tip is moved across the sample, the contact force causes the cantilever to bend according to changes in topography. In non-contact mode, 


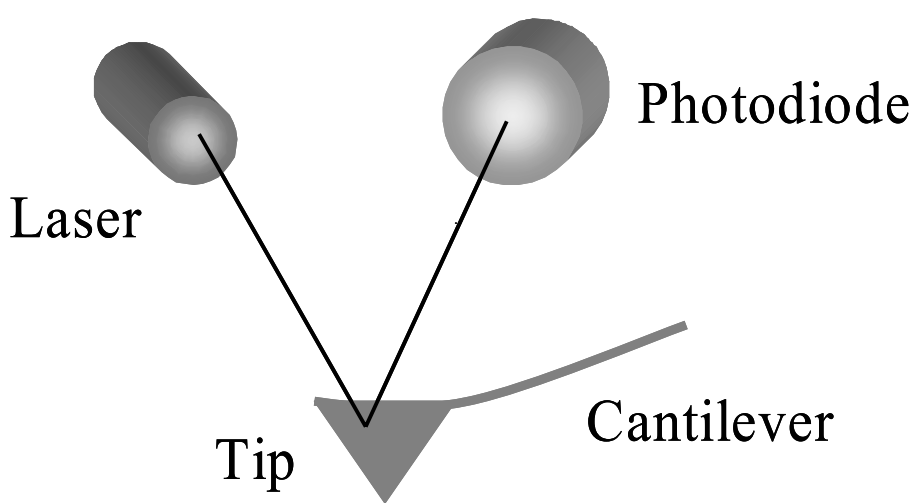

\section{Q0802000 Sample surface}

Figure 3.11: A schematic diagram of the AFM measurement setup.

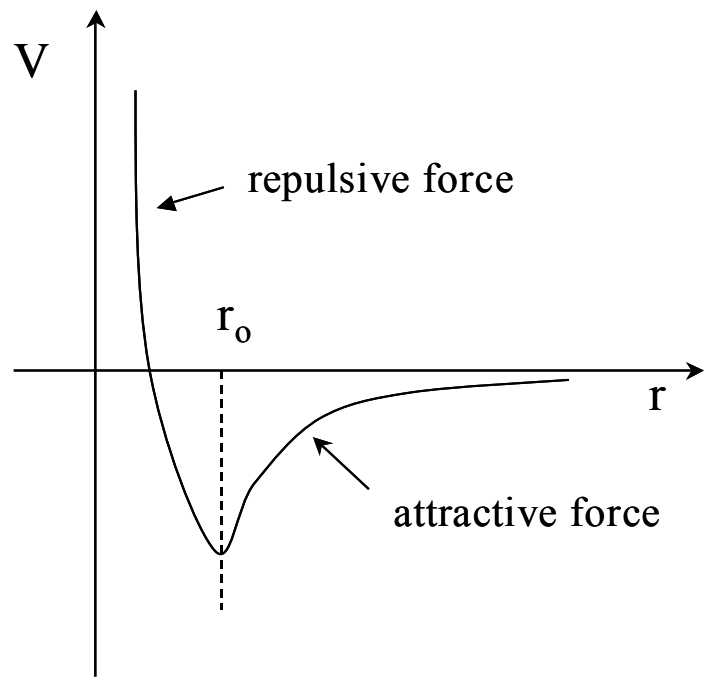

Figure 3.12: A schematic potential energy diagram for the interaction of two atoms.

the AFM derives topographic images from the measurements of attractive force. Intermittent (tapping) mode is very similar to non-contact mode. The oscillated cantilever tip is drawn closer to the sample surface and the tip only taps the surface for a very small fraction of its vibration period. It also eliminates lateral forces between the tip and the sample. 
For this thesis, ThermoMicroscopes AutoProbe CP Reseach was used in the non-contact AFM mode to examine the surface morphology and the border area between the implanted and non-implanted parts of the samples.

\subsubsection{Cathodoluminescence (CL)}

The term luminescence (from Latin "weak glow" [89]) was introduced by Wiedemann (1888). It describes the emission of light from both organic and inorganic solids (i.e. microorganisms, minerals), which are excited by some form of energy.

The interaction of an impinging electron beam with the sample produces plenty of different effects (see fig.3.13), such as an electron current, $x$-rayluminescence, cathodoluminescence $(\mathrm{CL})$, and thermoluminescence.

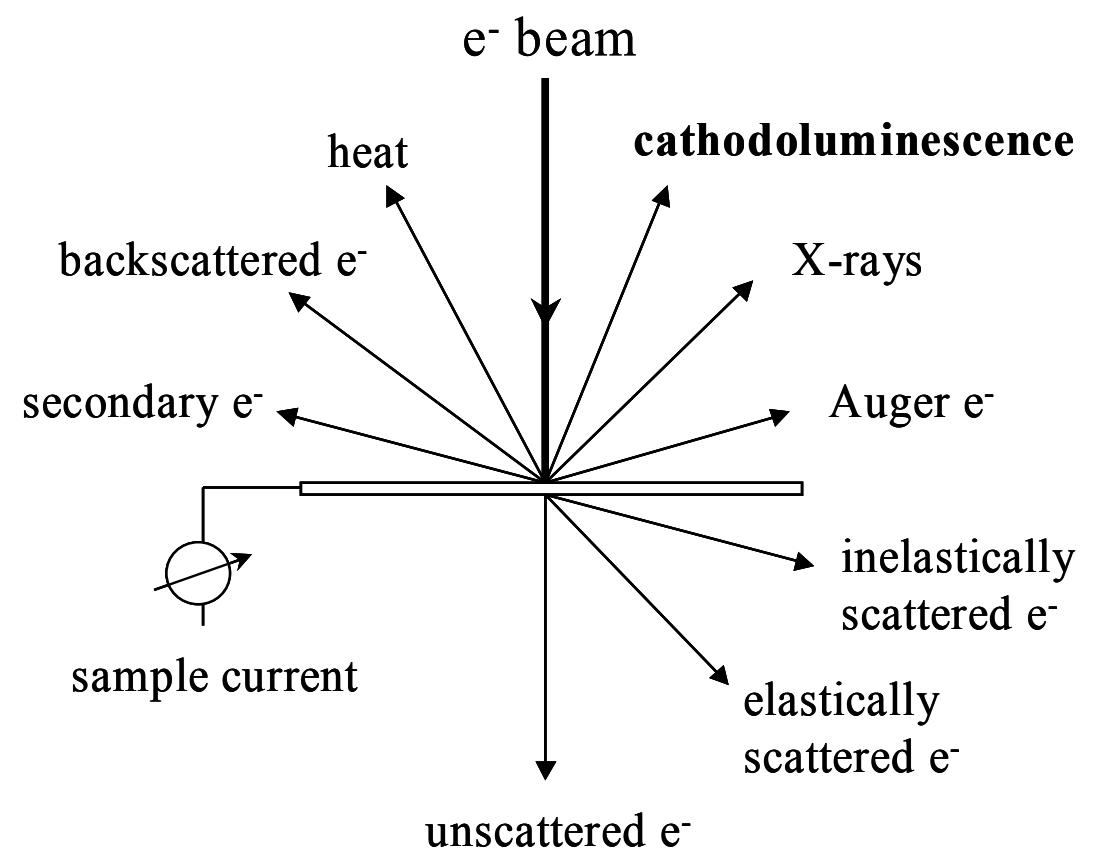

Figure 3.13: A schematic illustration of the processes resulting from electron bombardment.

There are two types of luminescence: intrinsic CL, which is characteristic of the host lattice and extrinsic CL, which arises from impurities. Intrinsic luminescence is increased by non-stoichiometry (vacancies), structural imperfections (radiation and shock damage), and impurities (non-activators). Activators are those impurities leading to extrinsic luminescence.

The general CL process can be divided into three stages: (1) absorption of the exciting 


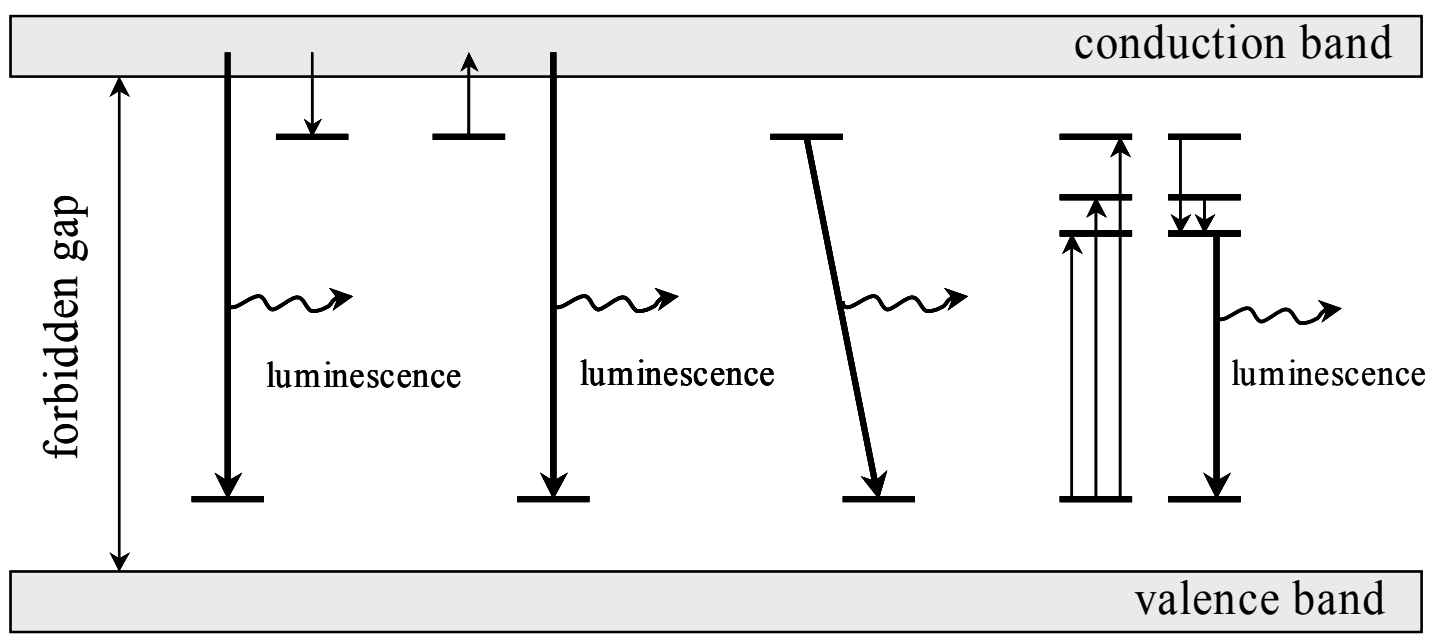

a

b

c

d

Figure 3.14: Charge transfer and luminescence emission in crystals proposed by $\mathrm{Kr}$ betschek et al. [92]: (a, b) band-to-impurity, (c) donor-acceptor pair transition, and (d) excitonic interaction.

energy; (2) transfer of the excitation energy, and (3) emission of light and the return to a non-excited state [90]. The first two steps mostly depend on the character of the excitation, whereas the last step depends on the type of luminescence center.

In insulators (in our case quartz), a broad energy gap ( $\geq 2 \mathrm{eV}$ [91]) separates the valence and the conduction band (fig.3.14). For cathodoluminescence the presence of luminescence centers (i.e. impurity ions, excited states of isolated atoms and ions, lattice defects [89]) is required, which create discrete energy levels in the gap. These activators can be divided into electron traps in the donor level (near the conduction band) and recombination sites in the acceptor level (near the valence band). Electron irradiation causes the electron to jump from the ground states to excited states. The de-excitation is a return to a state of lower energy, which is located inside the forbidden zone later. Excitation causes either electron trapping or their recombination with a luminescent or a non-luminescent center (fig.3.14 (a)). A photon is emitted in the case of a luminescent transition. For the impurities in a crystal lattice, the non-luminescent transitions occur as a result of absorption or emission of lattice vibrations (phonons). A trapped electron can be excited again, 


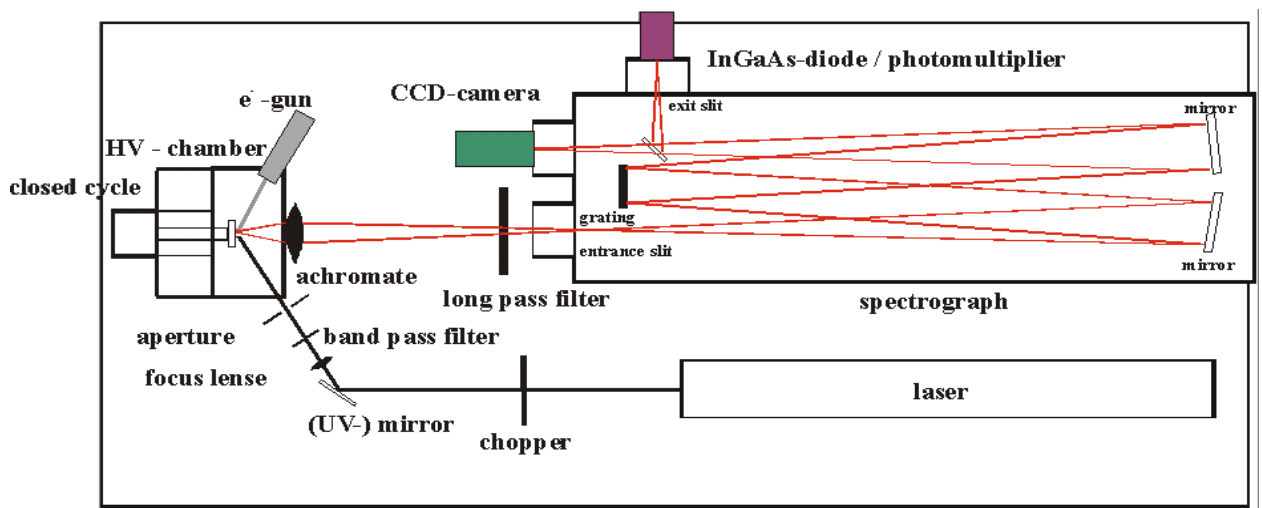

Figure 3.15: A schematic of the CL/PL setup.

jump within the conduction band, and recombine with an activator element level under photon emission (fig.3.14 (b)). If the energy difference between the electron trap and the luminescence level is small, a direct luminescent transition of the electron to the recombination center can occur (fig.3.14 (c)). The excitation of several energy levels following the relaxation and the luminescence emission of a single luminescent energy level is presented in fig.3.14 (d).

In this work, the CL studies were performed using a Specs Auger electron gun EQ-22 (see fig.3.15). The samples were cooled down to about $10 \mathrm{~K}$ by means of a closed-cycle helium cryostat. The CL light was collected by a photo-multiplier tube (Hamamatsu R928) after focussing into a Czerny-Turner spectrograph (Jobin Yvon $1000 \mathrm{M}$ ). The $5 \mathrm{keV}$ electron beam current was kept at $2 \mu \mathrm{A}\left(1 \mathrm{~W} / \mathrm{cm}^{2}\right)$. Each CL spectrum was collected for an integration time of $>700 \mathrm{~s}$ in steps of $1 \mathrm{~nm} / \mathrm{s}$ in the wavelength range of $200-900 \mathrm{~nm}$.

\subsubsection{Mechanical surface profilometry}

The step height between the non-implanted and the implanted part of the sample was monitored with a mechanical surface profiler Dektat ${ }^{3} \mathrm{ST}$ (vertical resolution about $3 \mathrm{~nm}$ [77]). The measurement was performed by scanning the surface with a diamond needle and recording the changes of its vertical position with respect to a reference level. In this way, 


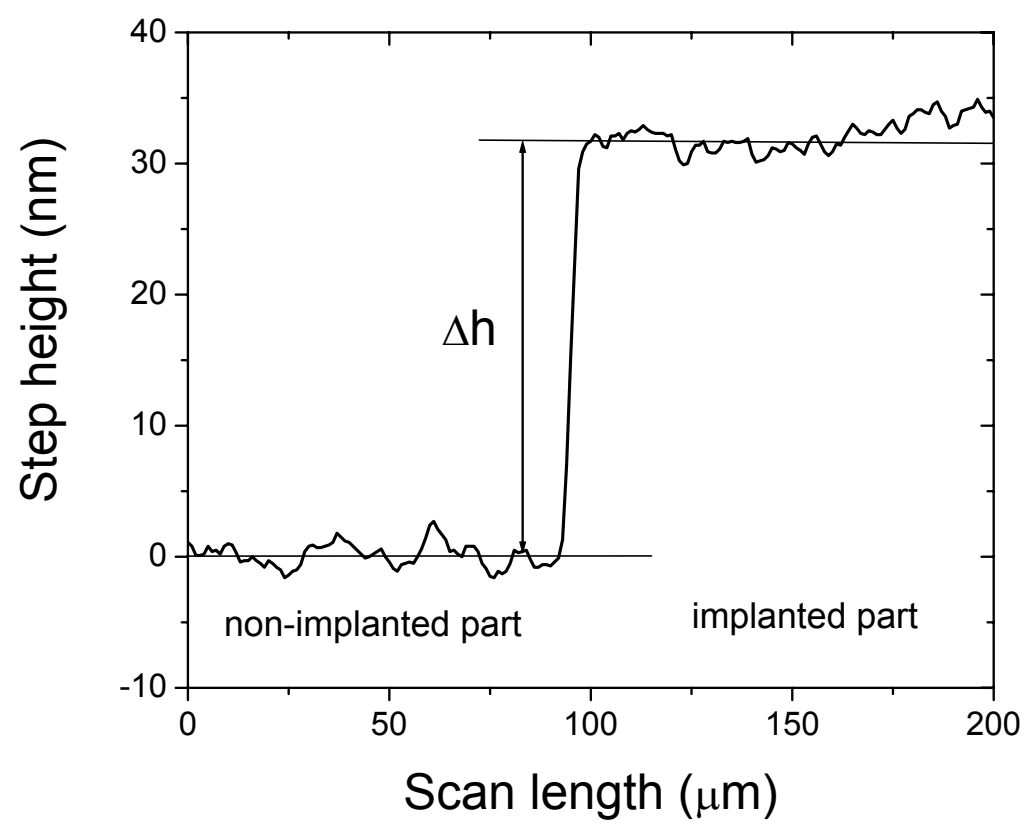

Figure 3.16: Typical surface profile of $\mathrm{Rb}$-ion irradiated $\alpha$-quartz showing the step height, $\Delta h$, between the non-irradiated and the irradiated part of sample.

by scanning the needle position across the surface, a map of the sample topography can be obtained.

In this work, the mechanical surface profilometry was used to check the information obtained from the RBS-C measurements, as there is a significant change in density between the amorphous and crystalline part of the sample. Figure 3.16 illustrates the typical surface profile of the $\mathrm{Rb}$-ion irradiated $\alpha$-quartz. During each irradiation, about one half of the surface area of the sample was covered with an Al foil. This preserved the crystalline part required for the reference level during the surface profiling. The implanted part of the sample is higher, due to a decrease in the density after ion irradiation. 


\section{SPEG after Rb implantation}

In this chapter the results on the solid-phase epitaxial regrowth of the amorphized layer in $\alpha-\mathrm{SiO}_{2}$ induced by $\mathrm{Rb}$ irradiation during thermal annealing in air or ${ }^{18} \mathrm{O}_{2}$ will be presented. The study was performed as a function of the temperature $(\leq 1170 \mathrm{~K})$, the implanted $\mathrm{Rb}$ fluence $(0.1-6) \times 10^{16}$ ions $/ \mathrm{cm}^{2}$, annealing time $(1-2 \mathrm{~h})$, and oxygen pressure (5 - 800 mbar). Rutherford Backscattering Channeling Spectrometry was used to characterize the damage profiles and $\mathrm{Rb}$ depth distributions. The role of the oxygen exchange between the annealing gas and the $\mathrm{SiO}_{2}$ matrix was highlighted by measuring the ${ }^{16} \mathrm{O}$ and ${ }^{18} \mathrm{O}$ profiles by means of Time-of-Flight Elastic Recoil Detector Analysis. The surface topography was investigated using an Atomic Force Microscope.

\subsection{Influence of annealing temperature}

\subsubsection{Epitaxy in air}

The objective of the present study of chemically guided epitaxy after $175 \mathrm{keV} \mathrm{Rb}$-ion implantation was to investigate the role of the temperature and the annealing atmosphere in the SPEG process. The $\alpha$-quartz samples were irradiated at $80 \mathrm{~K}$ with a fixed fluence of $2.5 \times 10^{16}$ ions $/ \mathrm{cm}^{2}$ and then isochronally annealed for 1 hour in air at temperatures between 843 and $1173 \mathrm{~K}$. RBS-Channeling data taken before and after implantation and each air-annealing step at the various temperatures are reported in fig.4.1 and compared with spectra measured in random (taken in rotating condition) and in-channel direction in a non-irradiated crystalline sample. The RBS-C random spectrum illustrated in fig.4.1 shows two edges, which correspond to the energies of those $\alpha$-particles backscattered from $\mathrm{Si}$ and $\mathrm{O}$ surface atoms, respectively. After irradiation, the height of the RBS$\mathrm{C}$ and random signal agree up to about $380 \mathrm{keV} \alpha$-energy, corresponding to a depth of $1780 \times 10^{15}$ at. $/ \mathrm{cm}^{2}$ and indicating that an amorphous layer has been formed. Below this energy the observed channeling yield decreases and thus reveals the presence of the orginally crystalline substrate underneath the top amorphous layer. From the value of this energy the position of the amorphous/crystalline $(\mathrm{a} / \mathrm{c})$ interface was determined. At annealing temperatures up to $1073 \mathrm{~K}$, the samples remained amorphous and the position 


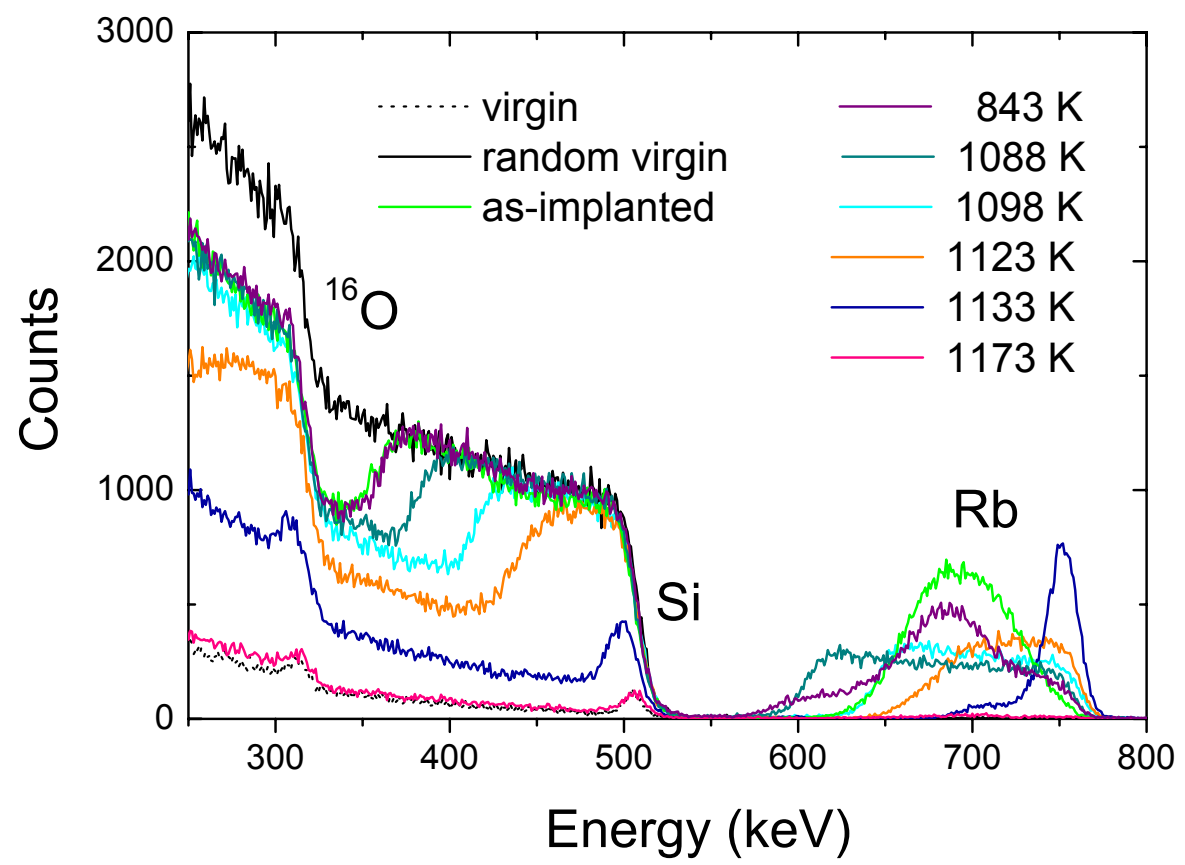

Figure 4.1: RBS-C spectra of virgin and $\mathrm{Rb}$-ion irradiated quartz samples at a fluence of $2.5 \times 10^{16} \mathrm{Rb} / \mathrm{cm}^{2}$ and after annealing in air for $1 \mathrm{~h}$ at the different temperatures. For increasing temperature one notes the gradual motion of the a/c interface and outdiffusion of $\mathrm{Rb}$. At $1173 \mathrm{~K}$, the $\alpha$-quartz matrix was fully recovered and all $\mathrm{Rb}$ has left the sample.

of the amorphous/crystalline interface hardly changed. Above this temperature, a planar movement of the a/c interface towards the surface was observed and partial epitaxy took place. Already at $1123 \mathrm{~K}$ about half of the amorphous layer thickness was epitaxially recovered. At $1133 \mathrm{~K}$, the coherent amorphous layer disappeared and only isolated damage zones and extended defects remained in the sample. By increasing the annealing temperature up to $1173 \mathrm{~K}$, complete SPEG was achieved and the RBS-C spectrum of the recrystallized substrate was identical to that of the virgin aligned one. The low minimum yield of about $5 \%$ for the virgin and the regrowth layer channeling spectra proves the good crystalline quality of the quartz samples before and after the recovery process.

The analysis of the RBS-C spectra also allowed us to monitor the Rb distribution during the recovery process. The $\mathrm{Rb}$ depth profiles extracted from the RBS data by means of the RUMP software package [85] will be discussed in more detail in section 4.4. At this point, it is interesting to note that the $\mathrm{Rb}$ distribution starts to diffuse throughout the amorphous layer (see fig.4.13), leading to a box-like Rb profile at $1023 \mathrm{~K}$. At $1073 \mathrm{~K}$, when the recrystallization process started, the back edge of the $\mathrm{Rb}$ profile was pushed out towards the surface. Similar behaviour was observed during SPEG after Cs ion implantation in $\alpha$ - 


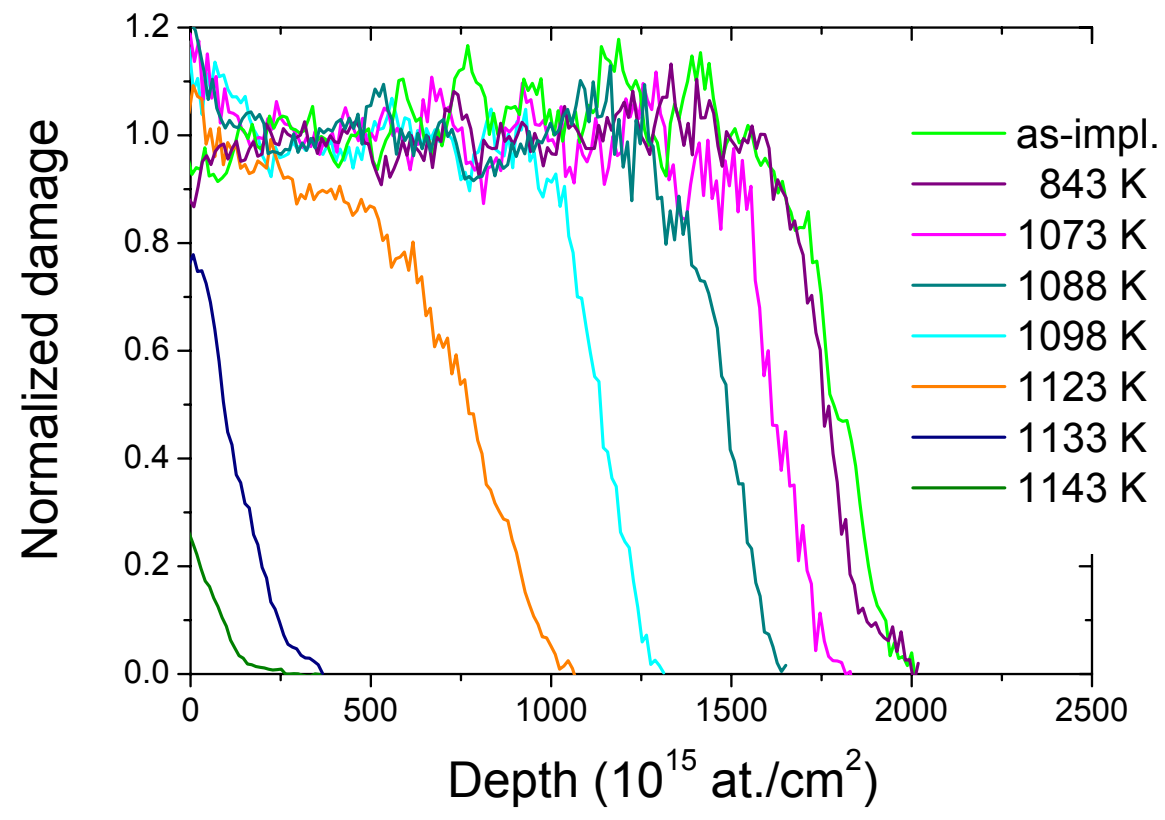

Figure 4.2: Progression of the amorphous/crystalline interface as a function of the annealing temperature. The data refer to the Si profiles of fig.4.1.

$\mathrm{SiO}_{2}$ [52] and during SPEG in Si after Au-ion implantation [94]. At $1123 \mathrm{~K}$, about half of the amorphous layer had epitaxially recovered and half of the implanted $\mathrm{Rb}$ content had diffused out of the sample. Complete out-diffusion of all the implanted $\mathrm{Rb}$ accompanies complete regrowth of the amorphous layer at $1173 \mathrm{~K}$.

Figure 4.2 presents the Si damage profiles deduced from the RBS-C spectra. After implantation the crystalline substrate was amorphized up to a depth of about $1780 \times 10^{15} \mathrm{at} . / \mathrm{cm}^{2}$. For an atomic density of $6.45 \times 10^{22}$ at./cm ${ }^{3}$ of amorphous $\mathrm{SiO}_{2}$ [8], the thickness corresponds to approximately $280 \mathrm{~nm}$. From the evolution of the amorphous layer thickness $d_{a}$ as a function of the annealing temperature during the time $t=1 \mathrm{~h}$, the regrowth velocity $v(T)$ of the a/c interface was extracted, $v(T)=\Delta d_{a}(T) / t$ (see table 4.1). The recrystallization rate $v(T)$ increased with temperature by one order of magnitude from $0.11 \times 10^{-9}$ $\pm 0.07 \mathrm{~cm} / \mathrm{s}(843 \mathrm{~K})$ to $7.67 \times 10^{-9} \pm 0.50 \mathrm{~cm} / \mathrm{s}(1173 \mathrm{~K})$. The temperature dependence of the recrystallization velocity, as shown in fig.4.3, indicates the superposition of two Arrhenius-type exponentials $v(T)=v_{o} \exp \left(-E_{a x} / k_{B} T\right)$, where $E_{a x}$ is the activation energy for the recrystallization. A linear fit yields the activation energies $E_{a x}^{L}=0.6 \pm 0.2 \mathrm{eV}$ and $E_{a x}^{H}=2.7 \pm 0.4 \mathrm{eV}$ in the low $(\mathrm{L})$ and high $(\mathrm{H})$ temperature regimes (below and above $1070 \mathrm{~K})$, respectively. The pre-exponential factors were deduced as: $v_{o}^{L}=25.1 \mathrm{~cm} / \mathrm{s}$ and $v_{o}^{H}=7.8 \times 10^{5} \mathrm{~cm} / \mathrm{s}$, in the low and high temperature regimes, respectively. These values of the activation energies suggest two different mechanisms in the two temperature regimes and are strictly attributed to the Rb out-diffusion (see section 4.4). 


\begin{tabular}{|c|c|c|}
\hline Temperature $(\mathrm{K})$ & $\mathrm{d}_{a}(\mathrm{~T})$ & $v(\mathrm{~T})\left(10^{-9} \mathrm{~cm} / \mathrm{s}\right)$ \\
\hline as-impl. & 1780 & - \\
\hline 843 & 1756 & $0.11 \pm 0.07$ \\
\hline 923 & 1723 & $0.25 \pm 0.14$ \\
\hline 973 & 1729 & $0.22 \pm 0.14$ \\
\hline 1023 & 1700 & $0.35 \pm 0.15$ \\
\hline 1073 & 1607 & $0.75 \pm 0.18$ \\
\hline 1088 & 1490 & $1.25 \pm 0.19$ \\
\hline 1098 & 1138 & $2.77 \pm 0.23$ \\
\hline 1113 & 987 & $3.42 \pm 0.24$ \\
\hline 1123 & 774 & $4.33 \pm 0.31$ \\
\hline 1133 & 115 & $7.17 \pm 0.46$ \\
\hline 1143 & 18 & $7.59 \pm 0.49$ \\
\hline 1173 & 0 & $7.67 \pm 0.50$ \\
\hline
\end{tabular}

Table 4.1: The regrowth velocity of the $\mathrm{a} / \mathrm{c}$ interface, $v(\mathrm{~T})$, at different annealing temperatures for Rb-irradiated $\alpha$-quartz. The thickness of the amorphous layer, $\mathrm{d}_{a}(\mathrm{~T})$, is also reported.

$\mathrm{T}(\mathrm{K})$

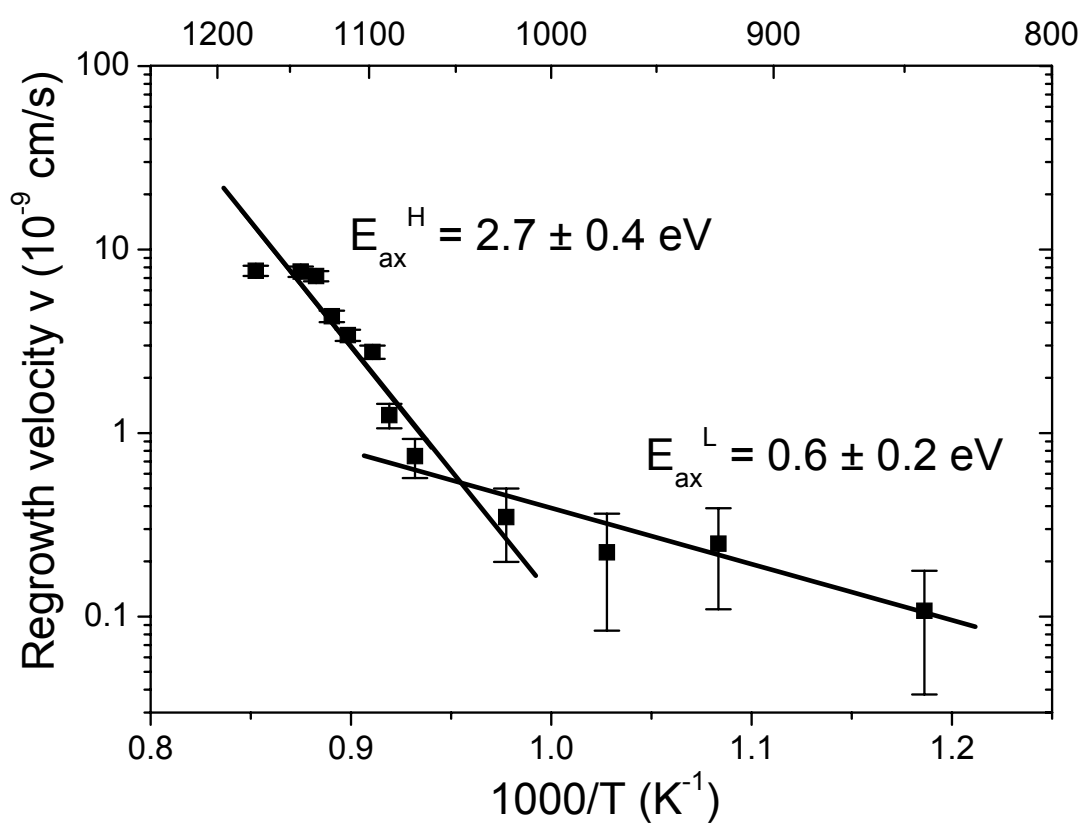

Figure 4.3: Speed $v(T)$ of the recrystallization front deduced from the Si signal displayed in fig.4.2. The two straight lines correspond to activation energies of $\mathrm{E}_{a x}^{L}=0.6$ $\pm 0.2 \mathrm{eV}$ (below $1070 \mathrm{~K}$ ) and $\mathrm{E}_{a x}^{H}=2.7 \pm 0.4 \mathrm{eV}$ (above $1070 \mathrm{~K}$ ). 


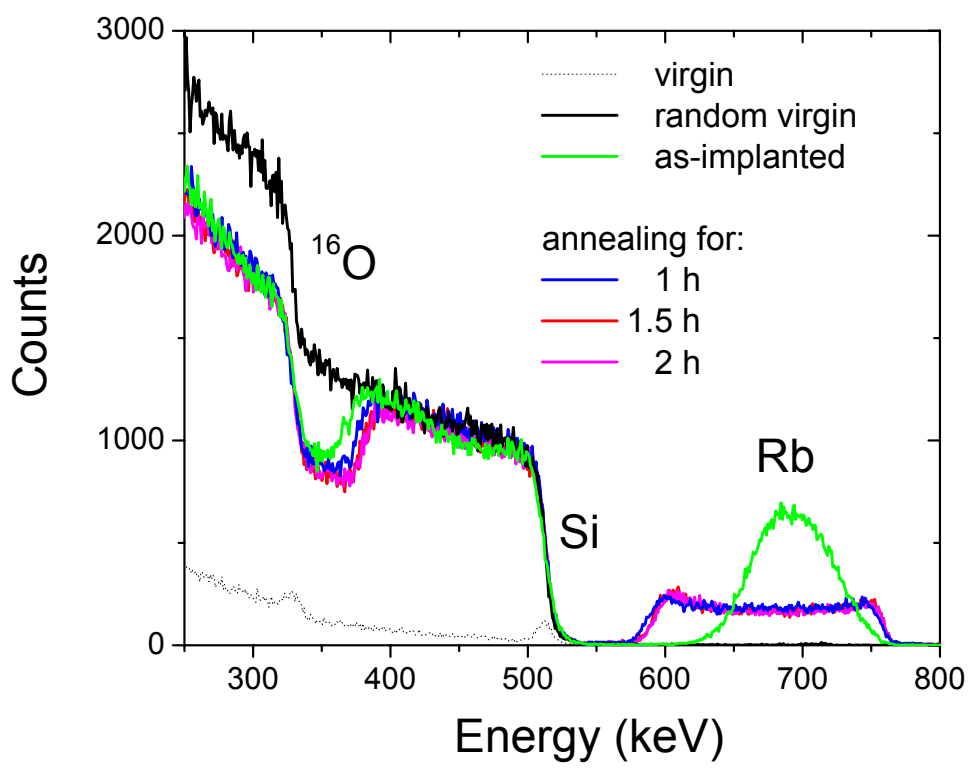

Figure 4.4: RBS-C spectra of $175 \mathrm{keV} \mathrm{Rb}$ implanted samples with an ion fluence of $2.5 \times 10^{16} \mathrm{Rb} / \mathrm{cm}^{2}$, annealed in an air atmosphere at $1023 \mathrm{~K}$ in the time range of $1-2 \mathrm{~h}$.

In the case of Cs implantation [55], the recrystallization velocity was parameterized by a single activation energy of $2.8 \pm 0.2 \mathrm{eV}$ and a pre-exponential factor of $1.5 \times 10^{4} \mathrm{~cm} / \mathrm{s}$. $\mathrm{E}_{a x}^{C s}$ is very close to the high-temperature value obtained after $\mathrm{Rb}$ implantation. Olson and Roth [65] demonstrated that epitaxial recrystallization in Si occurs at lower temperatures $(773-1023 \mathrm{~K})$ than in quartz, but the activation energy $\mathrm{E}_{a x}^{S i}=2.70 \pm 0.02 \mathrm{eV}$ is identical to our high-temperature value $\mathrm{E}_{a x}^{H}$. The main difference occurs in the value of the pre-exponential factor: $v_{o}=4.6 \times 10^{8} \mathrm{~cm} / \mathrm{s}$ in $\mathrm{Si}$, which is definitively much higher than in $\alpha$-quartz. This difference may result from a much higher recrystallization temperature in quartz than in Si. Fratello et al. [96] performed an investigation of the dependence of the growth rate of quartz crystal into fused silica and found an activation energy of $2.77 \mathrm{eV}(268 \mathrm{~kJ} / \mathrm{mol})$. This value is very close to $\mathrm{E}_{a x}^{H}$ of $\mathrm{Rb}(261 \mathrm{~kJ} / \mathrm{mol})$ and $\mathrm{E}_{a x}^{C s}$ of $\mathrm{Cs}(272 \mathrm{~kJ} / \mathrm{mol})$ [55], but significantly lower than the Si-O bonding energy, 4.57 $\mathrm{eV}(440 \mathrm{~kJ} / \mathrm{mol})$ [9]. Fratello et al. proposed a mechanism of quartz growth into amorphous silica involving breaking the $\mathrm{Si}-\mathrm{O}$ bond and its association with an hydroxyl group $(\mathrm{OH})$. A similarly activated process responsible for epitaxy can be also observed after $\mathrm{Rb}$-ion implantation. During annealing in oxygen, Rb ions interact with the bridging oxygen and weaken the strong covalent $\mathrm{Si}-\mathrm{O}$ bond of the inter-tetrahedral connections. The non-connected tetrahedral corners indicate the higher structural freedom of the network. This decreases the viscosity of the matrix and increases the probability of recrystallization $[44,97]$. At this point we mention, that the value of the Rb-O bond energy $(2.65$ 
$\mathrm{eV} \mathrm{[10])} \mathrm{is} \mathrm{much} \mathrm{closer} \mathrm{to} \mathrm{the} \mathrm{activation} \mathrm{energy} \mathrm{of} \mathrm{recrystallization} \mathrm{than} \mathrm{to} \mathrm{the} \mathrm{Si}-\mathrm{O}$ bond energy.

To find the influence of the annealing time on the recrystallization process and to test if it is possible to obtain SPEG at lower temperatures, a second series of measurements were performed at the fixed annealing temperature of $1023 \mathrm{~K}$. The same sample was used in each annealing treatment step. Figure 4.4 illustrates the RBS-C spectra before and after annealings in air at various times at a fluence of $2.5 \times 10^{16}$ ions $/ \mathrm{cm}^{2}$. Evidently, in this time range, the experiments performed are not successful with respect to epitaxy. No recovery at the amorphous-crystalline front was observed. After a 1-h annealing, Rb atoms were distributed throughout the full amorphous layer, leading to a box-like profile. However, no change in the Rb shape was observed with increasing annealing time, even after $2 \mathrm{~h}$. That indicates that the chosen temperature is clearly too low to initiate the regrowth of the $\mathrm{a} / \mathrm{c}$ interface towards the surface. Obviously, no change in the a/c interface position could strongly hinder the out-diffusion of $\mathrm{Rb}$, which occurred parallel to the movement of the damaged zone.

\subsubsection{Epitaxy in ${ }^{18} \mathrm{O}_{2}$-gas}

In order to study the behaviour of oxygen during the recrystallization process, the SPEG study was also performed by thermal annealing in a $98 \%$ enriched ${ }^{18} \mathrm{O}_{2}$ atmosphere. After implantation of $2.5 \times 10^{16} \mathrm{Rb} / \mathrm{cm}^{2}, 1 \mathrm{~h}$ isochronal annealings were performed between 673 $\mathrm{K}$ and $1173 \mathrm{~K}$.

Figure 4.5 shows representative RBS-C spectra, together with those of a non-irradiated sample. Similar to the air annealing described in the last section, this study again indicated a layer-by-layer recovery of the amorphous zone with increasing temperature. However, three distinct features are clearly observed as compared to air annealing experiments: (1) a large amount of external oxygen $\left({ }^{18} \mathrm{O}\right.$ peak at $360 \mathrm{keV} \alpha$-particle energy) was in-diffused inside the $\alpha$-quartz without changing its stoichiometry, (2) complete epitaxy was achieved at a lower temperature, and (3) much faster out-diffusion of $\mathrm{Rb}$ was observed. The progression of the epitaxial recovery is shown in fig.4.6.

Up to $883 \mathrm{~K}$, the samples remained completely amorphous after annealing and the position of the amorphous/crystalline interface did not change. Then, a small shift of the a/c interface towards the surface was observed at 923 - $1013 \mathrm{~K}$. By increasing the temperature to $1023 \mathrm{~K}$, about $40 \%$ of the damaged layer recrystallized. At $1098 \mathrm{~K}$, the coherent amorphous layer disappeared and only isolated damage zones and extended defects were left in the matrix. By increasing the temperaure to $1133 \mathrm{~K}$, the RBS-Channeling spectra of the implanted and the virgin sample annealed in ${ }^{18} \mathrm{O}_{2}$ were indistinguishable, thus confirming the achievement of complete SPEG.

The migration of $\mathrm{Rb}$ appears to be somewhat different than that in air, as can be seen in fig.4.5. At $673 \mathrm{~K}$ (not shown) almost no change in the shape of the Rb-profile was 


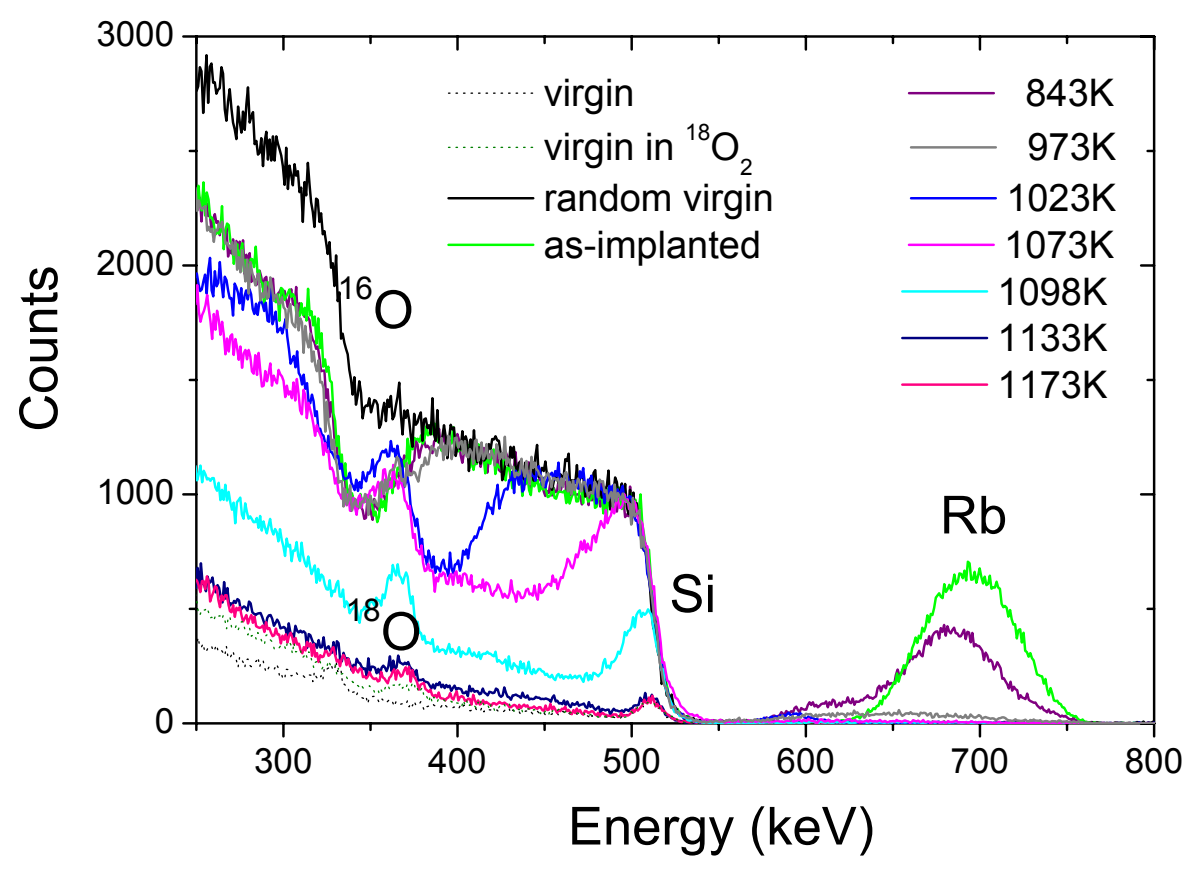

Figure 4.5: RBS-C spectra of $175-\mathrm{keV}$ Rb-ion implanted samples at a fluence of $2.5 \times 10^{16}$ $\mathrm{Rb} / \mathrm{cm}^{2}$, annealed in an ${ }^{18} \mathrm{O}_{2}$ atmosphere for $1 \mathrm{~h}$ between 843 and $1173 \mathrm{~K}$.

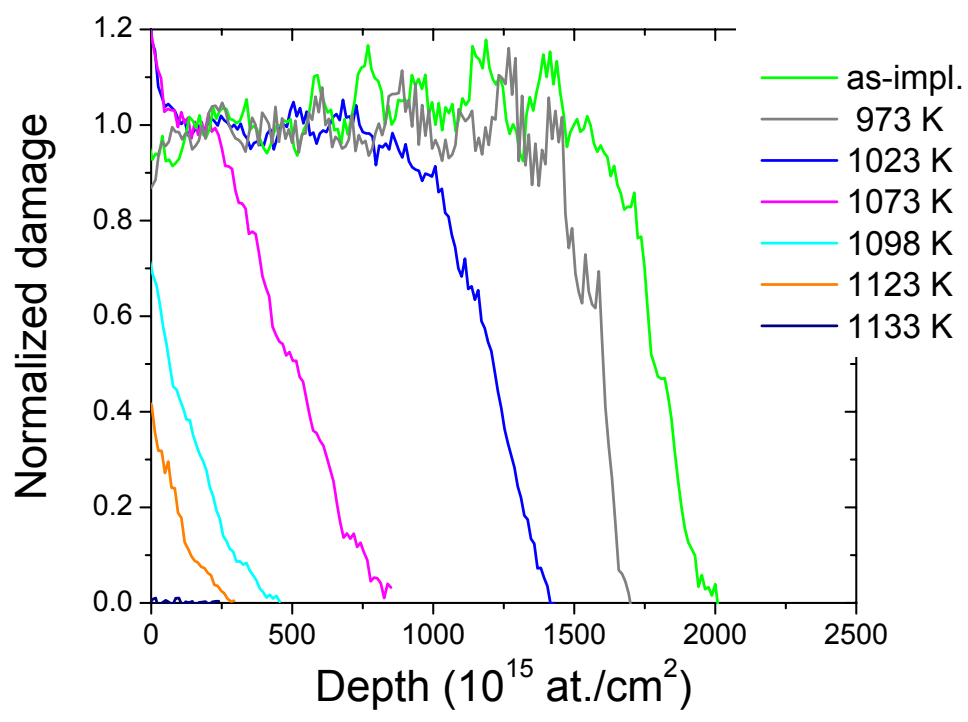

Figure 4.6: Depth distribution of the radiation damage as a function of the annealing temperature. The data refer to the Si profiles of fig.4.5. 


\begin{tabular}{|c|c|c|}
\hline Temperature $(\mathrm{K})$ & $\mathrm{d}_{a}(\mathrm{~T})$ & $v(\mathrm{~T})\left(10^{-9} \mathrm{~cm} / \mathrm{s}\right)$ \\
\hline as-impl. & 1780 & - \\
\hline 843 & 1740 & $0.17 \pm 0.08$ \\
\hline 883 & 1760 & $0.09 \pm 0.08$ \\
\hline 923 & 1603 & $0.76 \pm 0.15$ \\
\hline 973 & 1614 & $0.72 \pm 0.15$ \\
\hline 1013 & 1567 & $0.92 \pm 0.20$ \\
\hline 1023 & 1210 & $2.45 \pm 0.25$ \\
\hline 1073 & 510 & $5.47 \pm 0.35$ \\
\hline 1098 & 109 & $7.20 \pm 0.40$ \\
\hline 1123 & 41 & $7.49 \pm 0.47$ \\
\hline 1133 & 0 & $7.67 \pm 0.50$ \\
\hline
\end{tabular}

Table 4.2: The regrowth velocity of the a/c interface $v(T)$ at different annealing temperatures for $\mathrm{Rb}$-irradiated $\alpha$-quartz after annealing in an ${ }^{18} \mathrm{O}_{2}$ atmosphere. The thickness of the amorphous layer $\mathrm{d}_{a}(\mathrm{~T})$ is also reported.

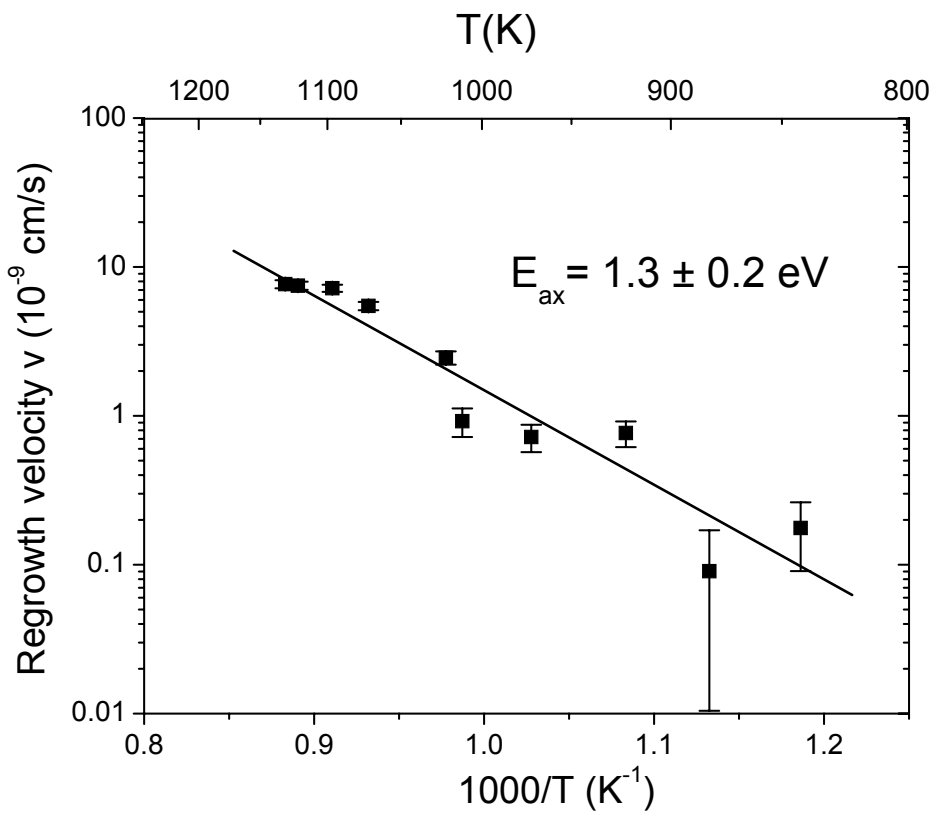

Figure 4.7: Arrhenius plot of the regrowth velocity, $v(\mathrm{~T})$, after annealing in an ${ }^{18} \mathrm{O}_{2}$ atmosphere. The straight line corresponds to an activation energy of $\mathrm{E}_{a x}=1.3$ $\pm 0.2 \mathrm{eV}$.

observed. Between 773 and $973 \mathrm{~K}, \mathrm{Rb}$ spreads through the amorphous zone. Evidently, during the annealing in ${ }^{18} \mathrm{O}_{2}, \mathrm{Rb}$ redistributes more quickly than in air. Above $973 \mathrm{~K}, \mathrm{Rb}$ totally disappeared from the damaged layer (for air annealing at $1173 \mathrm{~K}$ ), before SPEG 


\begin{tabular}{cccccccc}
\hline $\begin{array}{c}\text { Alkali } \\
\text { ions }\end{array}$ & $\begin{array}{c}\text { Energy } \\
(\mathrm{keV})\end{array}$ & $\begin{array}{c}\text { Fluence } \\
\left(10^{16} / \mathrm{cm}^{2}\right)\end{array}$ & $\begin{array}{c}\mathrm{Ann} . \\
\text { gas }\end{array}$ & $\begin{array}{c}\mathrm{T}_{S} \\
(\mathrm{~K})\end{array}$ & $\begin{array}{c}\mathrm{T}_{x} \\
(\mathrm{~K})\end{array}$ & $\begin{array}{c}\mathrm{E}_{a x} \\
(\mathrm{eV})\end{array}$ & Comments \\
\hline $\mathrm{Li}$ & 15 & 2.5 & ${ }^{18} \mathrm{O}_{2}$ & 870 & $970^{*}$ & - & {$[59]$} \\
\hline $\mathrm{Na}$ & 50 & 2.5 & air & 870 & $1070^{*}$ & - & {$[106]$} \\
\hline $\mathrm{Na}$ & 50 & 2.5 & ${ }^{18} \mathrm{O}_{2}$ & 870 & 970 & - & this thesis \\
\hline $\mathrm{Rb}$ & 175 & 2.5 & air & 1070 & 1170 & $0.6(2), 2.7(4)$ & this thesis \\
\hline $\mathrm{Rb}$ & 175 & 2.5 & ${ }^{18} \mathrm{O}_{2}$ & 970 & 1130 & $1.3(2)$ & this thesis \\
\hline $\mathrm{Cs}$ & 250 & 2.5 & air & 1070 & 1150 & $2.8(2)$ & {$[59]$} \\
\hline
\end{tabular}

Table 4.3: Processing parameters of chemically guided SPEG in quartz after alkali-ion implantation, where $\mathrm{T}_{S}$ denotes the temperature, at which SPEG started, $\mathrm{T}_{x}$ the recrystallization temperature, and $\mathrm{E}_{a x}$ the activation energy of the recrystallization. ${ }^{*}$ No complete epitaxy.

started. This confirms that the annealing atmosphere is a fundamental parameter in the SPEG process.

The regrowth velocity, $v(T)$, is plotted as a function of the annealing temperature in fig.4.7 (corresponding values are also reported in table 4.2). The recrystallization speed increases ( similar as in the case of air annealing) from $0.17 \times 10^{-9} \pm 0.08 \mathrm{~cm} / \mathrm{s}\left(843 \mathrm{~K}\right.$ ) to $7.67 \times 10^{-9}$ $\pm 0.50 \mathrm{~cm} / \mathrm{s}(1133 \mathrm{~K})$. However, the regrowth velocity at a given temperature is much faster in ${ }^{18} \mathrm{O}_{2}$ than in air, for example: at $1073 \mathrm{~K}, v(\mathrm{~T})=0.75 \times 10^{-9} \pm 0.18 \mathrm{~cm} / \mathrm{s}$ (air) versus $5.47 \times 10^{-9} \pm 0.35 \mathrm{~cm} / \mathrm{s}\left({ }^{18} \mathrm{O}_{2}\right)$.

The fit to the data suggests a single exponential behaviour with an activation energy of $E_{a x}=1.3 \pm 0.2 \mathrm{eV}$. This value is less than $50 \%$ of the high temperature value in air annealing (see tab.4.3). The pre-exponential factor $v_{o}=1.6 \times 10^{3} \mathrm{~cm} / \mathrm{s}$ is much lower than that observed for air annealing. Fratello et al. [96] found that oxidizing the samples causes higher rates of crystallization by changing annihilation sites (three-coordinated silicons) into active defects (non-bridging oxygens). These active defects enhance rearrangement rates due to higher structural freedom of the network, i.e. the tetrahedrons can move and reorient much more easily than the fully connected network.

For testing the influence of the annealing duration on SPEG, a set of samples was irradiated with $2.5 \times 10^{16} \mathrm{Rb}$-ion $/ \mathrm{cm}^{2}$ and annealed in ${ }^{18} \mathrm{O}_{2}$ gas at $1023 \mathrm{~K}$ for different annealing times. As compared to the previous case of air annealing, some important differences were detected: (1) the coherent radiation-damaged zone disappeared and almost full epitaxy occurred for increasing annealing time and (2) Rb out-diffusion was much faster.

RBS-C spectra measured before and after implantation and after each annealing step are shown in fig.4.8. After the first annealing hour, $40 \%$ of the amorphous layer thickness was epitaxially recovered and planar recovery of the a/c interface took place. The $\mathrm{Rb}$ had already totally out-diffused. By increasing the annealing time to $1.5 \mathrm{~h}$, the coherent amorphous layer disappeared, but no complete recovery was observed. A certain amount of damage and extended defects remained in the samples even after the 2-h annealing. Iso- 


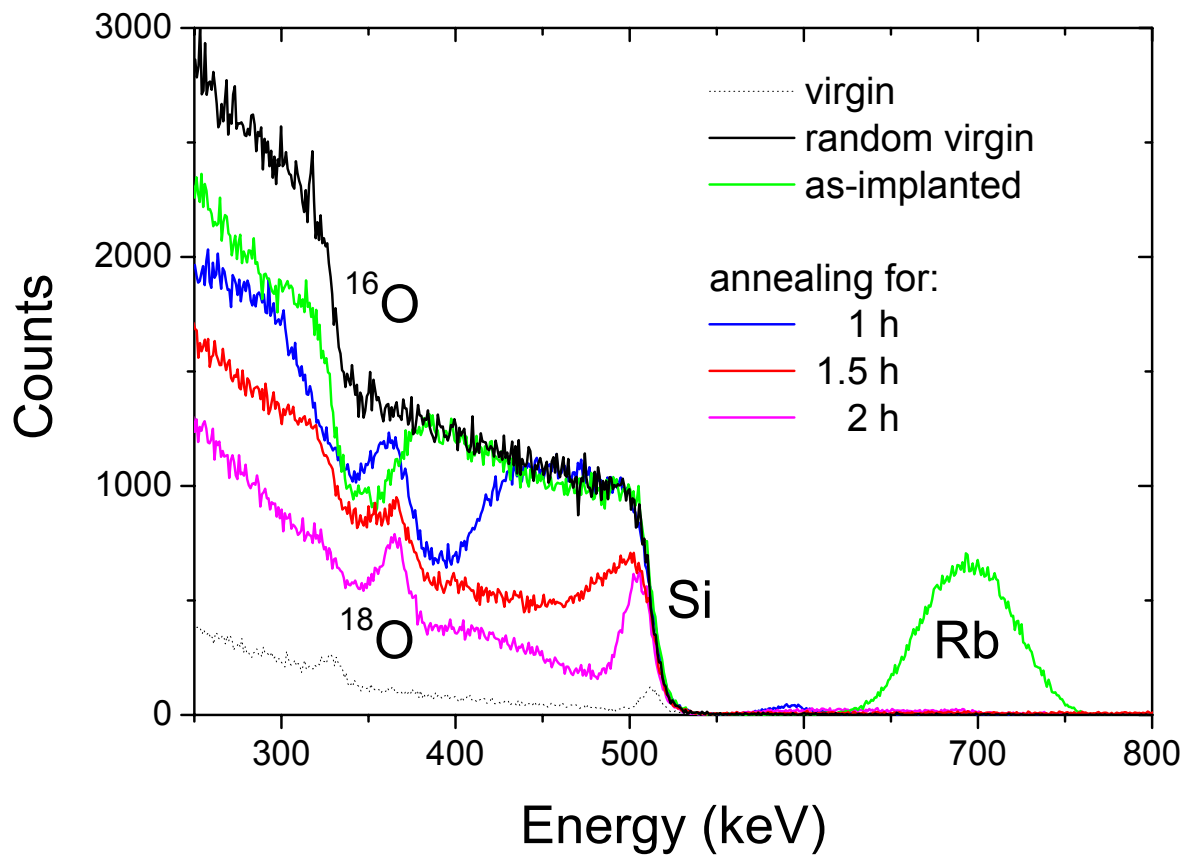

Figure 4.8: RBS-C spectra of $175 \mathrm{keV} \mathrm{Rb}$ implanted samples, all implanted with an ion fluence of $2.5 \times 10^{16} \mathrm{Rb} / \mathrm{cm}^{2}$ and annealed in an ${ }^{18} \mathrm{O}_{2}$ atmosphere at $1023 \mathrm{~K}$ in the time range of $1-2 \mathrm{~h}$.

lated damage zones remained, probably due to fast out-diffusion of $\mathrm{Rb}$. The implanted $\mathrm{Rb}$ had out-diffused during the first hour and, probably due to its absence, no complete recovery occurred, not even during a 2-h annealing. On the other hand, when the annealing temperature was increased to $1133 \mathrm{~K}$, complete SPEG took place even after 1-h annealing in ${ }^{18} \mathrm{O}_{2}$.

\subsection{Influence of $\mathrm{Rb}$ ion-fluence}

\subsubsection{Epitaxy in air}

A series of $175-\mathrm{keV} \mathrm{Rb}^{+}$irradiations at $80 \mathrm{~K}$ and 1-h or 2-h annealings at a fixed temperature of $1123 \mathrm{~K}$ in air were performed in order to study the influence of the Rb content and annealing time upon the SPEG process. The $\alpha$-quartz samples were implanted with nominal fluences of $4.7 \times 10^{15}, 1 \times 10^{16}, 2 \times 10^{16}, 2.5 \times 10^{16}, 3.4 \times 10^{16}$, and $5 \times 10^{16} \mathrm{Rb} / \mathrm{cm}^{2}$. Figures 4.9 (a)-(f) summarize the RBS-C results before and after each annealing. For comparison, the virgin aligned RBS-C spectrum is also shown; it has a minimum yield of 

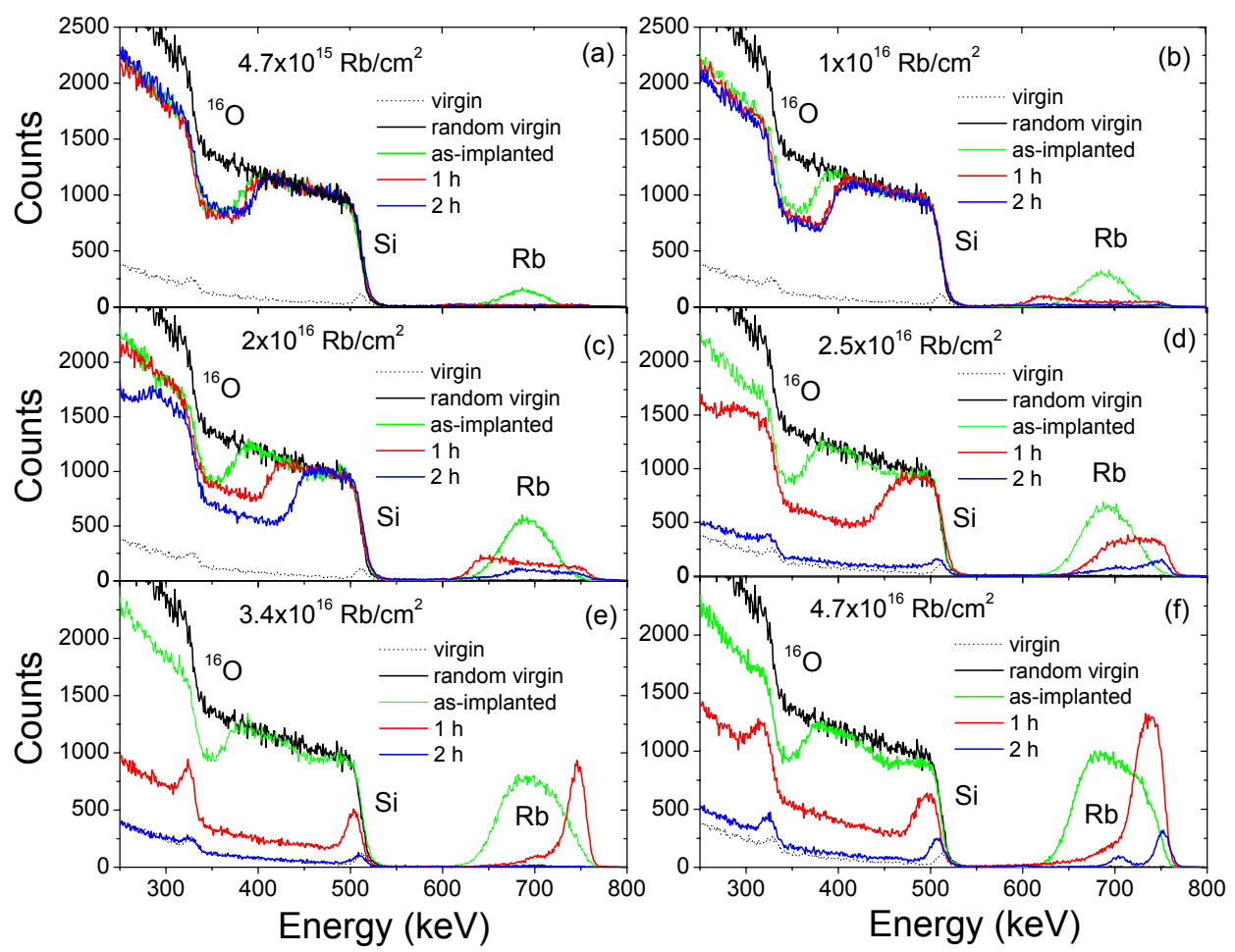

Figure 4.9: RBS-C spectra of virgin and $\mathrm{Rb}$-ion irradiated $\alpha$-quartz samples before and after 1-h and 2-h annealings at the fixed temperature of $1123 \mathrm{~K}$, measured for Rb-fluences of (a) $4.7 \times 10^{15}$, (b) $1.0 \times 10^{16}$, (c) $2.0 \times 10^{16}$, (d) $2.5 \times 10^{16}$, (e) $3.4 \times 10^{16}$, and (f) $4.7 \times 10^{16} \mathrm{Rb} / \mathrm{cm}^{2}$.

about $5 \%$ of the random spectrum. In the channeling measurements, the initial thickness of the amorphous layer varied between 1600 and $1800 \times 10^{15}$ at. $/ \mathrm{cm}^{2}$ for the lowest and highest fluences, respectively. This corresponds to thicknesses of 250 and $280 \mathrm{~nm}$. After a 1-h annealing of the samples implanted with $\leq 1 \times 10^{16} \mathrm{Rb} / \mathrm{cm}^{2}$, the channeling spectra (figs.4.9 (a)-(b)) showed nearly full amorphization of the front layer, with a slight reduction of the RBS-C yield with respect to the random level. While Rb had almost totally out-diffused from the samples after the 2-h annealing, the amorphized layer remained essentially unchanged. Above this fluence, recrystallization was clearly visible (see figs. 4.9 (c)-(f)) and increased with the Rb fluence and the annealing time. This clearly suggests that there exists a critical fluence of about $1 \times 10^{16} \mathrm{Rb}$-ions $/ \mathrm{cm}^{2}$ in order to initiate the recovery process. After implanting $2 \times 10^{16} \mathrm{Rb}$-ions $/ \mathrm{cm}^{2}$, the a/c front moved towards the surface during the 2-h annealing, leaving half the originally amorphous layer recrystallized. The $\mathrm{Rb}$ concentration profiles indicate a nearly uniform distribution inside the 


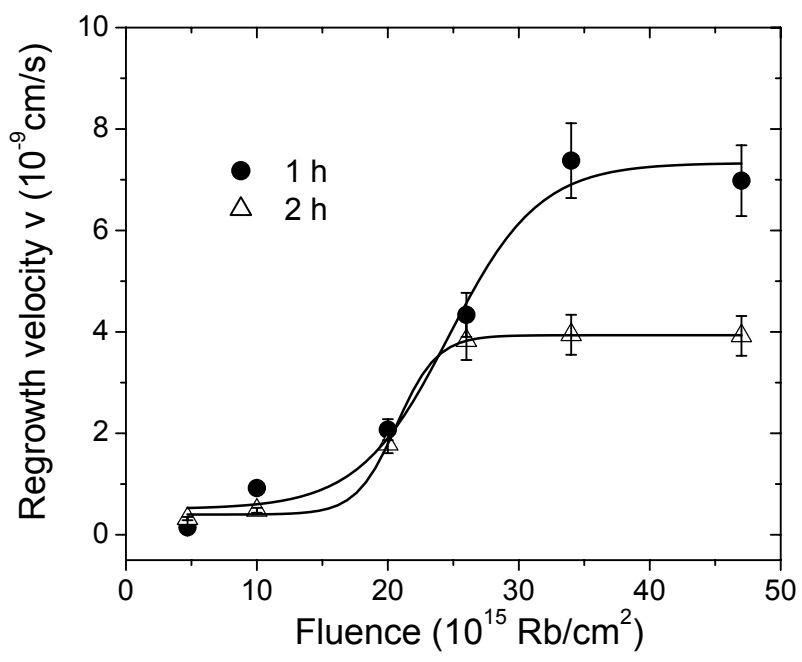

Figure 4.10: The regrowth velocity $v(\mathrm{~T})$ for 1 -h and 2-h annealings at $1123 \mathrm{~K}$ as a function of the implanted $\mathrm{Rb}$ fluence.

amorphous layer. At $2.5 \times 10^{16} \mathrm{Rb} / \mathrm{cm}^{2}$, approximately $60 \%$ of the amorphous layer had already recrystallized after the first hour and the $\mathrm{Rb}$ profile started to move to the surface. After the second annealing hour almost complete recrystallization was found. Only a small amount of the defects embedded in the crystalline matrix remained in the formerly amorphous region, as proven by the slightly increased backscattering yield relative to the virgin one; also, some $\mathrm{Rb}$ remained inside the matrix. For $\Phi=3.4$ and $4.7 \times 10^{16} \mathrm{Rb} / \mathrm{cm}^{2}$, the channeling spectra after $1-\mathrm{h}$ annealing were quite close to the virgin spectrum, indicating nearly full recrystallization. An annealing of only 2 hours at a fluence of $3.4 \times 10^{16}$ $\mathrm{Rb} / \mathrm{cm}^{2}$ led to full epitaxy and the RBS-C spectra of the implanted and virgin sample were indistinguishable. SPEG was accompanied by the complete out-diffusion of the implanted $\mathrm{Rb}$ ions. However, two hour annealings at a fluence of $4.7 \times 10^{16} \mathrm{Rb} / \mathrm{cm}^{2}$ initiated almost a full recrystallization, but some isolated damage zones and extended defects still remained in the sample due to the presence of $\mathrm{Rb}$ ions.

Evidently, the constant temperature series at $1123 \mathrm{~K}$ showed that complete SPEG strongly depends on the $\mathrm{Rb}$ content and the annealing time. A 1-h annealing of the sample implanted at even the highest fluence of $5 \times 10^{16} \mathrm{Rb} / \mathrm{cm}^{2}$ was not sufficient to recover singlecrystalline $\alpha$-quartz.

The regrowth velocity for both annealing times is plotted in fig.4.10 versus the integrated $\mathrm{Rb}$ content. This velocity depends strongly on the integrated $\mathrm{Rb}$ content, reaching saturation values at about $3.5 \times 10^{16} \mathrm{Rb} / \mathrm{cm}^{2}$. The recrystallization velocities up to a fluence of $2.5 \times 10^{16} \mathrm{Rb} / \mathrm{cm}^{2}$ after the first and second annealing hour are very close to each other. Above this fluence, the deduced regrowth velocities $v$ for 1 und 2-h annealings differ by a factor of two, for example, from $v=3.2 \times 10^{-9} \mathrm{~cm} / \mathrm{s}(1 \mathrm{~h})$ to $v=6.0 \times 10^{-9} \mathrm{~cm} / \mathrm{s}(2 \mathrm{~h})$ at 
$\Phi=3.4 \times 10^{16} \mathrm{Rb} / \mathrm{cm}^{2}$.

The enhancement of the recrystallization velocity with increasing alkali ion content was also observed in the case of Cs-implanted $\alpha$-quartz [55, 59]. It must be pointed out that this annealing was carried out at a temperature that was $50 \mathrm{~K}$ lower than in the case of $\mathrm{Rb}$ implantation, and the SPEG process was evidently much slower compared to the present case. For example, for the fluence of $2.5 \times 10^{16} \mathrm{Cs} / \mathrm{cm}^{2}$ a comparable quality of the recrystallized layer, according to RBS-C, was achieved after a 4-h annealing.

\subsubsection{Epitaxy in ${ }^{18} \mathrm{O}_{2}$-gas}

A 1-h annealing in an ${ }^{18} \mathrm{O}_{2}$ atmosphere at a fixed temperature of $1123 \mathrm{~K}$ and ${ }^{18} \mathrm{O}_{2}$-gas pressure of 300 mbar was carried out. The samples were implanted at fluences in the range of $1 \times 10^{15}$ to $6 \times 10^{16} \mathrm{Rb}$-ions $/ \mathrm{cm}^{2}$.

Figure 4.11 illustrates the RBS-C spectra of this series. In all the cases an amorphous layer was formed, whose thickness varied from $1500 \times 10^{15}$ at. $/ \mathrm{cm}^{2}\left(\Phi=1 \times 10^{15} \mathrm{Rb} / \mathrm{cm}^{2}\right)$ to $1900 \times 10^{15}$ at. $/ \mathrm{cm}^{2}\left(\Phi=6 \times 10^{16} \mathrm{Rb} / \mathrm{cm}^{2}\right)$, corresponding to depths between 230 and $295 \mathrm{~nm}$. The RBS-C spectra of the samples implanted up to $1 \times 10^{16} \mathrm{Rb} / \mathrm{cm}^{2}$ showed only a minor change in the position of the $\mathrm{a} / \mathrm{c}$ interface during annealing, but for increasing fluence the amorphization front was moving towards the surface, and partial epitaxy took place. The 1-h annealings of the samples irradiated up to $1.75 \times 10^{16} \mathrm{Rb}$-ions $/ \mathrm{cm}^{2}$ already resulted in a visible recrystallized zone, with about half the amorphous layer recovered. For $2.5 \times 10^{16} \mathrm{Rb} / \mathrm{cm}^{2}$, the coherent amorphous layer disappeared and only isolated damage zones and extended defects remained in the matrix. In contrast to air annealing, SPEG is more efficient during pure oxygen annealing. This is most evident for the sample irradiated with $3.5 \times 10^{16} \mathrm{Rb} / \mathrm{cm}^{2}$ and annealed in air, which did not fully recrystallize within $1 \mathrm{~h}$, but only within $2 \mathrm{~h}$. Moreover, these spectra still exhibited a slightly higher backscattering yield as compared to the "virgin aligned" sample. This difference disappeared only for $\geq 5 \times 10^{16} \mathrm{Rb}$-ions $/ \mathrm{cm}^{2}$.

After annealing in ${ }^{18} \mathrm{O}_{2}$, the implanted $\mathrm{Rb}$ ions quickly and completely out-diffused from all samples, even though no complete SPEG was achieved below $5 \times 10^{16} \mathrm{Rb} / \mathrm{cm}^{2}$. This phenomenon partially contradicts the results obtained after air annealing, where Rb was out-diffused from the sample more slowly and not completely, except for the full epitaxy. As already observed after annealing in air, under identical annealing conditions for example in the case of the sample irradiated with $2.5 \times 10^{16} \mathrm{Rb} / \mathrm{cm}^{2}$ - only half of the amorphous layer recovered and about $50 \%$ of the implanted $\mathrm{Rb}$ ions were retained inside the remaining amorphized zone. Therefore, if the $\mathrm{Rb}$ out-diffusion is slower, complete epitaxy is possible at lower fluences. 

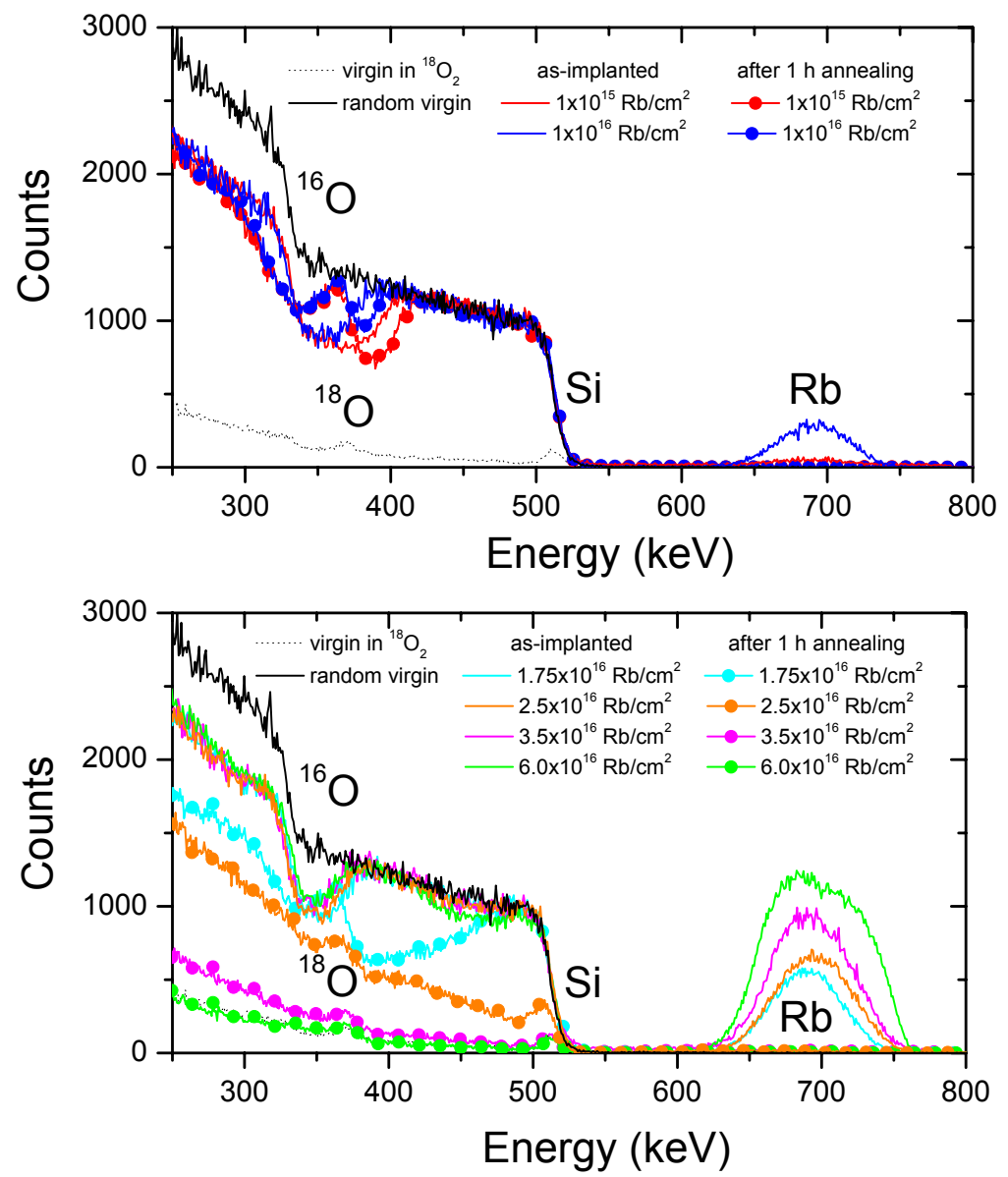

Figure 4.11: RBS-C spectra of 175-keV Rb-ion implanted samples at ion fluences in the range of: (a) $0.1-1.0 \times 10^{16}$ and (b) $1.75-6.0 \times 10^{16} \mathrm{Rb} / \mathrm{cm}^{2}$, before and after 1 -h annealing in an ${ }^{18} \mathrm{O}_{2}$ atmosphere at a fixed temperature of $1123 \mathrm{~K}$.

\subsection{Influence of ${ }^{18} \mathrm{O}_{2}$ pressure}

At this stage of the investigation, it was not clear whether the controlled supply of external oxygen had any influence on the SPEG process. In order to clarify this, a set of samples were implanted at a fixed fluence of $2 \times 10^{16} \mathrm{Rb}$-ions $/ \mathrm{cm}^{2}$ and annealed for $1 \mathrm{~h}$ at $1023 \mathrm{~K}$ in an ${ }^{18} \mathrm{O}_{2}$ atmosphere at a pressure varied between 5 and 800 mbar. The RBS-C spectra are shown in fig.4.12. For comparison, one sample was enclosed in an ampoule under a pressure of $5 \times 10^{-5}$ mbar and thermally annealed under the same conditions as 


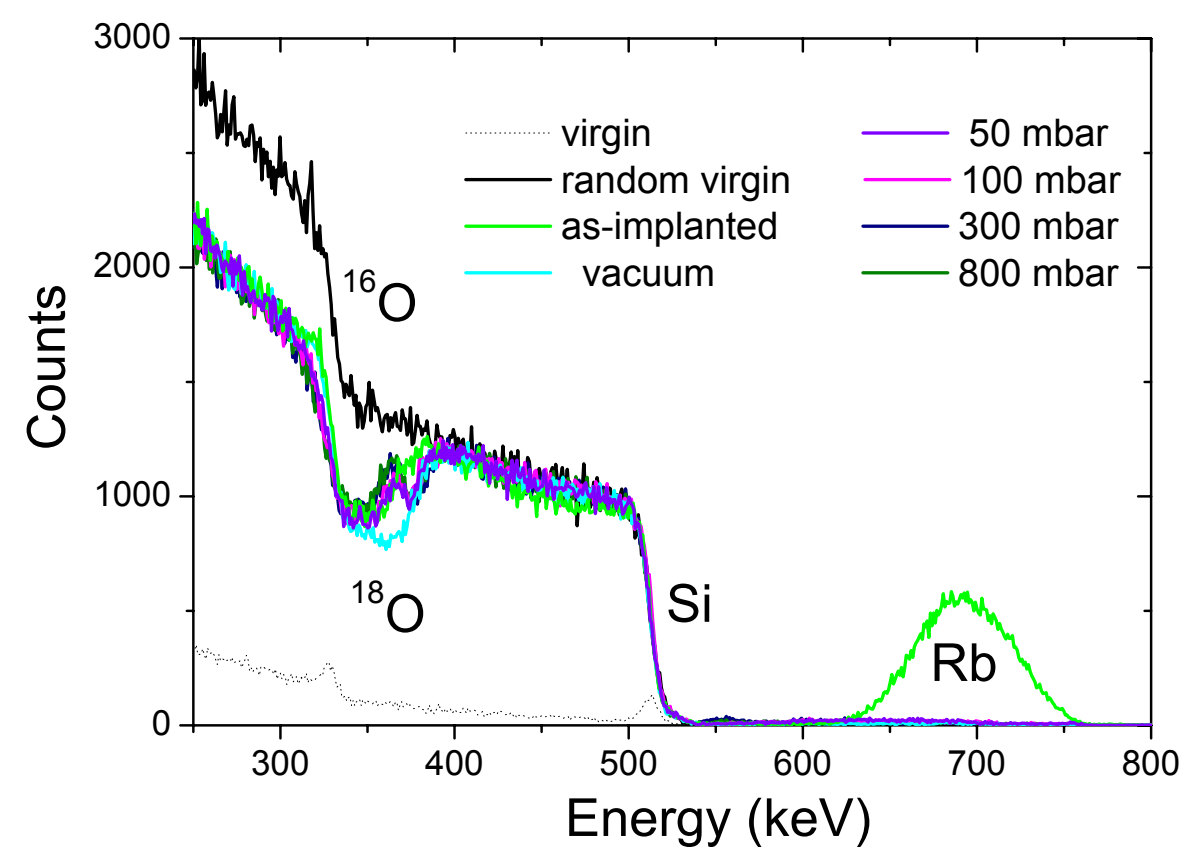

Figure 4.12: RBS-C spectra for Rb-implanted samples at a fluence of $2.0 \times 10^{16} \mathrm{Rb} / \mathrm{cm}^{2}$ after 1-h annealing in an ${ }^{18} \mathrm{O}_{2}$ atmosphere and a fixed temperature of 1023 $\mathrm{K}$ under ${ }^{18} \mathrm{O}_{2}$ pressure varied between 5 and 800 mbar.

the ${ }^{18} \mathrm{O}_{2}$ samples. Surprisingly, in all the cases the RBS-C analyses hardly showed any notable recovery of the amorphous layer. When the $\mathrm{Rb}$ fluence was increased to $2.5 \times 10^{16}$ $\mathrm{Rb}$-ions $/ \mathrm{cm}^{2}$, partial SPEG occurred at $1023 \mathrm{~K}$ and $300 \mathrm{mbar}{ }^{18} \mathrm{O}_{2}$ pressure. When the temperature was further increased to $1123 \mathrm{~K}$, almost the whole amorphous layer was recovered (fig.4.5). These experiments indicate that the oxygen gas pressure above a critical value has little influence on the epitaxial growth. The different SPEG rate in air and ${ }^{18} \mathrm{O}_{2}$ may be attributed to the slower oxygen exchange at the surface due to the presence of other gaseous species in air.

The implanted $\mathrm{Rb}$ species had completely out-diffused in all the cases. For comparison, the diffusivity of implanted $\mathrm{As}$ in crystalline $\mathrm{Si}$, at a fixed temperature, was found to increase with pressure, with a maximum increase by one order of magnitude [95]. The phenomenon that the diffusion coefficient increased with pressure suggests an interstitial character of the As migration in $\mathrm{Si}$. An increase in pressure would increase the concentration of interstitials, because their incorporation reduces the volume of the matrix. The opposite would be true for vacancies whose amount should decrease.

The effects of very high external pressure on the solid phase epitaxial regrowth rate were investigated in silicon [99] and silica [47,96]. The pressure was increased up to $20 \mathrm{kbar}$ in $\mathrm{Si}$ and $40 \mathrm{kbar}$ in silica. A strong exponential dependence of the growth rate on pressure 
was found. The results presented by Fuss et al. [100] explained how the static pressure influences the recrystallization in a $\mathrm{Li}_{2} \mathrm{O} \cdot 2 \mathrm{SiO}_{2}$ glass. The relatively high pressure appears to affect the crystal growth rate, $V$, and to move the nucleation rate, $I$, of the glass to lower temperatures. For example, by applying an external pressure of $>10 \mathrm{kbar}$ the crystal growth occurs at $673 \mathrm{~K}$, some $150 \mathrm{~K}$ lower than the onset temperature for this glass at atmospheric pressure. A smaller viscosity is suggested as a reason for the shift of $V$ and $I$ to lower temperatures.

The pressure-induced phase transition from tetrahedrally coordinated silicon ions at low pressure to octahedrally coordinated silicon ions at high pressure was found to occur in silica above $100 \mathrm{kbar}$ at room temperature [101]. The coordination changes were related to the increase in the interatomic distances and resulted in an increase in the reduced density.

We probably have not observed any such effects due to the much lower pressure used in the present study.

\subsection{Rb out-diffusion}

The $\mathrm{Rb}$ concentration profiles for the samples annealed in air at $843-1173 \mathrm{~K}$, as deduced from the RBS spectra are shown in fig.4.13. The Rb ion fluence was $2.5 \times 10^{16} \mathrm{Rb} / \mathrm{cm}^{2}$. The $\mathrm{Rb}$ distribution in the as-implanted sample resembles a Gaussian profile exhibiting its maximum at a depth of $675 \times 10^{15}$ at. $/ \mathrm{cm}^{2}$ with an FWHM of $603 \times 10^{15}$ at. $/ \mathrm{cm}^{2}$. This is in good agreement with the projected ion range $\mathrm{R}_{p}=645 \times 10^{15}$ at. $/ \mathrm{cm}^{2}$ obtained from the SRIM 2000 program [78], when assuming an atomic density of $6.45 \times 10^{22}$ at. $/ \mathrm{cm}^{3}$ of the amorphous substrate [8]. The extracted thickness of the amorphous layer, $1780 \times 10^{15}$ at. $/ \mathrm{cm}^{2}$, is more than twice that of the projected range.

During thermal annealing, the implanted $\mathrm{Rb}$ atoms tend to distribute uniformly over the amorphous layer and the concentration profiles become broader. After annealing at 1023 $\mathrm{K}$, the $\mathrm{Rb}$ profiles have box-like shapes, which can be interpreted in terms of a preferential diffusion of $\mathrm{Rb}$ atoms from a region of higher local concentration to a region of lower local concentration. This is associated with a change in the alkali diffusion coefficient in the damaged region, like that alkali in silicate glasses [102]. The diffusion coefficient of alkali ions increases with increasing concentration. Such a distribution of implanted species can also be affected by an increasing number of defects, such as Si-O broken bonds, oxygen vacancies, etc., which provide sites for trapping the diffusing alkali atoms or oxygen over the damaged layer [103]. Like in alkali-glass silicate during thermal treatment, the loosely-bound alkali would rapidly move towards the surface and out-diffuse. At $1023 \mathrm{~K}$, the $\mathrm{Rb}$ diffusion front reached the a/c interface. However, Rb did not diffuse inside the underlying crystalline matrix, due to the lower solubility of alkali in crystalline $\mathrm{SiO}_{2}$ [104]. At about $1073 \mathrm{~K}$, a planar movement of the a/c interface towards the surface was observed, which indicates epitaxial recrystallization of the amorphous $\mathrm{SiO}_{2}$ layer. 


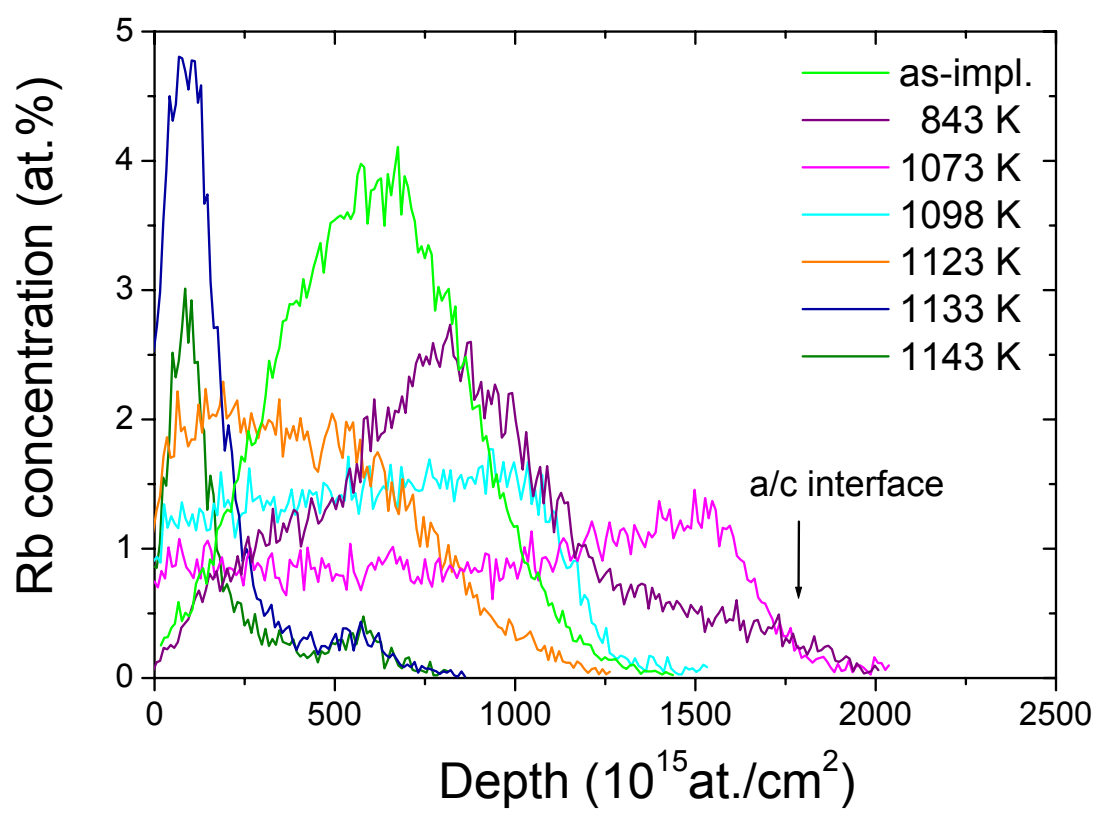

Figure 4.13: $\mathrm{Rb}$ concentration profiles as a function of the depth at different annealing temperatures in air.

The back edge of the $\mathrm{Rb}$ profile located near to the $\mathrm{a} / \mathrm{c}$ interface was pushed out of the recrystallized zone, hence the out-diffusion of $\mathrm{Rb}$ was controlled by the motion of the a/c interface. At $1173 \mathrm{~K}$, all the implanted Rb content had completely left the sample and full recrystallization was achieved.

The diffusion and loss of the implanted $\mathrm{Rb}$-ions from $\mathrm{SiO}_{2}$ can be described (similar to Cs diffusion [59]) by at least three steps:

1. Dissolution in the $\alpha-\mathrm{SiO}_{2}$ network: this process took place in the low temperature regime (up to about $1073 \mathrm{~K}$ ) and was accompanied by slow movement of the a/c interface with $E_{a x}^{L}=0.6 \pm 0.2 \mathrm{eV}$.

2. "Reflection" at the a/c interface due to its very low solubility in crystalline quartz [104] and diffusion towards the surface, which begins above $1073 \mathrm{~K}$. In this regime, the regrowth velocity of the damaged layer was much faster (parametrized by an activation energy of $2.7 \pm 0.4 \mathrm{eV}$ ). Rb diffuses out of the sample.

3. Finally, oxide formation and dissociation or evaporation at the sample surface.

From the RBS analysis it was also possible to estimate the activation energy for the $\mathrm{Rb}$ out-diffusion during the annealing treatment. The retained $\mathrm{Rb}$ fraction plotted (a) versus the annealing temperature in fig. 4.14 decreased very slowly down to about $1100 \mathrm{~K}$, but then rapidly decreased with increasing temperature. At $T_{1 / 2}^{R b}=1130 \pm 60 \mathrm{~K}$, correspond- 

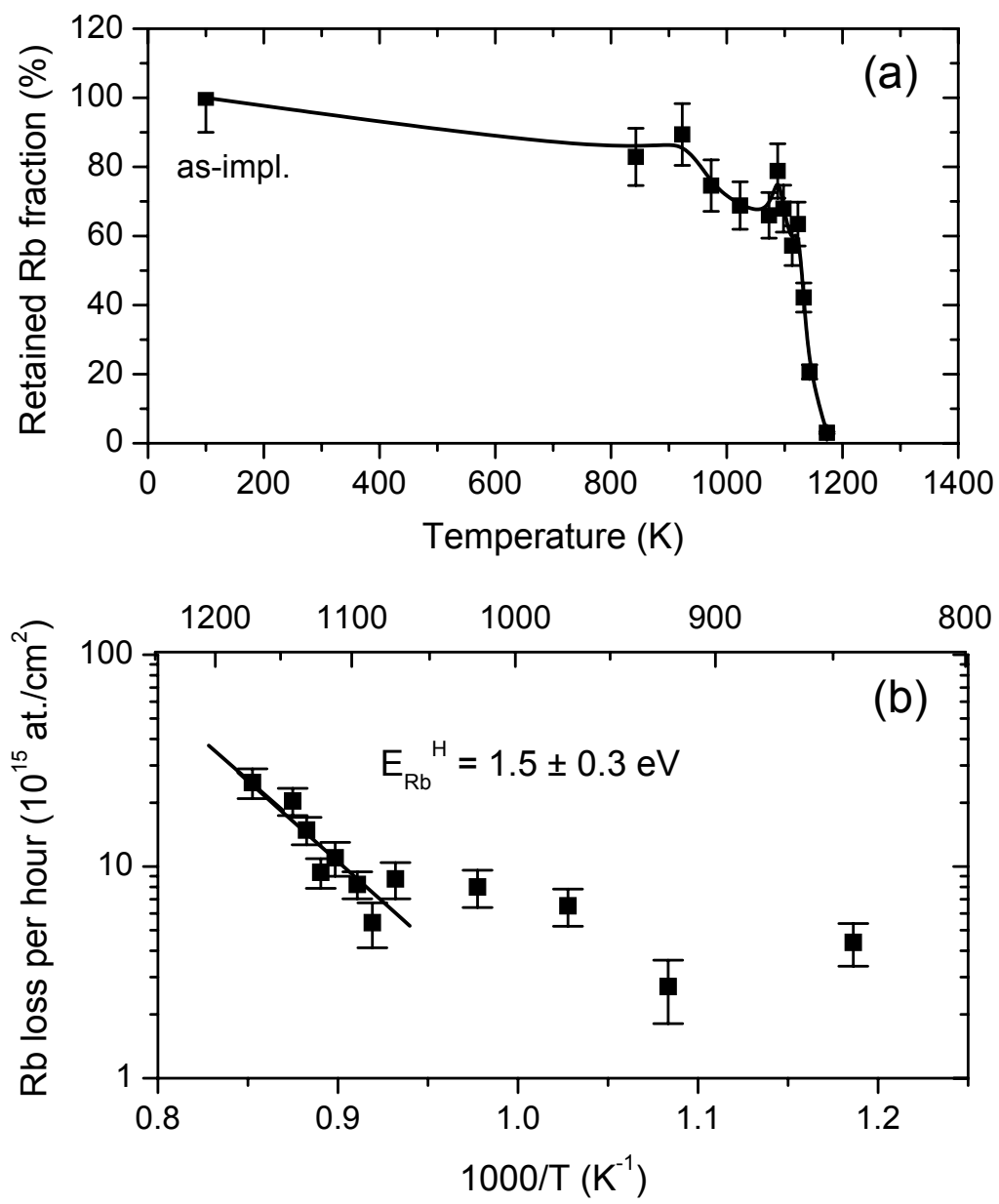

Figure 4.14: (a) Retained $\mathrm{Rb}$ fraction, integrated up to a depth of about $280 \mathrm{~nm}$ as a function of the annealing temperature. (b) Rb loss per hour plotted as a function of $1 / \mathrm{T}$.

ing to $57 \%$ of the melting point of quartz $\left(T_{m}=1983 \mathrm{~K}\right)$, half the $\mathrm{Rb}$ content had left the sample. This temperature is similar to the value found by Roccaforte [59] for Cs diffusion in $\mathrm{SiO}_{2}\left(T_{1 / 2}^{C s}=1065 \pm 48 \mathrm{~K}\right)$.

In fig. 4.14 (b), the Rb-loss in the high temperature range was parametrized by an Arrhenius dependence, involving an activation energy of $E_{R b}^{H}=1.5 \pm 0.3 \mathrm{eV}$. The low temperature regime was not fitted by an Arrhenius function, due to a high scatter of the data points. $E_{R b}^{H}$ is almost half the value of the activation energy of the recrystallization.

The diffusion of alkali ions in vitreous silica was investigated by Rothman et al. [107]. These authors observed that the diffusion coefficient strongly decreased with increasing 


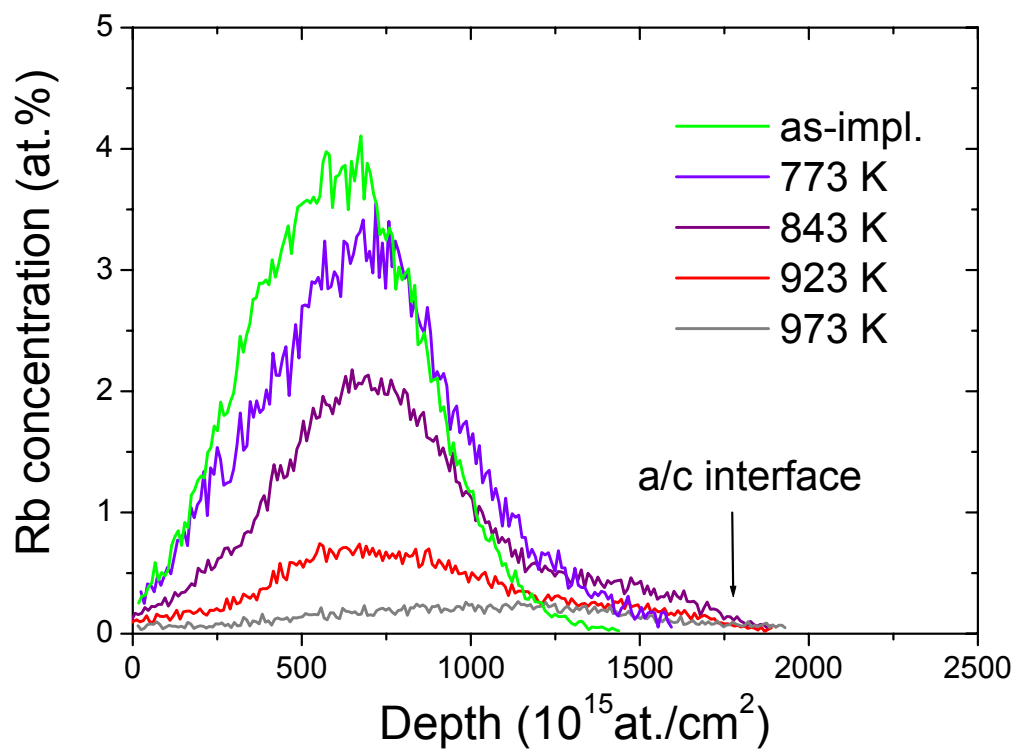

Figure 4.15: $\mathrm{Rb}$ concentration profiles as a function of the depth at different annealing temperatures in an ${ }^{18} \mathrm{O}_{2}$ atmosphere.

ionic radius (about two and a half orders of magnitude per row of the periodic table) and the activation energy increased with increasing ionic size. Three vitreous $\mathrm{SiO}_{2}$ materials were investigated (different impurity content). The activation energy for Rb diffusion varied in the range from $1.46 \pm 0.05 \mathrm{eV}$ to $2.06 \pm 0.09 \mathrm{eV}$. Our experimental value is very close to the activation energy of $1.55 \pm 0.13 \mathrm{eV}$ found for $\mathrm{Rb}$ diffusion near the surface (the same value was obtained for all the $\mathrm{v}-\mathrm{SiO}_{2}$ examined) and agrees very well with the theoretical value of $1.57 \mathrm{eV}$ calculated from the Anderson-Stuart model [108]. In the case of Cs-implanted $\alpha$-quartz [59], the activation energy was fitted over the whole experimental range $(773-1148 \mathrm{~K}): E_{C s}=0.98 \pm 0.01 \mathrm{eV}$. However, this value is approximately half of that found by Rothman et al. $\left(\mathrm{E}_{C s}=2.2 \pm 0.1 \mathrm{eV}\right)$ [107].

In the literature there are also some examples where the diffusion was a superposition of single diffusion processes with different diffusion coefficients [109, 110, 111, 112], due for example, to volume and grain boundary diffusion in polycrystalline materials [109]. Frischat $[109,110,111,112]$ also observed an anomalous diffusion behaviour of sodium in $\mathrm{SiO}_{2}$ glass. The tracer diffusion of ${ }^{22} \mathrm{Na}$ in a commercial $\mathrm{SiO}_{2}$ glass had been investigated in the temperature range from $443 \mathrm{~K}$ to $1273 \mathrm{~K}$. In the high temperature region $(873-1273 \mathrm{~K})$ the diffusion process was evaluated with a unique diffusion coefficient. Below about $873 \mathrm{~K}$, the diffusion of ${ }^{22} \mathrm{Na}$ was a superposition of two processes with coefficients $D_{1}$ (secondary process) $<D_{2}$ (the principal process). The discontinuities at about $846 \mathrm{~K}$ and $523 \mathrm{~K}$ in the Arrhenius plot of the diffusion coefficient were interpreted in terms of "quartz-like" and "cristobalite-like" elements in the structure of the glass. Also, 


\begin{tabular}{ccccccccc}
\hline Type & $\begin{array}{c}\text { Energy } \\
(\mathrm{keV})\end{array}$ & $\begin{array}{c}\text { Fluence } \\
\left(10^{16} / \mathrm{cm}^{2}\right)\end{array}$ & $\begin{array}{c}\text { Ann. } \\
\text { gas }\end{array}$ & $\begin{array}{c}\mathrm{T}_{S} \\
(\mathrm{~K})\end{array}$ & $\begin{array}{c}\mathrm{T}_{x} \\
(\mathrm{~K})\end{array}$ & $\begin{array}{c}\mathrm{T}_{1 / 2} \\
(\mathrm{~K})\end{array}$ & $\begin{array}{c}\mathrm{E}_{a x} \\
(\mathrm{eV})\end{array}$ & $\begin{array}{c}\mathrm{E}_{a} \\
(\mathrm{eV})\end{array}$ \\
\hline $\mathrm{Rb}$ & 175 & 2.5 & air & 1070 & 1170 & $1130(60)$ & $0.6(2), 2.7(4)$ & $1.5(3)$ \\
\hline $\mathrm{Rb}$ & 175 & 2.5 & ${ }^{18} \mathrm{O}_{2}$ & 970 & 1130 & $870(45)$ & $1.3(2)$ & $0.7(1)$ \\
\hline
\end{tabular}

Table 4.4: Processing parameters of chemically guided SPEG in quartz after alkali-ion implantation, where $\mathrm{T}_{S}$ is the temperature, at which SPEG started; $\mathrm{T}_{x}$ the recrystallization temperature; $\mathrm{T}_{1 / 2}$ the temperature at which half of the implanted species out-diffused; $\mathrm{E}_{a x}$ the activation energy of the recrystallization, and $\mathrm{E}_{a}$ the activation energy of Rb out-diffusion.

in homogeneous, binary $\mathrm{Na}_{2} \mathrm{O}-\mathrm{SiO}_{2}$ glasses the existence of at least two diffusion paths was found [111]. The higher diffusivity was suggested to be attributed to the $\mathrm{Na}_{2} \mathrm{O}$-rich, whereas the lower diffusivity was attributed to the $\mathrm{SiO}_{2}$-rich phase.

The evolution of the $\mathrm{Rb}$ concentration profiles obtained after annealing in ${ }^{18} \mathrm{O}_{2}$ gas for samples implanted with $\Phi=2.5 \times 10^{16} \mathrm{Rb} / \mathrm{cm}^{2}$ is presented in fig.4.15. The annealing temperature was varied in the range 673 to $1173 \mathrm{~K}$. The migration of the implanted species shows similar features as in the air annealing experiments. At $673 \mathrm{~K}$ (not shown), no change in the shape and concentration of the Rb-profile was detected. Then, by increasing the temperature to $773-973 \mathrm{~K}$ the $\mathrm{Rb}$ profiles become slightly broader and spread throughout the amorphous layer. However, no box-like profiles were observed and the shape of the broadened profiles was almost preserved. A similar profile broadening occurred after Li implantation [106] during annealing in ${ }^{18} \mathrm{O}_{2}$.

Figure 4.16 (a) summarizes the retained $\mathrm{Rb}$ fraction up to $1013 \mathrm{~K}$. The heat treatments produced a dramatic out-diffusion upon annealing at 673 - $973 \mathrm{~K}$. Above $973 \mathrm{~K}, \mathrm{Rb}$ had totally out-diffused from the samples (see fig.4.5).

Evidently, in the present study, Rb out-diffusion was much faster and occurred at a temperature that was $160 \mathrm{~K}$ lower than that in air annealing experiments. At $870 \pm 45 \mathrm{~K}$, half the implanted $\mathrm{Rb}$ fluence was out-diffused. This value corresponds to $44 \%$ of the melting point of quartz $\left(T_{m}=1983 \mathrm{~K}\right)$ and is much lower than the temperature discussed above. Actually, this number agrees very well with the critical temperatures of $\operatorname{Li}\left(T_{1 / 2}^{L i}=881 \pm\right.$ $59 \mathrm{~K}$ [106]) and $\mathrm{Na}\left(T_{1 / 2}^{N a}=840 \pm 50 \mathrm{~K}\right.$, see chapter 5) calculated for samples annealed in ${ }^{18} \mathrm{O}_{2}$ (see tab.7.1). Similarities between the concentration profiles suggest a similar diffusion mechanism in all cases.

From the Arrhenius plot of the Rb loss per hour shown in fig.4.16 (b), the activation energy for Rb out-diffusion, $E_{a}^{R b}=0.7 \pm 0.1 \mathrm{eV}$, was extracted. This number is about $50 \%$ lower than the high-temperature value of the activation energy of the $\mathrm{Rb}$ migration process in air. The recrystallization speed (parametrized by $E_{a x}=1.3 \pm 0.2 \mathrm{eV}$ ) is two times faster than Rb out-diffusion (table 4.4).

The correlation discussed here suggests that out-diffusion of the implanted alkali ions is less dependent on the ion mass than on the oxygen annealing atmosphere. 

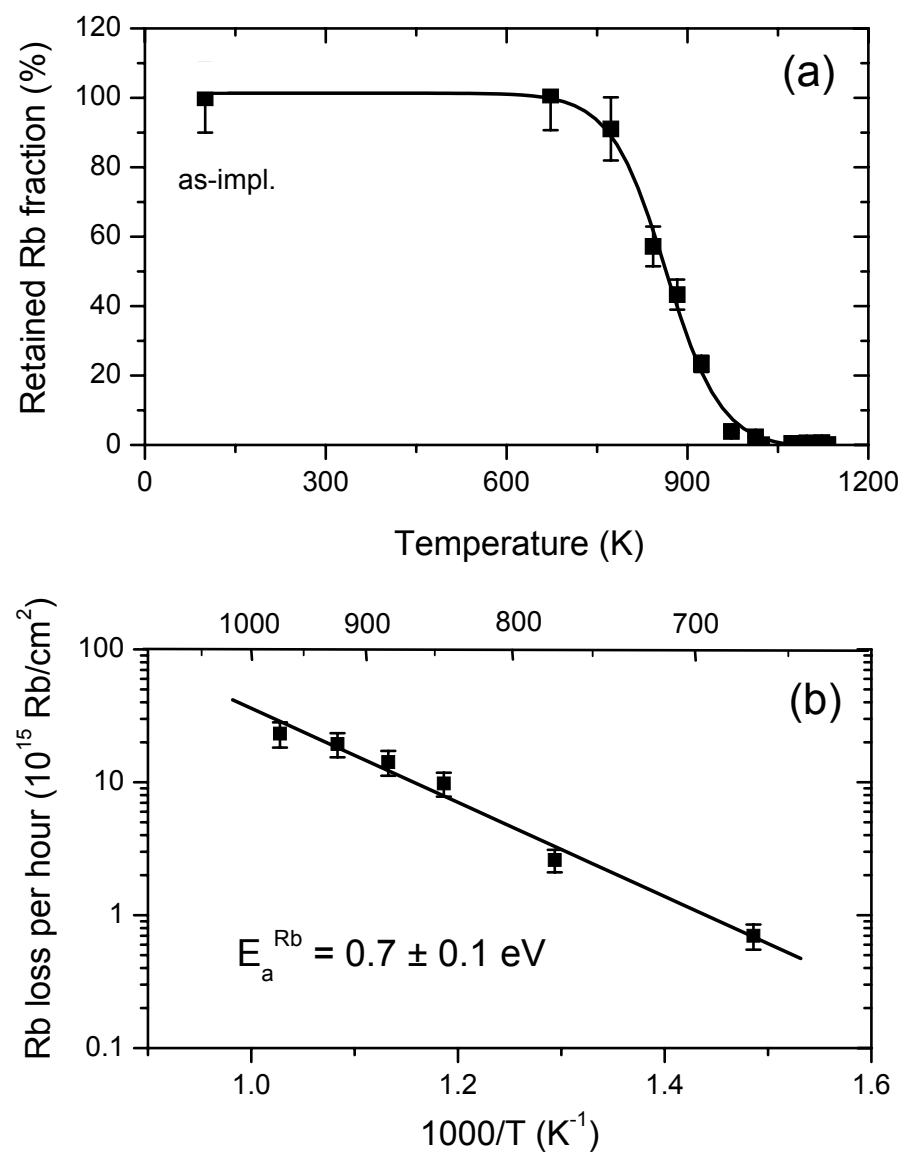

Figure 4.16: (a) Retained $\mathrm{Rb}$ fraction integrated over the full profile as a function of the annealing temperature. (b) Arrhenius dependence of the $\mathrm{Rb}$ loss per hour, corresponding to an activation energy $\mathrm{E}_{a}^{R b}=0.7 \pm 0.1 \mathrm{eV}$.

For completeness, the results of the fluence dependence are also briefly presented. The $\mathrm{Rb}$ loss was monitored for samples implanted with $4.7 \times 10^{15}-4.7 \times 10^{16} \mathrm{Rb} / \mathrm{cm}^{2}$ and annealed in air at a constant temperature of $1123 \mathrm{~K}$. The changes in the shape of the profiles (see fig.4.9) follows the mechanism previously discussed. The calculated value of the $\mathrm{Rb}$ concentration after 1 and 2-h annealings versus the $\mathrm{Rb}$ fluence is reported in fig.4.17. At $\Phi=4.7 \times 10^{15} / \mathrm{cm}^{2}, \mathrm{Rb}$ had totally left the amorphized layer, even after of only $1 \mathrm{~h}$ annealing. For the remaining samples, after the first hour of annealing, approximately $50 \%$ of the initial $\mathrm{Rb}$ concentration was retained in the samples. Only for the highest fluence we observed a lower loss $(\sim 40 \%)$ of $\mathrm{Rb}$. Above $2 \times 10^{16} / \mathrm{cm}^{2}$, the Rb profiles showed a tendency to move towards the surface. After 2 hours of annealing, the Rb totally left 


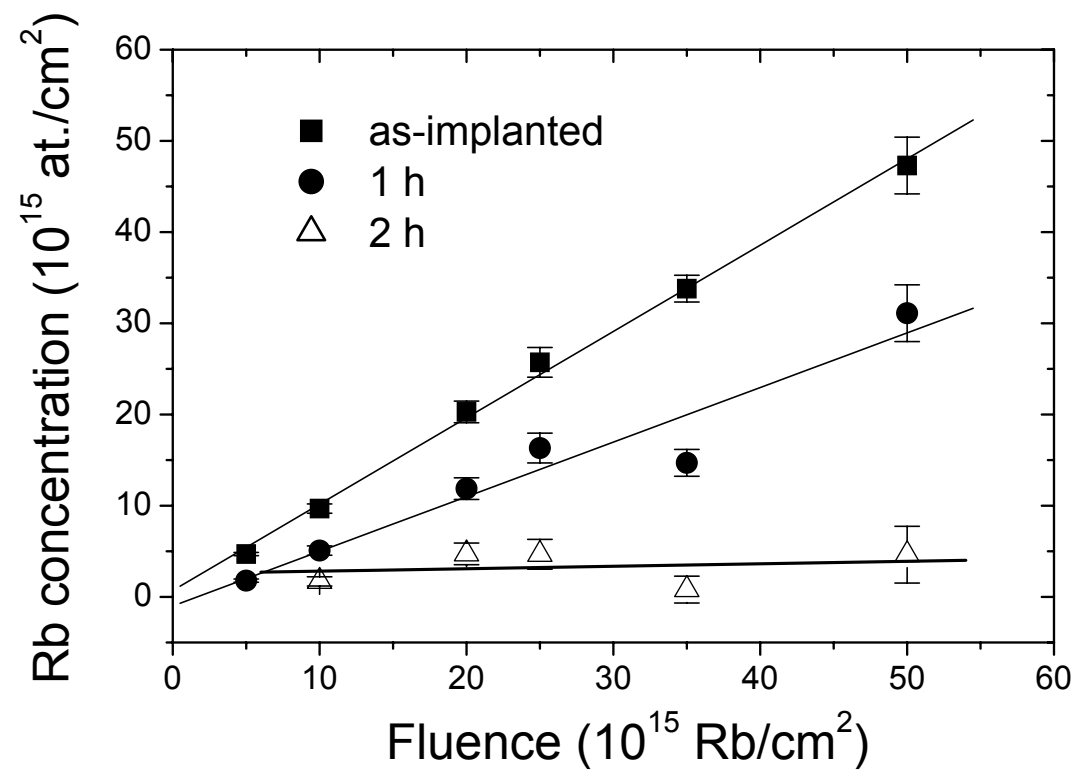

Figure 4.17: $\mathrm{Rb}$ concentration integrated over the full profile as a function of the $\mathrm{Rb}$ fluence.

the samples implanted with fluences of $1 \times 10^{16}$ and $3.4 \times 10^{16} / \mathrm{cm}^{2}$. A small amount of the implanted species was still found inside the remainning radiation-damaged zones.

In all other cases the implanted $\mathrm{Rb}$ had quickly and completely out-diffused from the matrix, therefore the results are not presented here.

\subsection{Oxygen migration during thermal annealing}

Understanding the role and diffusion of oxygen during SPEG in $\alpha$-quartz is an important issue. The use of ${ }^{18} \mathrm{O}_{2}$ tracer gas and TOF-ERDA was essential, as this technique provided the individual fractions of ${ }^{16} \mathrm{O}$ and ${ }^{18} \mathrm{O}$ as a function of depth. Annealing in ${ }^{18} \mathrm{O}_{2}$ atmosphere indeed led to the in-diffusion of ${ }^{18} \mathrm{O}$ and out-diffusion of ${ }^{16} \mathrm{O}$, i.e. the isotope exchange ${ }^{18} \mathrm{O} \Leftrightarrow{ }^{16} \mathrm{O}$ between the surface layer and the annealing gas as noted previously in the case of $\mathrm{Na}[59,105]$ and $\mathrm{Cs}[52,53,59]$ irradiation.

As a first result we verified that the ${ }^{18} \mathrm{O}$ and ${ }^{16} \mathrm{O}$ concentrations added up to the stoichiometry of $\mathrm{SiO}_{2}$, independent of depth and treatment. In fig.4.18, the typical shape of the depth profiles of ${ }^{16} \mathrm{O},{ }^{18} \mathrm{O}$, and Si measured by means of the TOF-ERDA technique for $\mathrm{Rb}$ irradiated $\alpha$-quartz with a fluence of $0.5 \times 10^{16} \mathrm{Rb} / \mathrm{cm}^{2}$ and annealed at $1123 \mathrm{~K}$ are presented. 


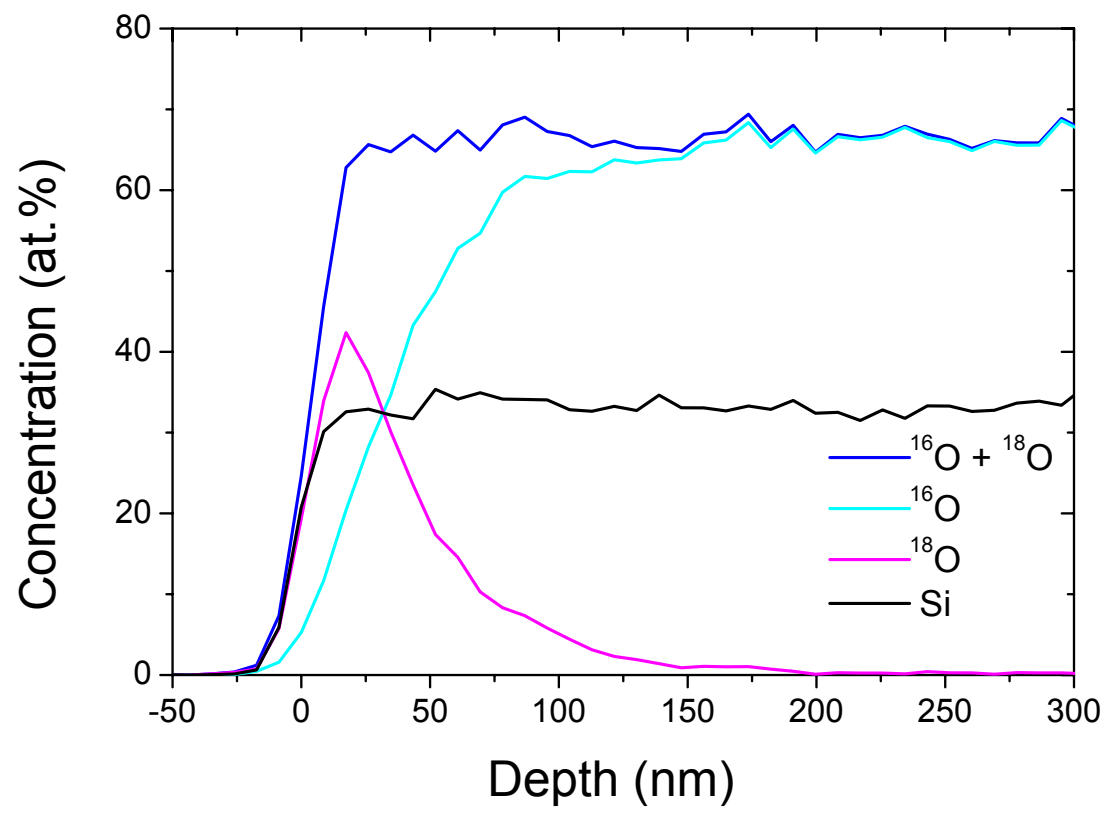

Figure 4.18: The depth profiles of ${ }^{16} \mathrm{O},{ }^{18} \mathrm{O}$, and Si measured by TOF-ERDA for $\mathrm{Rb}$ implanted $\alpha$-quartz with an implanted fluence of $0.5 \times 10^{16} \mathrm{Rb} / \mathrm{cm}^{2}$ and annealed at $1123 \mathrm{~K}$.

TOF-ERDA spectra were taken for samples irradiated at an $\mathrm{Rb}$ fluence of $2.5 \times 10^{16} \mathrm{Rb} / \mathrm{cm}^{2}$ and annealed in ${ }^{18} \mathrm{O}_{2}$ gas for $1 \mathrm{~h}$ up to $1133 \mathrm{~K}$.

The ${ }^{18} \mathrm{O}$ depth distributions in the radiation-damaged zone after annealing at different temperatures are summarized in fig.4.19 (a). The concentrations of the ${ }^{18} \mathrm{O}$ isotope in the pure $\alpha$-quartz sample and in the as-implanted one (at $80 \mathrm{~K}$ ) were almost identical. The ${ }^{16} \mathrm{O} \Longleftrightarrow{ }^{18} \mathrm{O}$ exchange between the matrix and the annealing gas evidently became stronger with increasing annealing temperature. At $673 \mathrm{~K}$ only a very small amount of ${ }^{18} \mathrm{O}$ was detected near the surface. Up to $973 \mathrm{~K}$, a much stronger exchange was observed in the region close to the surface (in the first $50 \mathrm{~nm}$ of the damaged part) than in the deeper-lying part of the amorphous region (from 50 to $280 \mathrm{~nm}$ ). The effect of the oxygen in-diffusion becomes stronger after $\mathrm{Rb}$ has completely out-diffused from the samples. By increasing the temperature, ${ }^{18} \mathrm{O}$ reached the position of the a/c interface, while beyond the implanted region of about $280 \mathrm{~nm}$ the ${ }^{18} \mathrm{O}$ concentration was in accordance with the natural isotope abundance. This is due to the extremely low diffusivity of oxygen in crystalline $\mathrm{SiO}_{2}$ [59]. A sudden enhancement of ${ }^{18} \mathrm{O}$ was observed at $1023 \mathrm{~K}$, where SPEG started. The ${ }^{18} \mathrm{O}$ concentration had a maximum of about $42 \%$ at the surface and slowly decreased inside the damaged layer. At $1123 \mathrm{~K}$, where almost complete SPEG was achieved, once again a higher ${ }^{18} \mathrm{O}$ yield was measured. Due to $\mathrm{Rb}$-beam amorphization of $\alpha-\mathrm{SiO}_{2}$, the density of the matrix decreased by about $19 \%$. The diffusion channels become larger 

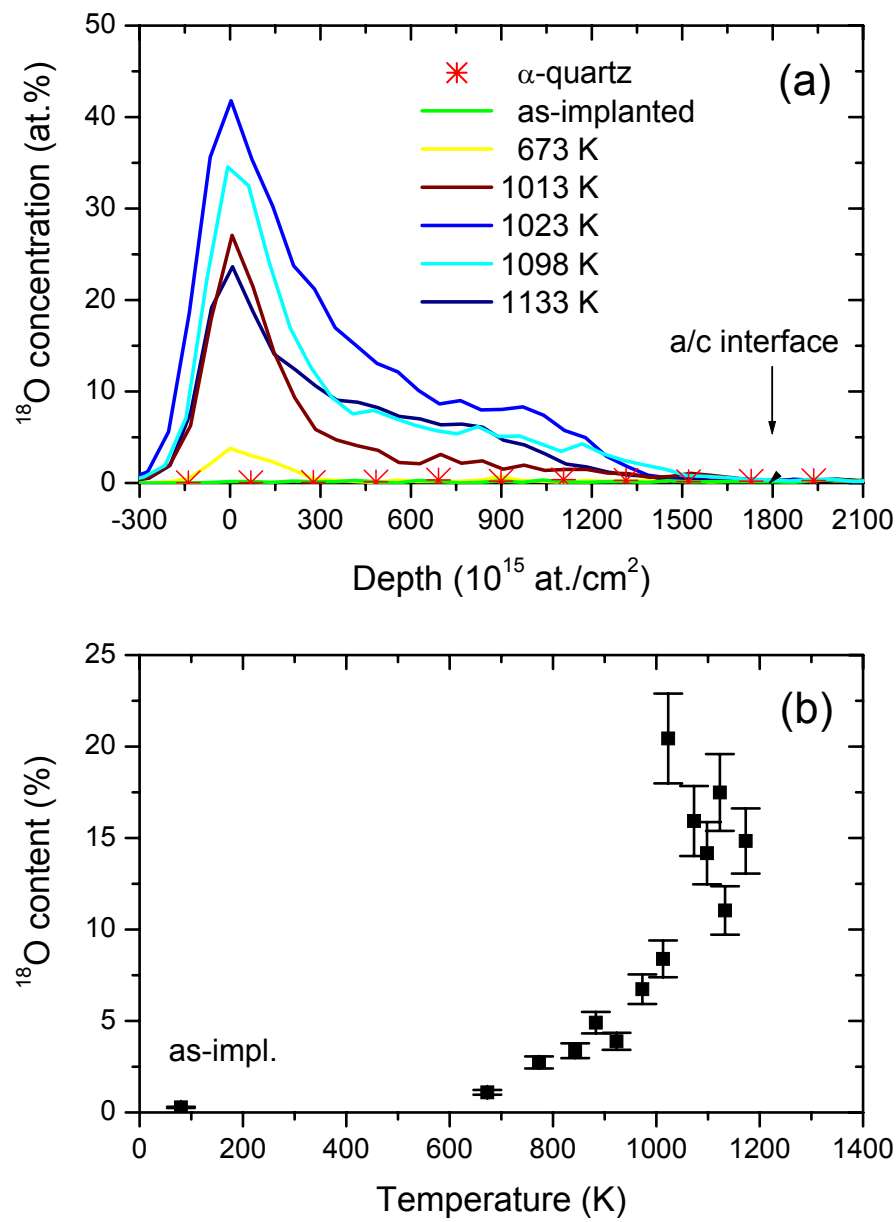

Figure 4.19: (a) ${ }^{18} \mathrm{O}$ concentration profiles measured by TOF-ERDA for $\mathrm{Rb}$-implanted samples, annealed at $673-1133 \mathrm{~K}$ for $1 \mathrm{~h}$. (b) ${ }^{18} \mathrm{O}$ content intergated up to the $\mathrm{a} / \mathrm{c}$ interface, as a function of the annealing temperature.

(about $3 \AA$ ) in size and are comparable to the diameter of the molecular oxygen [115]. The energy barriers for oxygen migration in amorphized $\mathrm{SiO}_{2}$ are expected to be smaller than in crystalline $\mathrm{SiO}_{2}$ and, consequently, the oxygen diffusion coefficient in quartz is much lower than in amorphous $\mathrm{SiO}_{2}$ and is parametrized by activation energies in the range 2.02 to $2.38 \mathrm{eV}$ [9].

Figure 4.19 (b) shows the integrated content of in-diffused ${ }^{18} \mathrm{O}$ up to the a/c interface as a function of the annealing temperature. The ${ }^{18} \mathrm{O}$ content is given by:

$$
f^{18} O=\frac{\int c\left({ }^{18} O\right) d x}{\int c\left({ }^{18} O\right) d x+\int c\left({ }^{16} O\right) d x}
$$




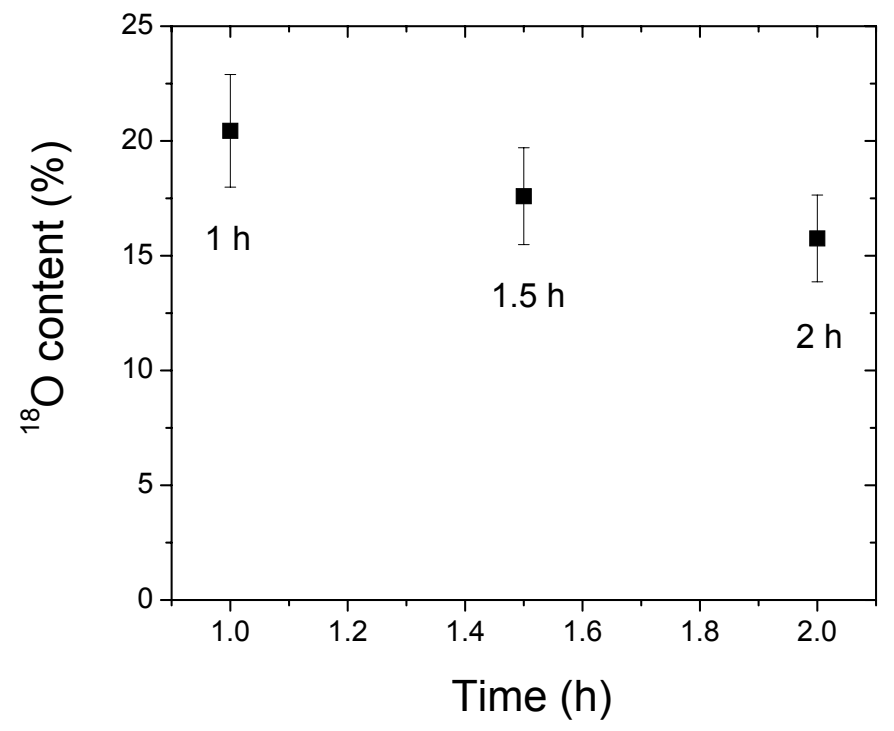

Figure 4.20: ${ }^{18} \mathrm{O}$ content integrated up to the a/c interface, as a function of the annealing time for $\mathrm{Rb}$-implanted samples at an ion fluence of $2.5 \times 10^{16} \mathrm{Rb} / \mathrm{cm}^{2}$ and annealed at $1023 \mathrm{~K}$.

where $\int c^{18} \mathrm{O}$ and $\int c^{16} \mathrm{O}$ denote the integrated ${ }^{18} \mathrm{O}$ and ${ }^{16} \mathrm{O}$ contents stored in the amorphized layer.

The total ${ }^{18} \mathrm{O}$ content increased with the annealing temperature by $15-20 \%$ up to about $1000 \mathrm{~K}$. Note a possible decrease in the ${ }^{18} \mathrm{O}$ content between $1000 \mathrm{~K}$ and $1200 \mathrm{~K}$.

In order to find the influence of the $\mathrm{Rb}$ fluence on the oxygen in-diffusion, a set of samples was implanted at a fluence of $2.5 \times 10^{16} \mathrm{Rb} / \mathrm{cm}^{2}$ and annealed in ${ }^{18} \mathrm{O}_{2}$ at $1023 \mathrm{~K}$ for different annealing times. Figure 4.20 illustrates the evolution of the corresponding ${ }^{18} \mathrm{O}$ content versus the annealing time. During the $1-\mathrm{h}$ annealing, a large amount of ${ }^{18} \mathrm{O}$ diffused into the sample up to the a/c interface (about 20\%). However, this amount was almost independent of the annealing time (compare the results of the 1.5-h and 2-h annealing), probably because the $\mathrm{Rb}$ had already out-diffused during the first hour. Furthermore, because of the absence of $\mathrm{Rb}$, no complete crystalline recovery occurred, not even during the 2-h annealing.

TOF-ERDA measurements were also applied to monitor the migration of ${ }^{18} \mathrm{O}$ during the 1 -h heating process at $1123 \mathrm{~K}$ for samples irradiated with varying $\mathrm{Rb}$-ion fluences of up to $6 \times 10^{16} \mathrm{Rb} / \mathrm{cm}^{2}$. As shown in figure 4.21 (a), the ${ }^{18} \mathrm{O} \Leftrightarrow{ }^{16} \mathrm{O}$ exchange was clearly enhanced with increasing $\mathrm{Rb}$ fluence. Up to about $1.75 \times 10^{16} \mathrm{Rb} / \mathrm{cm}^{2}$, the ${ }^{18} \mathrm{O}$ profiles remained almost unchanged and the in-diffusing ${ }^{18} \mathrm{O}$ was located mainly in the first $75 \mathrm{~nm}$ of the amorphous layer. RBS-C confirmed the correlation between the concentration profiles of the tracer gas and the recovery of the amorphous layer. At $1.75 \times 10^{16} \mathrm{Rb} / \mathrm{cm}^{2}$ movement of the a/c interface was observed (see fig.4.11). At $2.5 \times 10^{16} \mathrm{Rb} / \mathrm{cm}^{2},{ }^{18} \mathrm{O}$ started to 

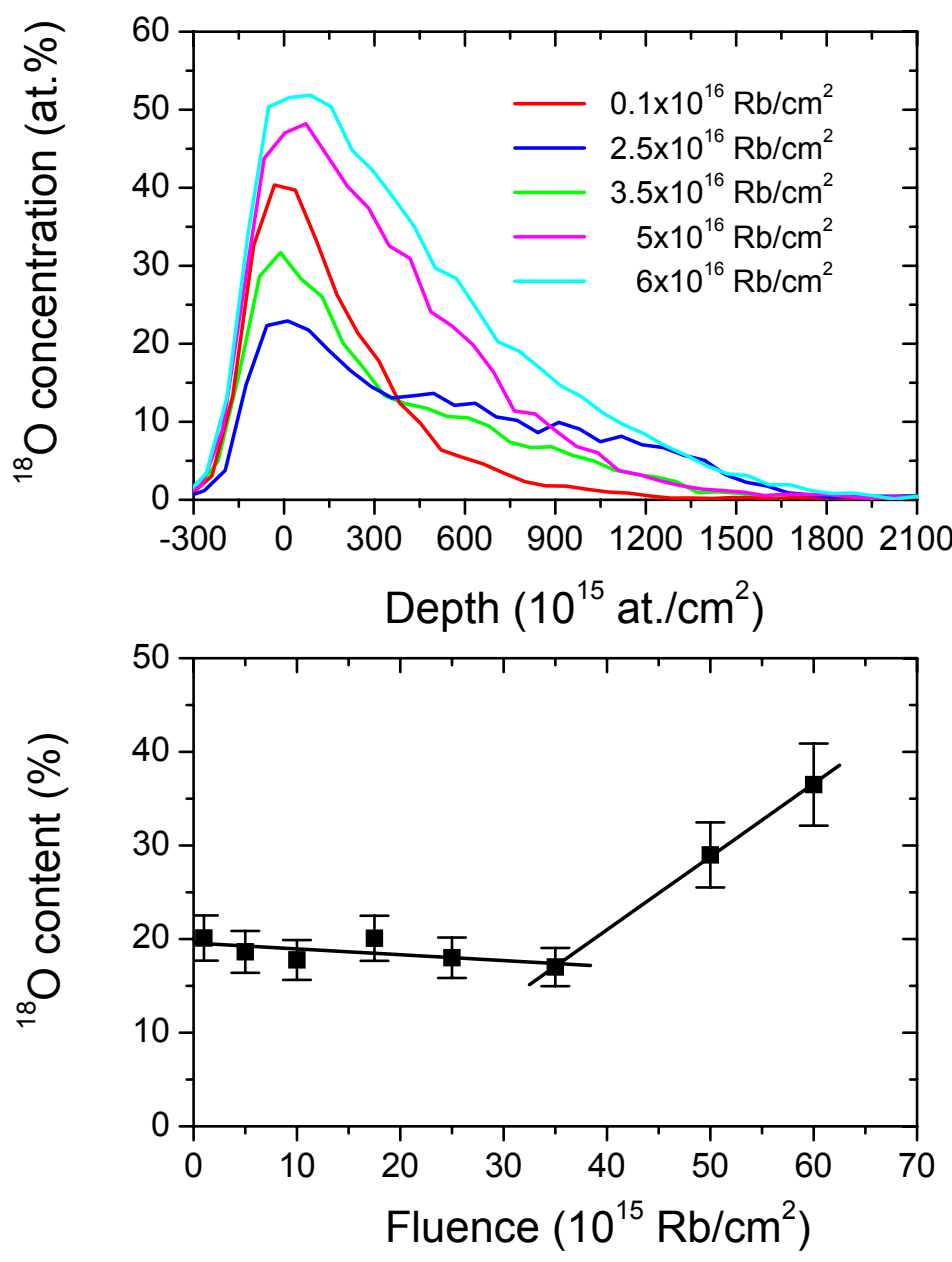

Figure 4.21: (a) ${ }^{18} \mathrm{O}$ concentration profiles measured by TOF-ERDA for Rb-implanted samples at ion fluences in the range $0.1-6 \times 10^{16} \mathrm{Rb} / \mathrm{cm}^{2}$, annealed for $1 \mathrm{~h}$ in an ${ }^{18} \mathrm{O}_{2}$ atmosphere at $1123 \mathrm{~K}$. (b) ${ }^{18} \mathrm{O}$ content integrated up to the a/c interface for different fluences.

be "dissolved" into the $\mathrm{SiO}_{2}$ network: the height of the ${ }^{18} \mathrm{O}$ profiles increased, but the integrated ${ }^{18} \mathrm{O}$ content remained constant (see fig.4.21 (b)) up to $3.5 \times 10^{16} \mathrm{Rb} / \mathrm{cm}^{2}$. For the two highest fluences of $5 \times 10^{16}$ and $6 \times 10^{16} \mathrm{Rb} / \mathrm{cm}^{2}$ (full SPEG), both the height and the width of the ${ }^{18} \mathrm{O}$ profiles increased strongly, indicating appreciable in-diffusion of ${ }^{18} \mathrm{O}_{2}$. It can be concluded that the implanted alkali ion fluence at a fixed annealing temperature affects to some extent both the amount of the in-diffused oxygen and the quality of the epitaxial regrowth. This correlation can be explained by the high chemical reactivity of alkali with oxygen and network modification caused by the presence of alkali ions.

The RBS-C results obtained for samples $\left(\Phi=2.0 \times 10^{16} \mathrm{Rb} / \mathrm{cm}^{2}, \mathrm{~T}_{A}=1023 \mathrm{~K}\right)$ examined 

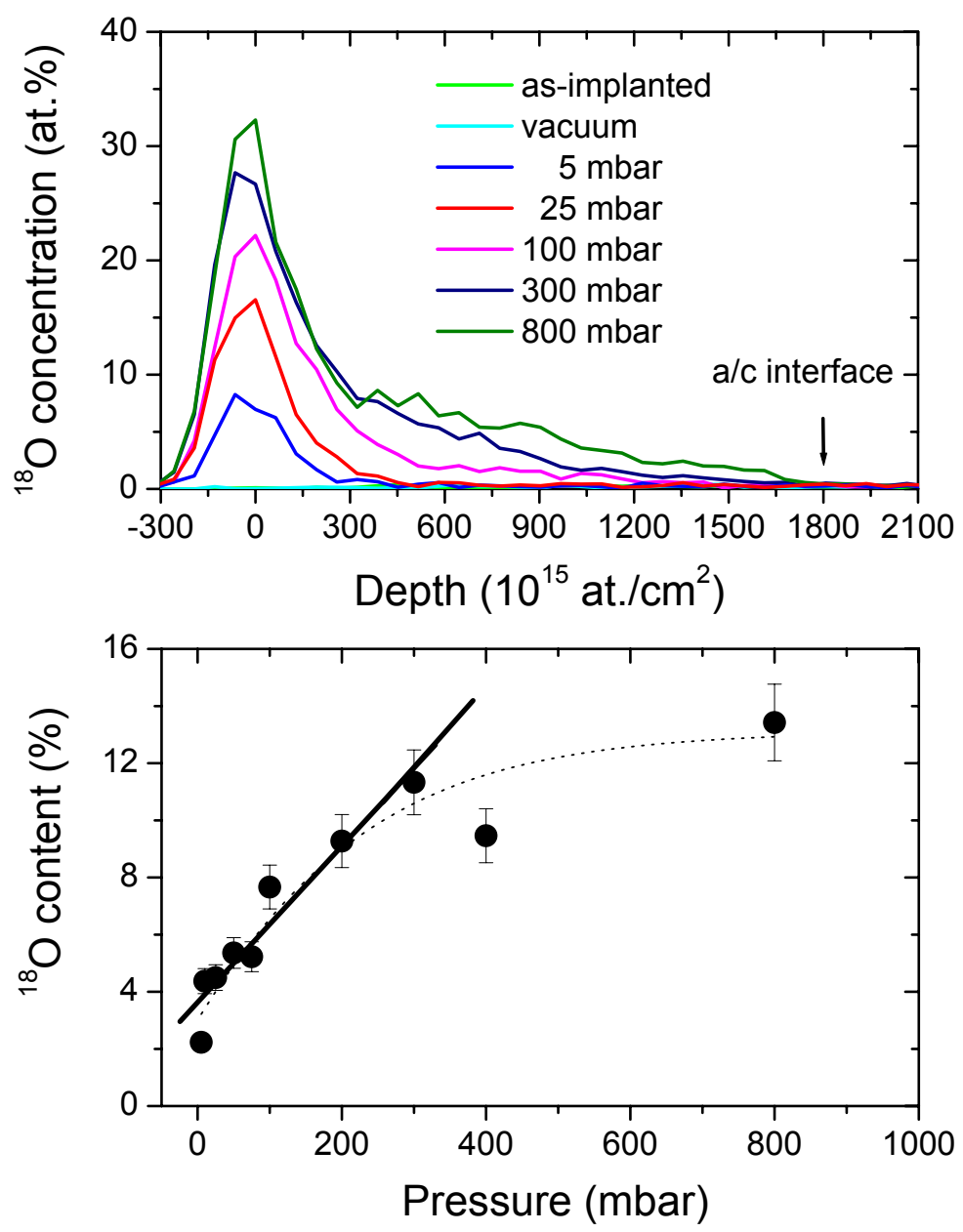

Figure 4.22: (a) ${ }^{18} \mathrm{O}$ concentration profiles measured by TOF-ERDA for $\mathrm{Rb}$-implanted samples at an ion fluence of $2.0 \times 10^{16} \mathrm{Rb} / \mathrm{cm}^{2}$ after $1 \mathrm{~h}$ annealing in an ${ }^{18} \mathrm{O}_{2}$ atmosphere at $1023 \mathrm{~K}$ under ${ }^{18} \mathrm{O}_{2}$ pressure varied between 5 and 800 mbar. (b) ${ }^{18} \mathrm{O}$ content integrated up to the a/c interface as a function of the ${ }^{18} \mathrm{O}_{2}$ pressure.

under different ${ }^{18} \mathrm{O}_{2}$ pressures showed no recovery of the damaged layer (see fig.4.12). However, as reported in fig.4.22 (a), the TOF ERD analyses revealed that for increasing oxygen pressure, the exchange between native ${ }^{16} \mathrm{O}$ and external ${ }^{18} \mathrm{O}$ became stronger. Up to 100 mbar, the distribution of the tracer ${ }^{18} \mathrm{O}$ atoms further broadened near the surface, but was still located within the first $50 \mathrm{~nm}$ of the amorphous layer. At $800 \mathrm{mbar}$, the exchange of the oxygen isotopes peaked at a maximum value of about $33 \%$ and ${ }^{18} \mathrm{O}$ reached the $\mathrm{a} / \mathrm{c}$ interface, but did not diffuse across this interface into the $\alpha$-quartz. Figure 4.22 (b) indicates that the total amount of ${ }^{18} \mathrm{O}$ penetrated into the damaged layer linearly increased 
with increasing ${ }^{18} \mathrm{O}_{2}$ pressure and saturated at about 300 mbar. This result confirms the trend found by Schaeffer [114] that the diffusion of oxygen depends linearly on the oxygen partial pressure. Such a dependence suggests that $\mathrm{O}_{2}$ is the diffusing species and not monoatomic oxygen vacancies or ions, which show non-linear dependence on the oxygen pressure [9]. Moreover, it is difficult to find the correlation between the Rb out-diffusion and the ${ }^{18} \mathrm{O}_{2}$ pressure, because in all cases $\mathrm{Rb}$ completely left the samples. When the $\mathrm{Rb}$ fluence was increased to $2.5 \times 10^{16} \mathrm{Rb} / \mathrm{cm}^{2}$, partial SPEG occurred at $1023 \mathrm{~K}$ in $300 \mathrm{mbar}$ ${ }^{18} \mathrm{O}_{2}$ pressure. When the temperature was further increased to $1123 \mathrm{~K}$, almost the whole amorphous layer had recovered (fig.4.11 (b)).

We may summarize the findings in the following conclusions:

- minimum amounts of $\mathrm{Rb}$ and oxygen are required for complete SPEG;

- no appreciable oxygen in-diffusion occurs in the absence of $\mathrm{Rb}$;

- the stoichiometry of the amorphous $\mathrm{SiO}_{2}$ layer does not change due to the ${ }^{18} \mathrm{O} \Leftrightarrow$ ${ }^{16} \mathrm{O}$ exchange between external ${ }^{18} \mathrm{O}$ and native ${ }^{16} \mathrm{O}$;

- the oxygen gas pressure probably influences the epitaxial growth above a critical value;

- the critical temperature for achieving complete SPEG decreases for increasing Rb fluence.

It is clear from the above results that the topological freedom of the $\mathrm{SiO}_{4}$ network, which is necessary for achieving complete SPEG, appears to be jointly controlled by the annealing temperature, the density of implanted alkali ions, and the presence of external oxygen. The presence of alkali ions and oxygen is necessary, but not sufficient to achieve complete epitaxy. The oxygen exchange process facilitates the diffusion of $\mathrm{Rb}$ in such a way that it provides the topological freedom for the $\mathrm{SiO}_{4}$ network. However, complete recrystallization is realized only above a critical temperature, $\mathrm{Rb}$ fluence, and pressure.

\subsection{Surface topography}

The Atomic Force Microscope (AFM) cannot identify the crystalline structure or the chemical composition of the surface layer, but it is a very useful tool to resolve nanoscale surface characteristics. In the context of ion implantation and oxygen-induced reactions in quartz, the AFM may also be helpful to verify swelling or compaction phenomena, which are due to amorphization and recrystallization. As the implantation conditions provided a rather sharp boundary between irradiated and non-irradiated regions, AFM was employed to evaluate the step height, $\Delta \mathrm{h}$, at this boundary. The AFM study was applied to analyse the selected samples annealed in air or in an ${ }^{18} \mathrm{O}_{2}$ atmosphere. Typical AFM data at the border area between the implanted and the non-implanted part showing the step height, 


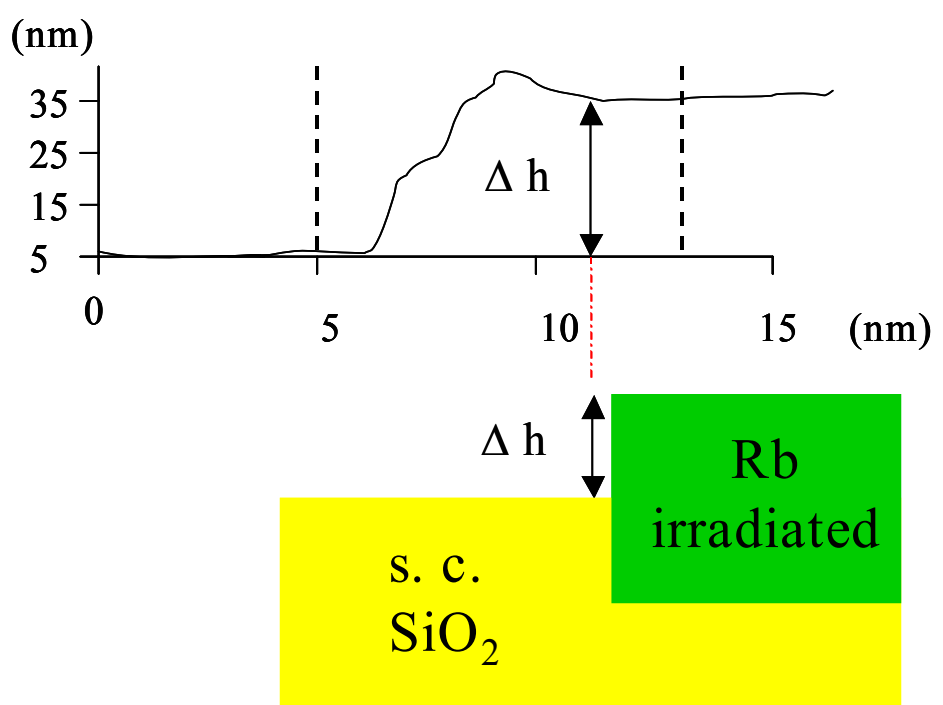

Figure 4.23: Typical AFM raw data obtained for the height difference $\Delta \mathrm{h}$ at the border between the implanted and non-implanted part of the sample.

$\Delta \mathrm{h}$, are illustrated in fig.4.23.

The step height $\Delta \mathrm{h}$ was measured for various implantation and annealing conditions. As an example, fig.4.24 (a) shows this quantity as a function of the annealing temperature for samples annealed in an ${ }^{18} \mathrm{O}_{2}$ gas. The step height after implantation of $2.5 \times 10^{16} \mathrm{Rb}$ ions $/ \mathrm{cm}^{2}$ was $24 \pm 2 \mathrm{~nm}$. When SPEG started (973 K), the step height started to decrease, until at $1133 \mathrm{~K}$ it reached zero when full epitaxy was achieved. Evidently, the AFM measurements showed a recovery of the volume density and confirmed very well the results obtained via RBS-C. At this temperature, the roughness of the regrown surface was larger than that of the non-irradiated part of the sample. After the $1173 \mathrm{~K}$ annealing, the step height turned out to be slightly negative, suggesting some change in density or loss of material, possibly by evaporation.

For the same set of samples, the difference in the step height between the non-irradiated and irradiated part of the sample was also measured by means of a profilometer (see fig.4.24 (b)). Mechanical surface profiling confirmed the AFM observations very well. The step height started to decrease at $973 \mathrm{~K}$ and subsequently decreased with increasing temperature. The surface profile at $1173 \mathrm{~K}$ showed again, similarly to the AFM results, that the irradiated area was below the non-irradiated part of the sample.

A similar change in the step height was also observed after annealing in air. The AFM study showed that the implanted and non-implanted part of the sample was almost on the same height level after achieving complete SPEG (not shown).

The step height, $\Delta \mathrm{h}$, was also measured via AFM for various oxygen pressures (see 4.3), but no differences relative to the results just shown were found (no shift in $\Delta \mathrm{h}$ was de- 


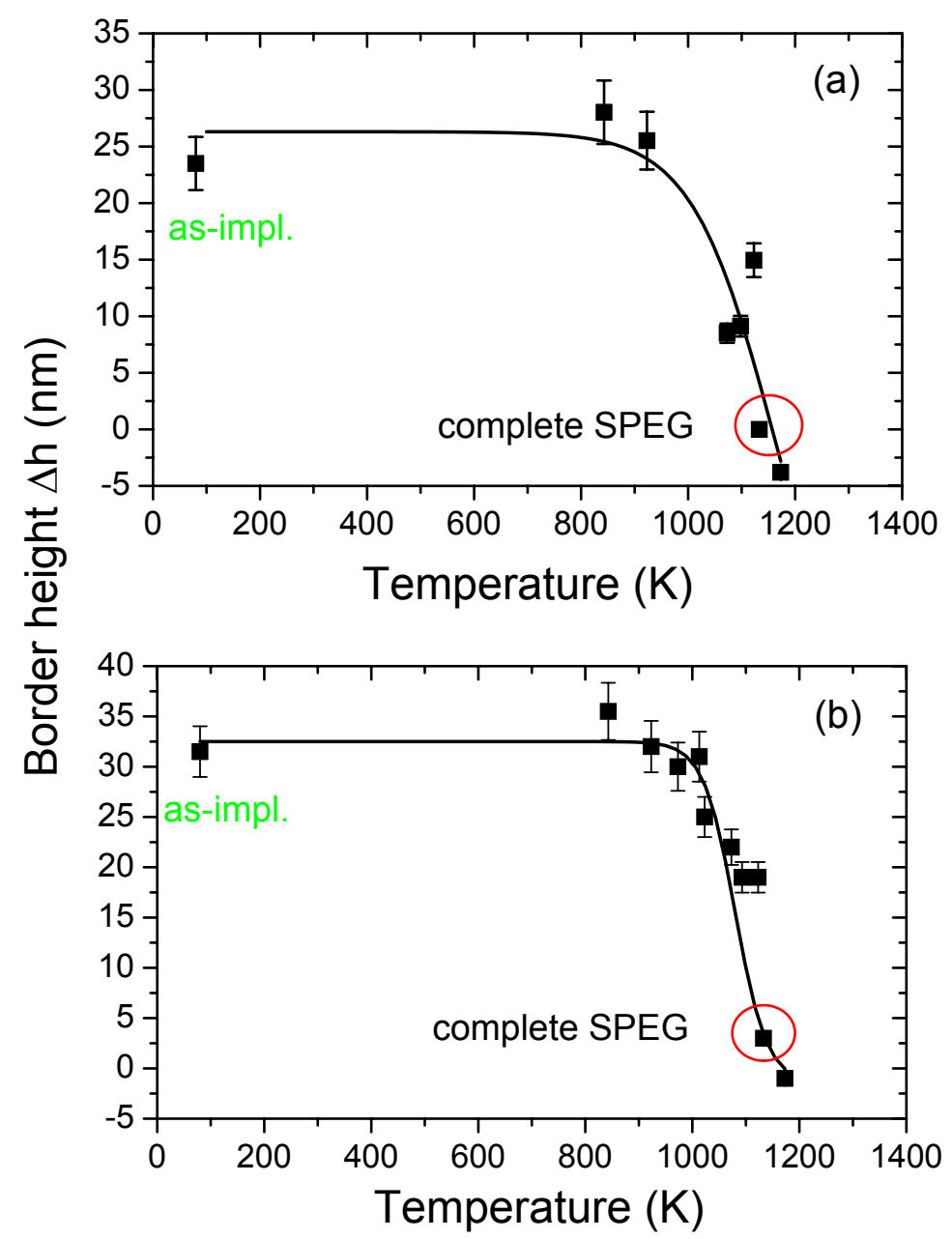

Figure 4.24: The height difference $\Delta \mathrm{h}$ at the border area between the irradiated $(\Phi=$ $2.5 \times 10^{16} \mathrm{Rb} / \mathrm{cm}^{2}$ ) and non-irradiated part of the samples as a function of the annealing temperature ( 843 - $1173 \mathrm{~K}$ ) measured by AFM (a) and a mechanical surface profiler (b).

tected).

The surface of the implanted sample was almost completely smooth. AFM topographies measured after a 1-h annealing in ${ }^{18} \mathrm{O}_{2}$ at different temperatures and fluences are reported in fig.4.25. The lowest annealing temperature did not produce any detectable structural changes (these samples were amorphous). Obvious changes in the surface topography appeared when the recovery set in. The AFM image taken after achieving complete SPEG at $1173 \mathrm{~K}$ showed fine grainy structures on the surface (see fig.4.25 (a)). For higher implanted fluences, these small structures combined to produce bigger and bigger structures with increasing fluence as shown in fig.4.25 (b) and (c) for the cases of 3.5 and $5 \times 10^{16}$ 


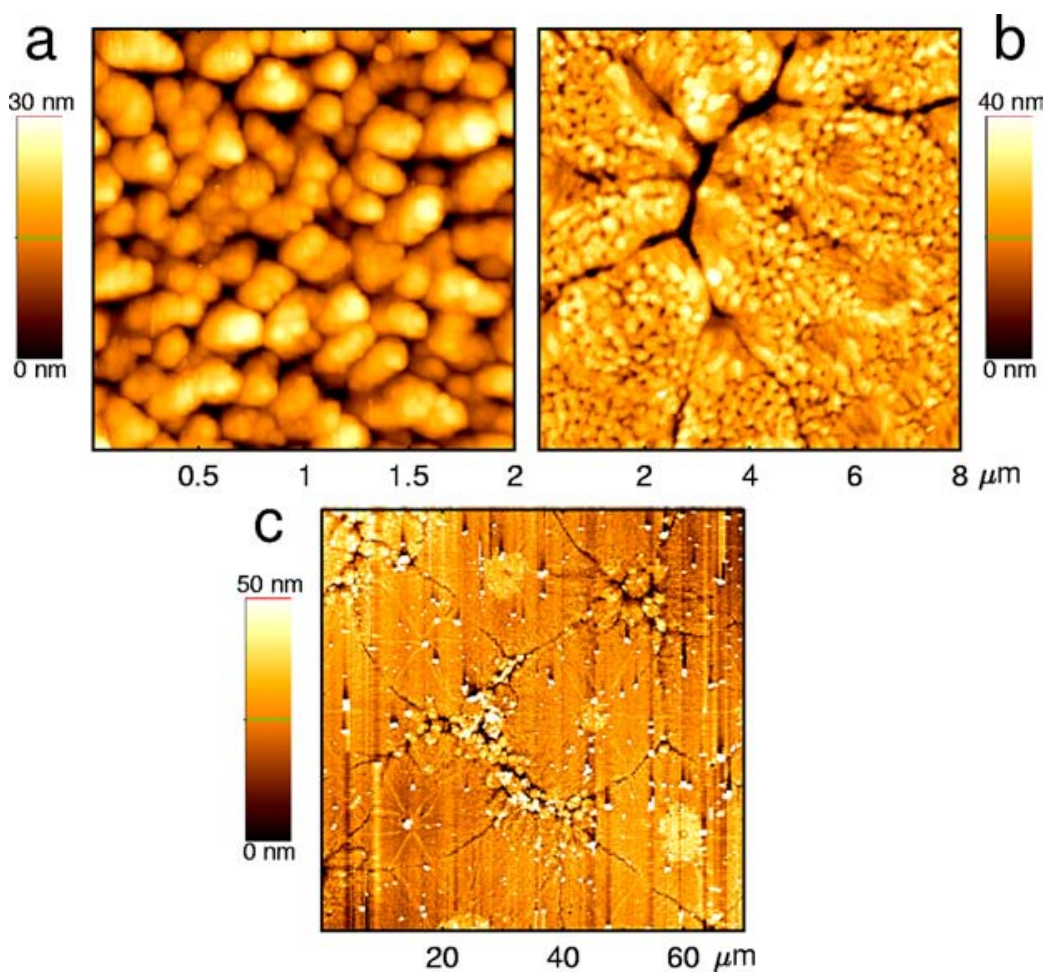

Figure 4.25: Plan-view AFM topography images of $\alpha$-quartz samples implanted with $\mathrm{Rb}^{+}$-ions and annealed in ${ }^{18} \mathrm{O}_{2}$ at: (a) $1173 \mathrm{~K}\left(\Phi=2.5 \times 10^{16} \mathrm{Rb} / \mathrm{cm}^{2}\right)$, (b) $1123 \mathrm{~K}\left(\Phi=3.5 \times 10^{16} \mathrm{Rb} / \mathrm{cm}^{2}\right)$, and (c) $1123 \mathrm{~K}\left(\Phi=5 \times 10^{16} \mathrm{Rb} / \mathrm{cm}^{2}\right)$.

$\mathrm{Rb} / \mathrm{cm}^{2}$ implantations, respectively. Such regrowth mechanisms suggest Ostwald ripening $[125,126]$, where the larger structure grew at the expense of the smaller structure because the surface energy for larger structures is lower than for smaller structures.

The images obtained for air-annealed samples (fixed fluence $\Phi=2.5 \times 10^{16} \mathrm{Rb}$-ions $/ \mathrm{cm}^{2}$, temperature dependence) showed completely different features compared to the ${ }^{18} \mathrm{O}_{2}$ experiments. Again, after annealing at a low temperature no surface structures were visible. At $1133 \mathrm{~K}$, the continuous amorphous layer had disappeared. Then, annealing at $1143 \mathrm{~K}$ (almost full recrystallization, but some Rb still left in the sample) led to the crystallization of ring-like structures with an average diameter of about $15 \mathrm{~nm}$. The most evident behaviour displayed by the AFM images is the increase in the size of these features (as already observed in the case of ${ }^{18} \mathrm{O}_{2}$ annealing). By increasing the annealing temperature to $1173 \mathrm{~K}$ (total SPEG), the diameter of this structure and the height of the centered "island" approximately doubled (see fig.4.26).

The AFM study did not show any topological changes for samples examined under different ${ }^{18} \mathrm{O}_{2}$ pressures and annealed at $1023 \mathrm{~K}$. However, after annealing in an ${ }^{18} \mathrm{O}_{2}$ atmosphere under a pressure of 50 mbar (complete SPEG) at $1173 \mathrm{~K}$ a hexagonal-shaped nanostructure was produced by SPEG. Probably, the observed crystallized structure is tridymite [91], which has a hexagonal symmetry and occurs at high temperatures and low 


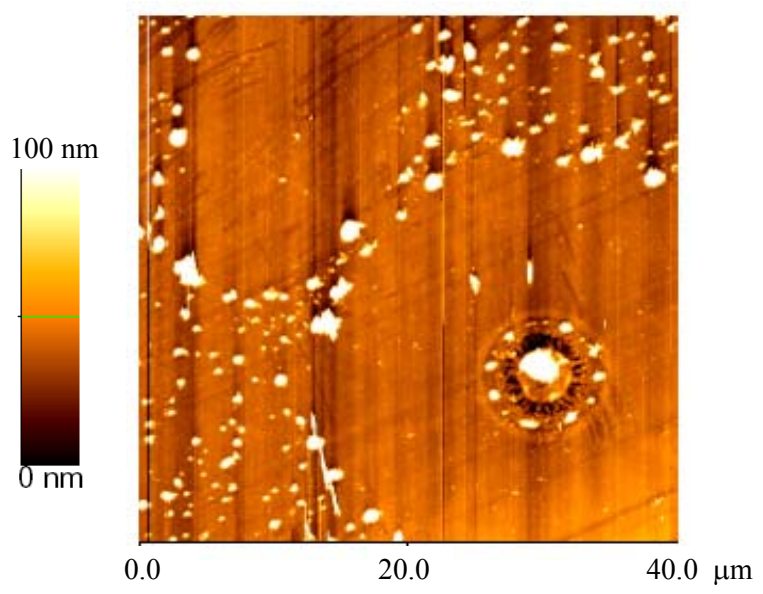

Figure 4.26: AFM image taken for an $\alpha$-quartz sample implanted at a fluence of $2.5 \times 10^{16}$ $\mathrm{Rb} / \mathrm{cm}^{2}$ and annealed in air at $1173 \mathrm{~K}$.
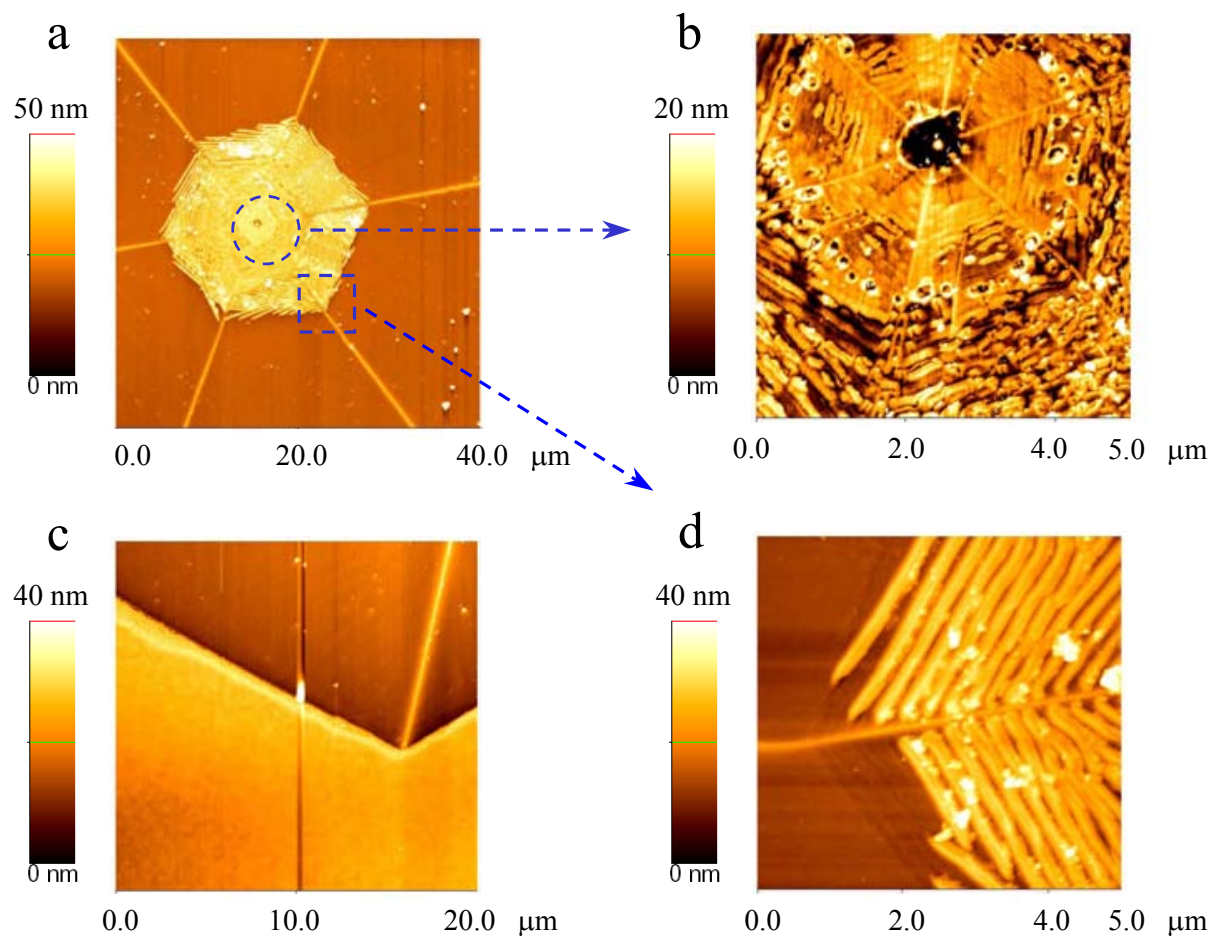

Figure 4.27: (a) Plan-view AFM topography image of an $\alpha$-quartz sample implanted with $\mathrm{Rb}^{+}$-ions at a fluence of $2 \times 10^{16} \mathrm{Rb} / \mathrm{cm}^{2}$ and annealed in an ${ }^{18} \mathrm{O}_{2}$ atmosphere under a pressure of 50 mbar at $1173 \mathrm{~K}$. (b), (d) The zoom of the crystal center and the edge, respectively. (c) The side edge of the structure. 
pressures [1]. In order to achieve a complete understanding of the formation of surface structures, further investigation need to be performed.

As already mentioned, the AFM imaging gave a direct view of the recrystallized structure and had proven to be an appropriate instrument for investigating the topology of the recovered $\alpha$-quartz surfaces. From the above observations, it can be concluded that the AFM results are consistent with the RBS-C measurements (on average) and illustrate the fundamental influence of fluence, temperature, and oxygen supply on the morphology of the recrystallized surface. It is, however, evident that lateral structures appear at the surface whose properties and symmetries require further investigation. 


\section{SPEG after Na-implantation}

\subsection{Transport processes}

The behaviour of implanted Na during thermal annealing was previously studied by Bolse and Harbsmeier [8, 42, 119] via Extended X-Ray Absorption Spectroscopy (EXAFS) and Rutherford Backscattering-Channeling Spectroscopy (RBS-C). However, attempts made to achieve recystallization of the damaged zones have generally not been successful. Roccaforte et al. [59] reported almost full SPEG after Na irradiation in crystalline $\alpha$-quartz and annealing in air. The present investigation extends the preliminary findings to annealing in an ${ }^{18} \mathrm{O}_{2}$ atmosphere, monitoring the Na migration and ${ }^{18} \mathrm{O} \Leftrightarrow{ }^{16} \mathrm{O}$ exchange, and also gives a detailed study of fluence dependence.

$\alpha$-quartz was irradiated at liquid nitrogen temperature with $50-\mathrm{keV} \mathrm{Na}$ ions at a fluence of $2.5 \times 10^{16} \mathrm{Na} / \mathrm{cm}^{2}$ and then annealed for 1 hour in ${ }^{18} \mathrm{O}_{2}$ gas up to a temperature of $1123 \mathrm{~K}$. Figure 5.1 presents RBS-C spectra taken for virgin, Na-implanted, and annealed samples. After the Na implantation, the quartz was amorphized up to about $200 \mathrm{~nm}$, as measured by RBS in channeling geometry. Upon thermal annealing up to $873 \mathrm{~K}$, the crystallization front started to move towards the surface and then by further increasing the annealing temperature crystallization suddenly reached the virgin level. Almost full SPEG occurred between 873 and $973 \mathrm{~K}$, with some damage left in the sample. After annealing at $1123 \mathrm{~K}$, the sample was in a state which cannot be distinguished from the virgin state any more. At the lowest annealing temperature, the recrystallization speed was $0.7 \times 10^{-9} \mathrm{~cm} / \mathrm{s}$ and increased by one order of magnitude, reaching $5.4 \times 10^{-9} \mathrm{~cm} / \mathrm{s}$ at $973 \mathrm{~K}$. On the other hand, when annealing was carried out in air, almost complete recovery of the amorphous layer was achieved at a temperature that was $100 \mathrm{~K}$ higher [59]. However, some isolated damage zones remained in the recrystallized part and the quality of the recrystallized layer was not as good as in the case of ${ }^{18} \mathrm{O}_{2}$. A comparable quality of the recovered zone after $\mathrm{Rb}$ implantation was achieved at $1133 \mathrm{~K}$. Evidently, by combining $\mathrm{Na}$ irradiation and ${ }^{18} \mathrm{O}_{2}$ annealing, SPEG can be obtained at a lower temperature than with $\mathrm{Rb}$ implantation. In order to investigate the role of the Na fluence, a set of the samples was irradiated at the fixed fluence of $5 \times 10^{16} \mathrm{Na} / \mathrm{cm}^{2}$ and annealed for $1 \mathrm{~h}$ at $773-1123 \mathrm{~K}$ (see fig.5.2). The $\alpha$-quartz was amorphized up to a depth of about $1340 \times 10^{15} \mathrm{at} / \mathrm{cm}^{2}$ (about $210 \mathrm{~nm}$ ). Clearly, annealing up to $873 \mathrm{~K}$ did not cause any shift of the a/c interface. By increasing 


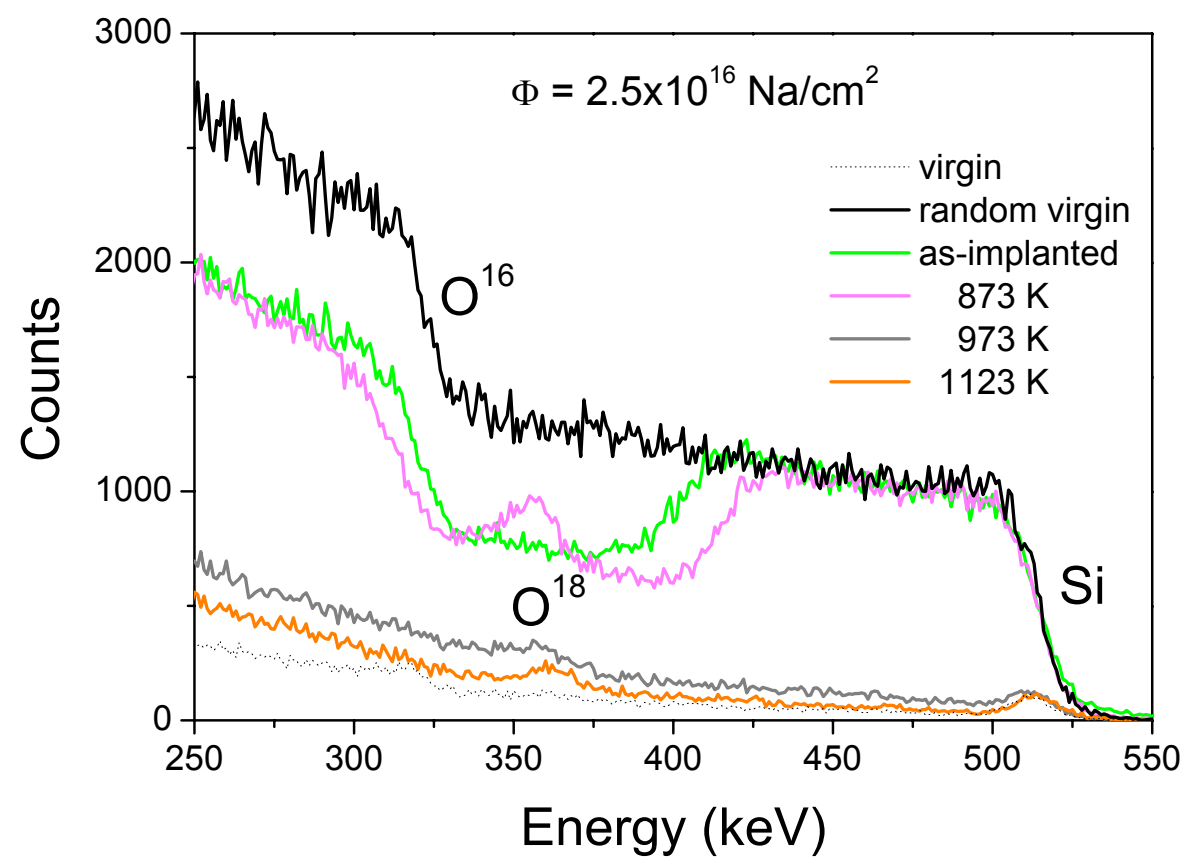

Figure 5.1: RBS-C spectra of 50-keV Na-ion implanted samples at an ion fluence of $2.5 \times 10^{16} \mathrm{Na} / \mathrm{cm}^{2}$ before and after $1-\mathrm{h}$ annealing in an ${ }^{18} \mathrm{O}_{2}$ atmosphere at temperatures varied in the range $873-1123 \mathrm{~K}$.

the temperature to $923 \mathrm{~K}$ the coherent amorphous part disappeared, but still the RBS-C spectrum showed a slightly higher backscattering yield than for the virgin aligned one. Annealing at $1073 \mathrm{~K}$ initiated the full recovery of the crystalline matrix. As compared to the results at $2.5 \times 10^{16} \mathrm{Na} / \mathrm{cm}^{2}$, the increased $\mathrm{Na}$ fluence seems to slightly hinder the recrystallization velocity in the low temperature region. For example, at $873 \mathrm{~K}, \mathrm{v}(\mathrm{T})=$ $0.35 \times 10^{-9} \mathrm{~cm} / \mathrm{s}$ which is half the value found for $2.5 \times 10^{16} \mathrm{Na} / \mathrm{cm}^{2}$. Also, higher temperatures were required to obtain a comparable quality of the recovered zone. The trend of air annealing experiments was also verified this time. Complete regrowth was not achieved, not even at $1023 \mathrm{~K}$, though the same amount of $\mathrm{Na}$ was inside the sample [59]. The results of this part of experiments are summarized in table 5.1 and compared with the Rb results. To optimize SPEG after Na implantation the fluence dependence was studied at two fixed annealing temperatures: 923 and $1123 \mathrm{~K}$ for $1 \mathrm{~h}$. The Na concentration was varied in the broad range between $1 \times 10^{14}$ to $1 \times 10^{17} \mathrm{Na} / \mathrm{cm}^{2}$. In all the cases, quartz was amorphized and the thickness of the damaged zone varied between 730 and $1480 \times 10^{15}$ at. $/ \mathrm{cm}^{2}(113$ to $230 \mathrm{~nm}$, for the lowest and highest fluence, respectively).

The effect of heat treatment at $923 \mathrm{~K}$ is shown in fig.5.3. At $1 \times 10^{16} \mathrm{Na} / \mathrm{cm}^{2}$ no change in the damaged structure was observed, but a dramatic recovery of the amorphous zone started above this fluence. At $2.5 \times 10^{16} \mathrm{Na} / \mathrm{cm}^{2}$, only a slightly higher dechanneling yield 


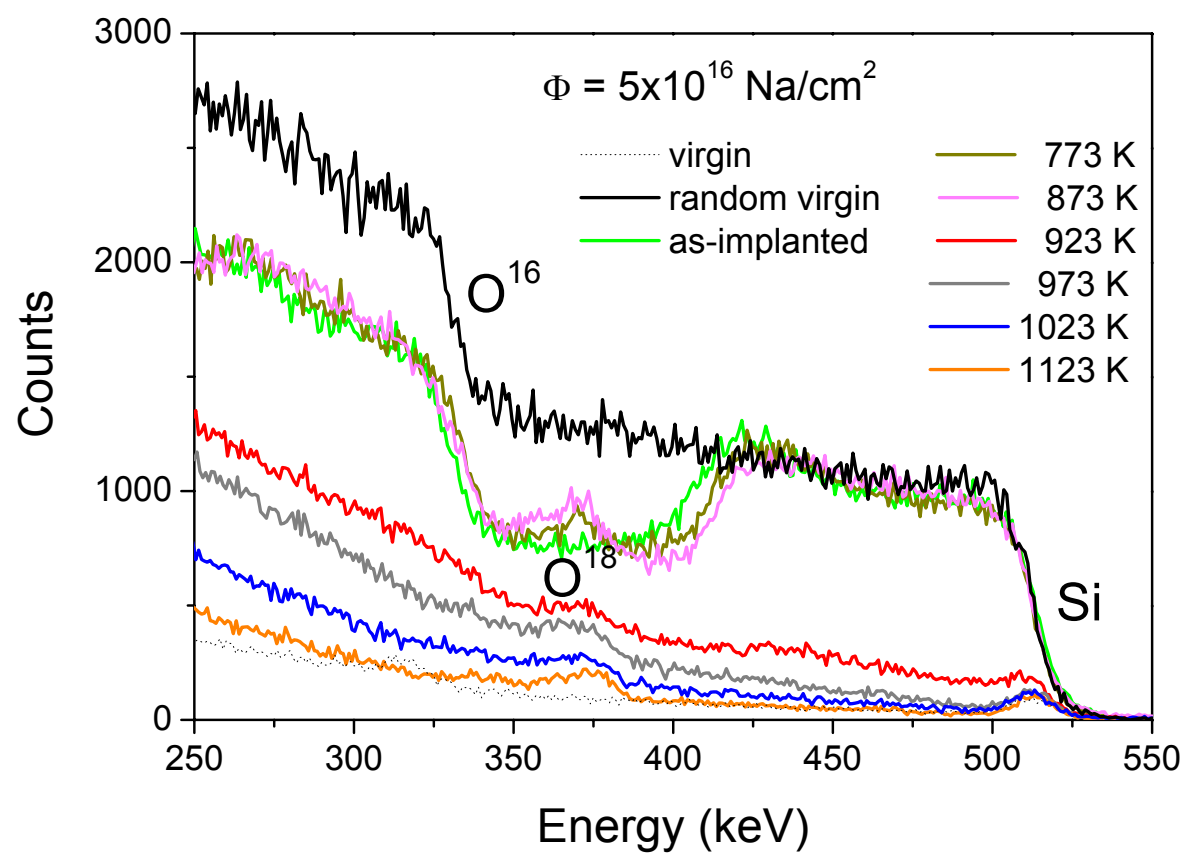

Figure 5.2: RBS-C spectra of 50-keV Na-ion implanted samples at ion fluence 5.0x $10^{16}$ $\mathrm{Na} / \mathrm{cm}^{2}$ before and after $1-\mathrm{h}$ annealing in an ${ }^{18} \mathrm{O}_{2}$ atmosphere at temperatures varied in the range $773-1123 \mathrm{~K}$.

as compared to the virgin aligned spectrum was observed, probably due to the stable defects still left in the sample, which completely disappeared at $5 \times 10^{16} \mathrm{Na} / \mathrm{cm}^{2}$. On the other hand, no significant movement of the a/c interface was detected at a fluence of $2.5 \times 10^{16}$ $\mathrm{Rb} / \mathrm{cm}^{2}$.

The second series of measurements was performed at the fixed annealing temperature of $1123 \mathrm{~K}$ (see fig.5.4). The recrystallization front advanced very slowly for the two lowest fluences $\left(1 \times 10^{14}\right.$ and $\left.1 \times 10^{15} \mathrm{Na} / \mathrm{cm}^{2}\right)$. A further increase in the Na fluence up to $1 \times 10^{16}$ $\mathrm{Na} / \mathrm{cm}^{2}$ caused planar recovery of about $20 \%$ of the amorphous layer. By increasing the fluence up to $2.5 \times 10^{16} \mathrm{Na} / \mathrm{cm}^{2}$, the RBS-C spectrum of the recrystallized part matched the virgin aligned one perfectly. In the case of $\mathrm{Rb}$, the amorphized region had completely crystallized at a fluence of $3.5 \times 10^{16} \mathrm{Na} / \mathrm{cm}^{2}$.

As already observed in the case of $\mathrm{Rb}$, after $\mathrm{Na}$ implantation the SPEG process also appeared above a critical fluence and temperature. An increase in the regrowth thickness with increasing $\mathrm{Na}$ concentration was observed. This finding may be comparable with those obtained after $\mathrm{Rb}$ implantation. With respect to the results obtained after $\mathrm{Rb}$ implantation, the Na-doping seems to be more efficient than Rb to achieve SPEG at lower temperatures. Concerning the role of the alkali and oxygen in the mechanism of epitaxy, fig.5.5 (a) and fig.5.5 (b) combine the $\mathrm{Na}$ and ${ }^{18} \mathrm{O}$ profiles obtained after $2.5 \times 10^{16}$ and 


\begin{tabular}{cccccccc}
\hline $\begin{array}{c}\text { Alkali } \\
\text { ions }\end{array}$ & $\begin{array}{c}\text { Energy } \\
(\mathrm{keV})\end{array}$ & $\begin{array}{c}\text { Fluence } \\
\left(10^{16} / \mathrm{cm}^{2}\right)\end{array}$ & $\begin{array}{c}\text { Ann. } \\
\text { gas }\end{array}$ & $\begin{array}{c}\mathrm{T}_{S} \\
(\mathrm{~K})\end{array}$ & $\begin{array}{c}\mathrm{T}_{x} \\
(\mathrm{~K})\end{array}$ & $\begin{array}{c}\mathrm{E}_{a x} \\
(\mathrm{eV})\end{array}$ & Comments \\
\hline $\mathrm{Na}$ & 50 & 2.5 & ${ }^{18} \mathrm{O}_{2}$ & 870 & 970 & - & this thesis \\
\hline $\mathrm{Na}$ & 50 & 5 & ${ }^{18} \mathrm{O}_{2}$ & 870 & 1020 & - & this thesis \\
\hline $\mathrm{Rb}$ & 175 & 2.5 & air & 1070 & 1170 & $0.6(2), 2.7(4)$ & this thesis \\
\hline $\mathrm{Rb}$ & 175 & 2.5 & ${ }^{18} \mathrm{O}_{2}$ & 970 & 1130 & $1.3(2)$ & this thesis \\
\hline $\mathrm{Cs}$ & 250 & 2.5 & air & 1070 & 1150 & $2.8(2)$ & [59] \\
\hline
\end{tabular}

Table 5.1: Processing parameters of chemically guided SPEG in quartz after alkali-ion implantation, where $\mathrm{T}_{S}$ is the temperature, at which SPEG started, $\mathrm{T}_{x}$ the recrystallization temperature, and $\mathrm{E}_{a x}$ the activation energy of the recrystallization.

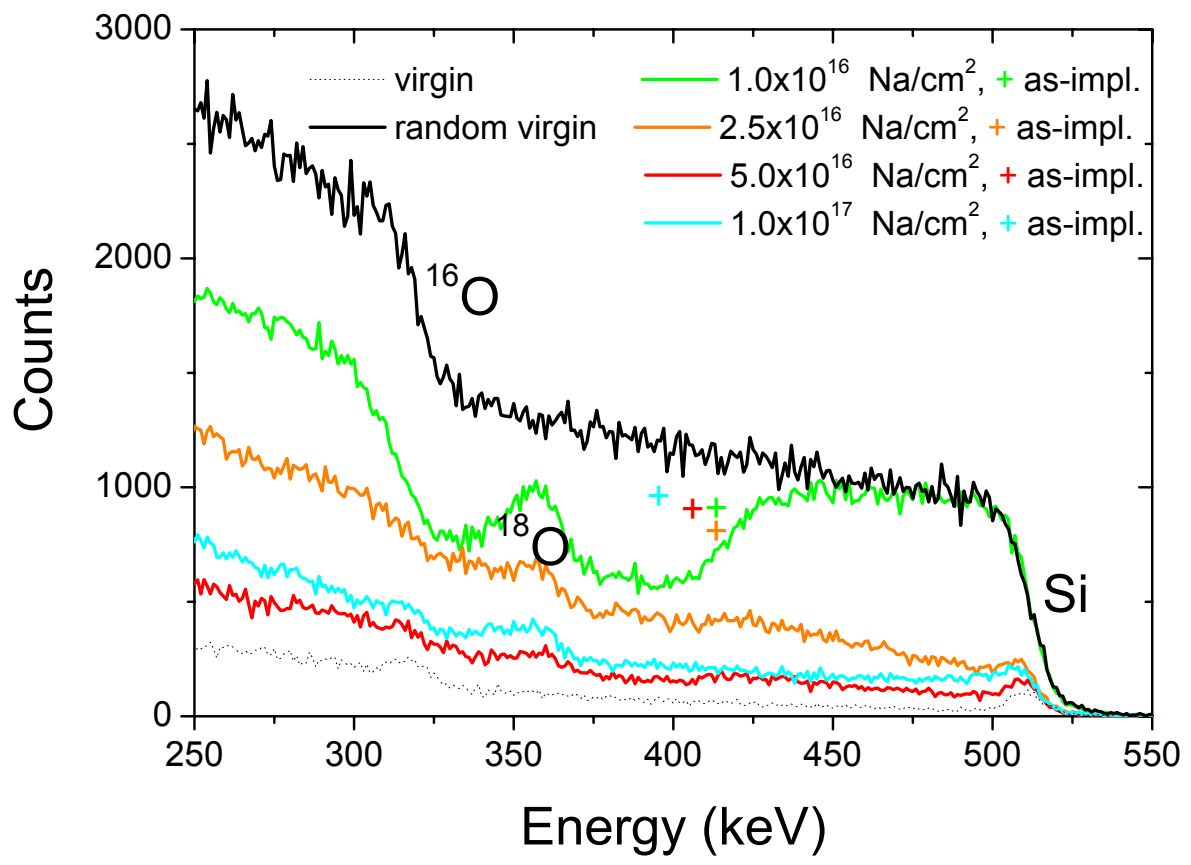

Figure 5.3: RBS-C spectra of 50-keV Na-ion implanted samples at a ion fluences in the range of $1.0-10.0 \times 10^{16} \mathrm{Na} / \mathrm{cm}^{2}$ after 1-h annealing in an ${ }^{18} \mathrm{O}_{2}$ atmosphere at a fixed temperature of $923 \mathrm{~K}$. The crosses indicate the position of the a/c interface for as-implanted samples.

$5.0 \times 10^{16} \mathrm{Na} / \mathrm{cm}^{2}$ implantations followed by thermal annealing.

The behaviour of the implanted $\mathrm{Na}$ and the in-diffused ${ }^{18} \mathrm{O}_{2}$ was monitored by TOFERDA measurements. The diffusion of $\mathrm{Na}$ started at $773 \mathrm{~K}$ (the first investigated temperature at a fluence of $5.0 \times 10^{16} \mathrm{Na} / \mathrm{cm}^{2}$ ). Heating the samples led to rapid motion of the implanted Na. Already at $973 \mathrm{~K}$ no more Na was observed in the amorphous zone for both 


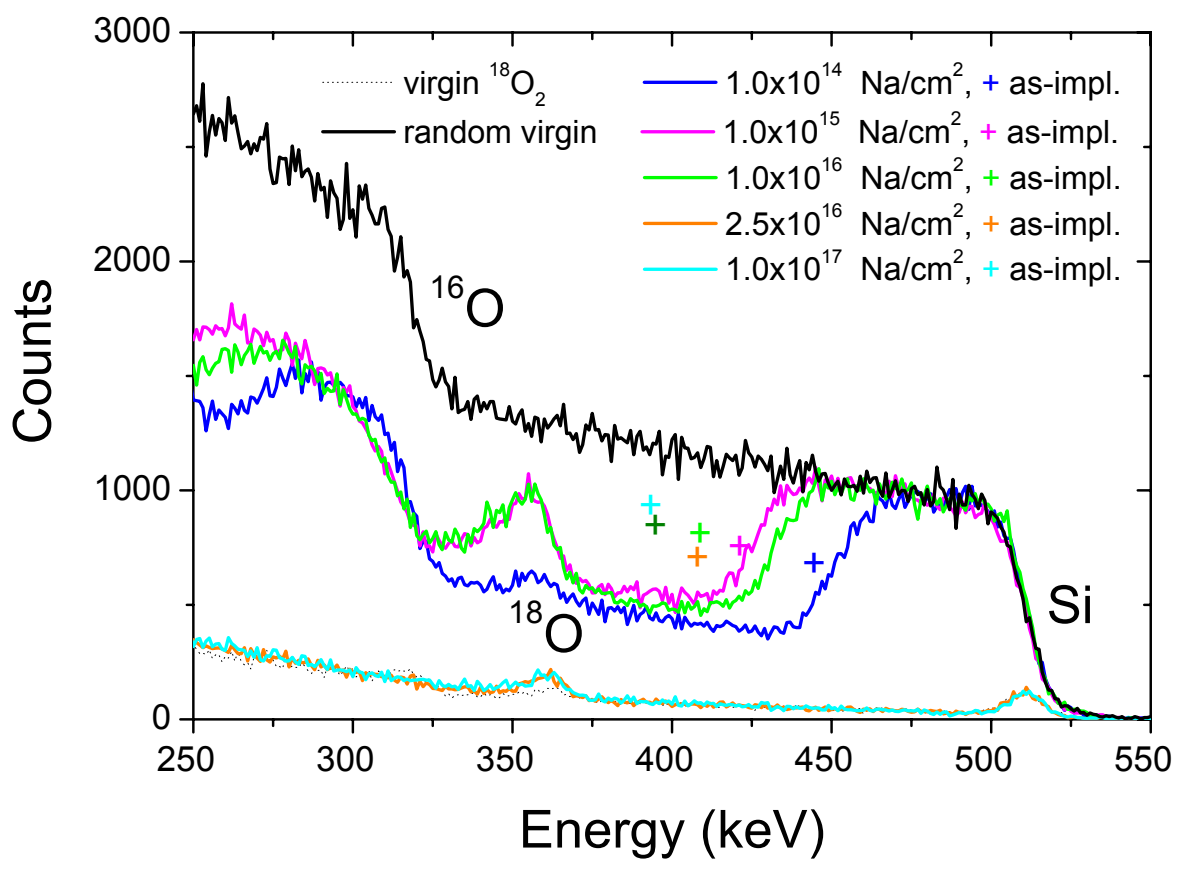

Figure 5.4: RBS-C spectra of 50-keV Na-ion implanted samples at ion fluences in the range of $0.01-10.0 \times 10^{16} \mathrm{Na} / \mathrm{cm}^{2}$ after 1 -h annealing in an ${ }^{18} \mathrm{O}_{2}$ atmosphere at a fixed temperature of $1123 \mathrm{~K}$. The crosses indicate the position of the $\mathrm{a} / \mathrm{c}$ interface for as-implanted samples.

fluences; Na out-diffusion was much faster than that of Rb. Meier et al. [120] investigated self-diffusion of sodium $\left(D^{*}{ }_{N a}\right)$ and rubidium $\left(D^{*}{ }_{R b}\right)$ in $\mathrm{Na}_{2} \mathrm{O}-\mathrm{Rb}_{2}-\mathrm{SiO}_{2}$ glass melts. The diffusion of $\mathrm{Na}$ ions was independent of the $\mathrm{Rb}_{2} \mathrm{O}$ content, whereas the $\mathrm{Rb}$ migration strongly depended on the $\mathrm{Na}_{2} \mathrm{O}$ concentration. $D^{*}{ }_{\mathrm{Na}}$ was 3 - 4 orders of magnitude higher than $D^{*}{ }_{R b}$. Those findings are also in agreement with the corellation found in $\mathrm{Na}-\mathrm{Rb}$ borate glasses, where Na diffusion was always much faster than $\mathrm{Rb}$ diffusion [121].

In the present study, it was not possible to calculate the activation energy of the $\mathrm{Na}$ loss, due to the rapid out-diffusion from the matrix (there were only a small number of data points).

The trend of ${ }^{18} \mathrm{O}$ in-diffusion, already observed after $\mathrm{Rb}$ implantation, is also verified in the case of $\mathrm{Na}$ implantation. By increasing the annealing temperature, the exchange between native ${ }^{16} \mathrm{O}$ and external ${ }^{18} \mathrm{O}$ became stronger. Up to $873 \mathrm{~K}$ (at both fluences), the distributed ${ }^{18} \mathrm{O}$ tracer was limited to the top $50 \mathrm{~nm}$. Further increasing the temperature hardly changed the height of the ${ }^{18} \mathrm{O}$ profile for $2.5 \times 10^{16} \mathrm{Na} / \mathrm{cm}^{2}$, but a completely different situation was observed for the fluence of $5.0 \times 10^{16} \mathrm{Na} / \mathrm{cm}^{2}$. When increasing the annealing temperature, the penetration of the migrated ${ }^{18} \mathrm{O}$ increased and reached a maximum of about 50 at.\% at the surface $(1123 \mathrm{~K})$. The correlation between out diffusion 


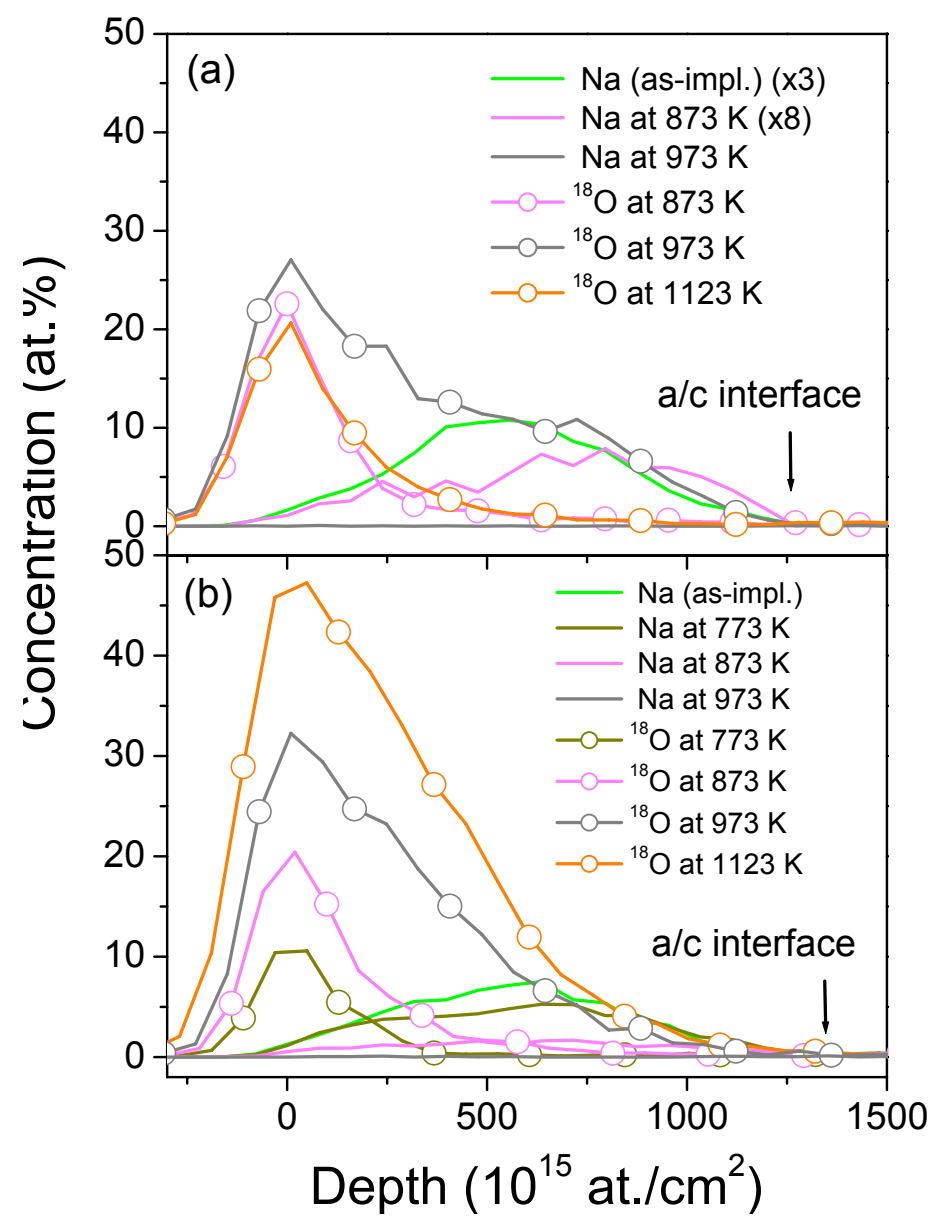

Figure 5.5: $\mathrm{Na}$ and ${ }^{18} \mathrm{O}$ concentration profiles obtained in the TOF-ERDA analyses of $\alpha$-quartz samples irradiated with $2.5 \times 10^{16} \mathrm{Na} / \mathrm{cm}^{2}$ (a) and $5.0 \times 10^{16} \mathrm{Na} / \mathrm{cm}^{2}$ (b).

of $\mathrm{Na}$ and oxygen migration can be see in fig.5.6. It shows the fraction of $\mathrm{Na}$ retained in the samples relative to the implanted $\mathrm{Na}$ fluence and the average ${ }^{18} \mathrm{O}_{2}$ concentration in the amorphous layer. Evidently, there is no significant difference between the results obtained for these two fluences (except for the ${ }^{18} \mathrm{O}$ content after the $1123 \mathrm{~K}$ annealing, but the reason for this effect is not known). At $\mathrm{T}_{A}=830 \pm 50 \mathrm{~K}$ half the implanted $\mathrm{Na}$ out-diffused from the matrix. This temperature is quite close to the one found in the case of $\mathrm{H}$ out-diffusion, $\mathrm{T}_{A}=820 \pm 50 \mathrm{~K}$ [59].

Finally, the migration of ${ }^{18} \mathrm{O}$ in the samples implanted at different fluences and annealed at 923 or $1123 \mathrm{~K}$, as obtained in the TOF-ERDA measurements (illustrated in fig.5.7) will be discussed. For both temperatures, the implanted Na completely left the radiationdamaged zone. Two different types of behaviour of ${ }^{18} \mathrm{O}$ motion were monitored. At $923 \mathrm{~K}$ (no epitaxy was detected by RBS-C), the ${ }^{18} \mathrm{O}$ depth distribution was located in the first 50 


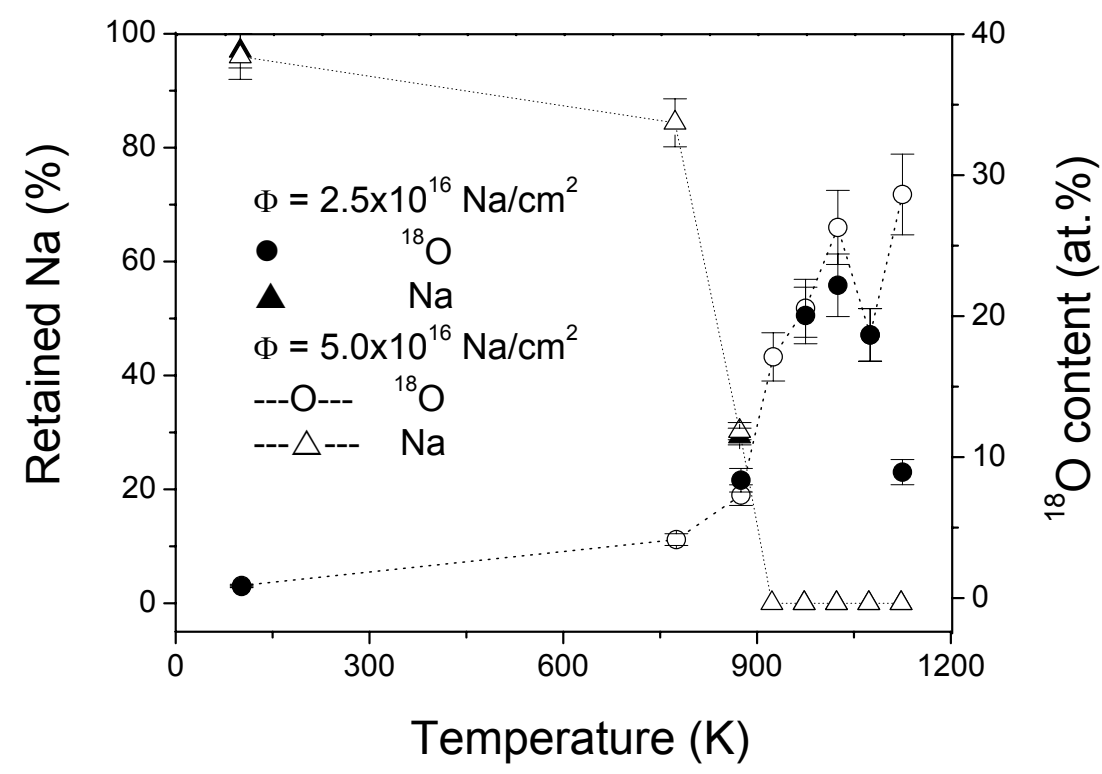

Figure 5.6: Average fractions of $\mathrm{Na}$ retained in the samples (relative to the total implanted $\mathrm{Na}$ content) and of ${ }^{18} \mathrm{O}$ having entered the samples.

$\mathrm{nm}$ of the amorphous layer and peaked at about 30 at.\% (see fig.5.7 (a)). By increasing the fluence (the epitaxy set in), the height of the ${ }^{18} \mathrm{O}$ peak did not change, but ${ }^{18} \mathrm{O}$ started to distribute uniformly up to the a/c interface. On the other hand, at $1123 \mathrm{~K}$ (see fig.5.7 (b)), the shape of the isotope profile was well preserved in all the samples. The ion irradiation enhanced the oxygen exchange, but the peak position remained in the near surface region. The height of the concentration profiles increased with increasing fluence and reached a maximum at about 45 at.\%. The integrated ${ }^{18} \mathrm{O}$ amount in the amorphous layer for both temperatures is shown in fig.5.7 (c). Evidently, the ${ }^{18} \mathrm{O}$ content increases for increasing $\mathrm{Na}$ fluence (at both temperatures) and then seems to become constant. Note the rather high scattering of the data-points, above $1050 \mathrm{~K}$.

In conclusion, a strong increase in the oxygen isotope exchange was observed along with a total out-diffusion of alkali ions and recrystallization of the damaged region. The trend in oxygen migration with both alkali ions ( $\mathrm{Rb}$ and $\mathrm{Na}$ ) is very similar and the exchange appears to be independent of the alkali-ion. However, the critical temperature for achieving complete epitaxy decreases for decreasing ion size (faster out-diffusion of $\mathrm{Na}$ than $\mathrm{Rb}$ ). Also the recrystallization rate was increasing with increasing alkali content. 

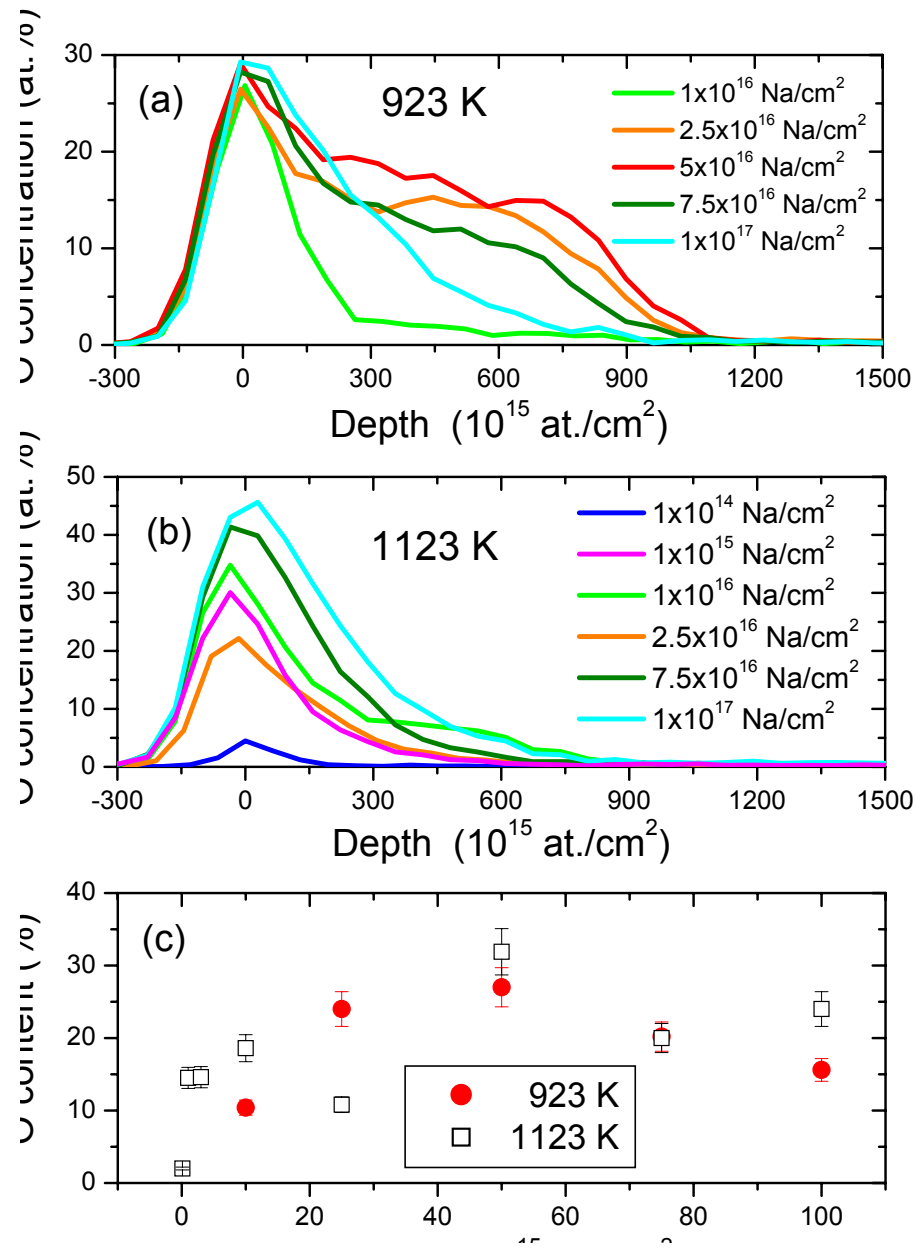

Figure 5.7: ${ }^{18} \mathrm{O}$ concentration profiles measured by means of TOF-ERDA for Naimplanted samples in the range $0.01-10.0 \times 10^{16} \mathrm{Na} / \mathrm{cm}^{2}$ after 1 -h annealing in an ${ }^{18} \mathrm{O}_{2}$ atmosphere at a fixed temperature of $923 \mathrm{~K}$ (a) or $1123 \mathrm{~K}(\mathrm{~b})$; (c) ${ }^{18} \mathrm{O}$ content integrated up to the a/c interface for different fluences (solid symbols $923 \mathrm{~K}$, open symbols $1123 \mathrm{~K}$ ).

\subsection{Surface topography}

In an attempt to achieve a more complete understanding of SPEG after Na implantation of $\alpha$-quartz, AFM mapping was performed for selected samples implanted with $2.5 \times 10^{16}$ or $5.0 \times 10^{16} \mathrm{Na} / \mathrm{cm}^{2}$ and annealed at various temperatures for 1 hour in ${ }^{18} \mathrm{O}_{2}$.

As an example, fig.5.8 displays an AFM image of the border between the implanted and non-implanted $\mathrm{SiO}_{2}$ taken from the sample implanted with $50 \mathrm{keV} \mathrm{Na}$ ions at a fluence of $5.0 \times 10^{16} \mathrm{Na} / \mathrm{cm}^{2}$. The measurements of the height difference, $\Delta \mathrm{h}$, at the border area were not performed for this set of samples.

Figures 5.9 and 5.10 illustrate surface topographies obtained after implantation of $2.5 \times 10^{16}$ 


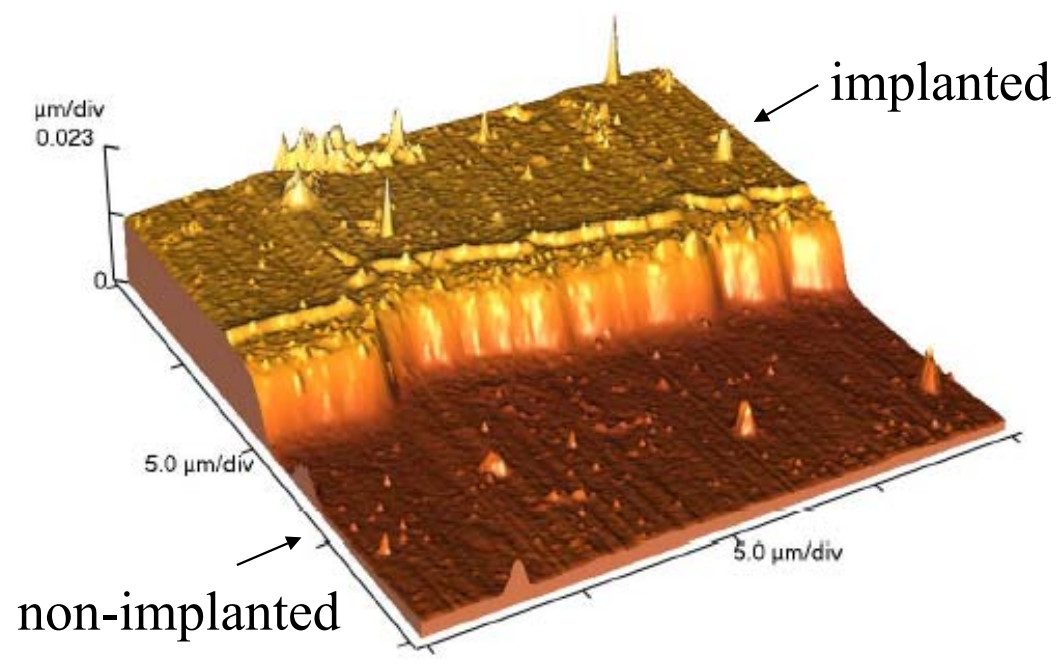

Figure 5.8: AFM topography image of the interface between the irradiated and nonirradiated region for an as-implanted sample at a fluence of $5.0 \times 10^{16} \mathrm{Na} / \mathrm{cm}^{2}$.

or $5.0 \times 10^{16} \mathrm{Na} / \mathrm{cm}^{2}$ and annealed in ${ }^{18} \mathrm{O}_{2}$.

The topography image in fig.5.9 (a) demonstrates the surface morphology of the sample before annealing at a $2.5 \times 10^{16} \mathrm{Na} / \mathrm{cm}^{2}$. In this AFM image, one can probably recognize the channels or pathways according to the random network model [128]. This kind of structural arrangement was also observed in $\mathrm{Na}_{2} \mathrm{O}-\mathrm{SiO}_{2}$ glass [168]. However, compared to silica glass the channel diameters are much smaller, probably resulting from the much higher Na concentration.

The AFM topographies taken from the samples which were annealed at $1023 \mathrm{~K}, 1073 \mathrm{~K}$, and $1123 \mathrm{~K}$ are shown in fig.5.9 (b) - (d). There is no evidence of any structure formation below $1023 \mathrm{~K}$ (no full recovery). The first features on the surface occurred at 1023 $\mathrm{K}$ (complete SPEG). Then, by increasing the annealing temperature, a drastic growth of surface structures was observed, but only up to $1073 \mathrm{~K}$. This kind of structure propagation may suggest Oswald ripening [125], as already found in the case of Rb implantation for fluence dependence experiments. Unexpectedly, above this temperature, a reduction of the surface structures was observed, but the size of the structures was comparable to that formed at $1073 \mathrm{~K}$. This suggests that annealing at $1123 \mathrm{~K}$ increases the recrystallization rate. Consequently, the recovery occurs much faster than at lower temperatures, leaving less time to develop the large structures.

The changes in the topography after implantation $5.0 \times 10^{16} \mathrm{Na} / \mathrm{cm}^{2}$ and annealing in ${ }^{18} \mathrm{O}_{2}$ gas for $1 \mathrm{~h}$ at different temperatures are presented in fig.5.10. For the amorphized samples, no patterning was visible on the surface. At $973 \mathrm{~K}$ (see fig.5.10 (a)), the AFM micrograph 

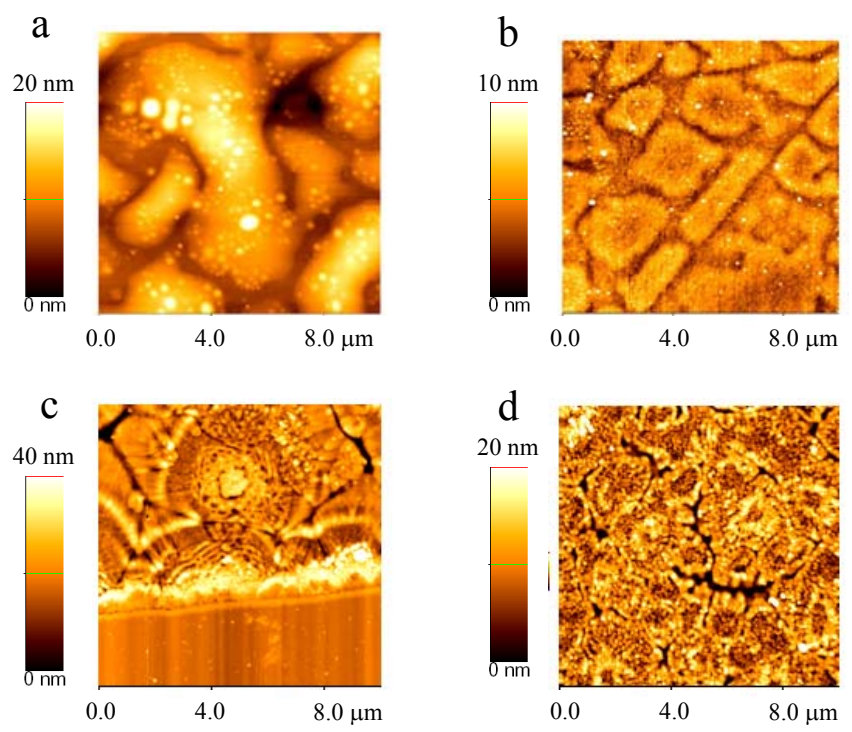

Figure 5.9: Plan-view AFM topography images of $\alpha$-quartz samples implanted with 50 $\mathrm{keV} \mathrm{Na}{ }^{+}$-ions at a fluence of $2.5 \times 10^{16} \mathrm{Na} / \mathrm{cm}^{2}$ (a) and annealed in ${ }^{18} \mathrm{O}_{2}$ gas at 1023 (b); $1073 \mathrm{~K}(\mathrm{c})$, and $1123 \mathrm{~K}(\mathrm{~d})$.
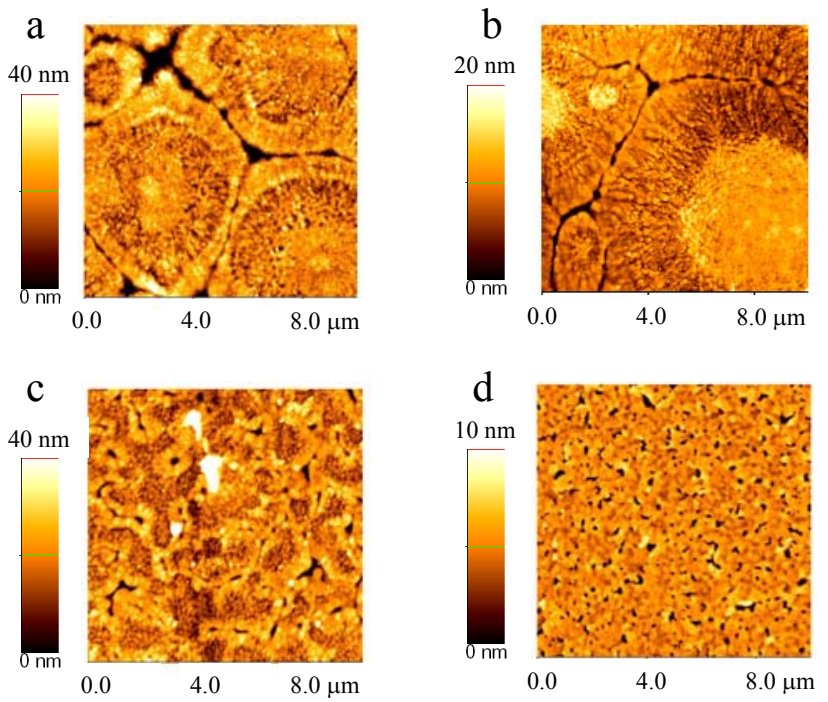

Figure 5.10: Plan-view AFM topography images of $\alpha$-quartz samples implanted with 50 $\mathrm{keV} \mathrm{Na}{ }^{+}$-ions at a fluence of $5 \times 10^{16} \mathrm{Na} / \mathrm{cm}^{2}$ and annealed in ${ }^{18} \mathrm{O}_{2}$ gas at $973 \mathrm{~K}(\mathrm{a}) ; 1023 \mathrm{~K}$ (b); $1073 \mathrm{~K}$ (c), and $1123 \mathrm{~K}$ (d). 
shows well developed structures, whose size is comparable to those on the samples annealed at $1073 \mathrm{~K}$ and a fluence of $2.5 \times 10^{16} \mathrm{Na} / \mathrm{cm}^{2}$ (fig.5.9 (c)). Again, the growth in the pattern dimensions was observed with increasing annealing temperature (see fig.5.10 (b)). However, this kind of surface reconstruction took place only up to $1023 \mathrm{~K}$. Then annealing at $1073 \mathrm{~K}$ (see fig.5.10 (c)) leads to the formation of much smaller features as compared to higher temperatures. A similar surface arrangement was already found in the case of the fluence $2.5 \times 10^{16} \mathrm{Na} / \mathrm{cm}^{2}$ at $1123 \mathrm{~K}$. The surface morphologies in these two cases are almost identical $\left(2.5 \times 10^{16} \mathrm{Na} / \mathrm{cm}^{2}\right.$ at $1123 \mathrm{~K}$ and $5.0 \times 10^{16} \mathrm{Na} / \mathrm{cm}^{2}$ at $\left.1073 \mathrm{~K}\right)$. The highest annealing temperature $(1123 \mathrm{~K}$, fig.5.10 (d)) evidently resulted in a strong decrease in the size of the recrystallized structures. These findings are in agreement with results of recrystallization of amorphized polycrystalline silicon films on $\mathrm{SiO}_{2}$ [167]. The size of the structures is determined by the nucleation rate and the growth velocity and was found to decrease with increasing annealing temperature.

The AFM results presented here also confirmed those obtained by RBS-C measurements. Evidently, the size of the structures is highly correlated with the concentration of the implanted ions and annealing temperature. There exists a critical temperature for the regrowth of the surface structures. Annealing below the critical temperature favors the formation of larger surface structures and annealing above the critical temperature favours the formation of smaller ones. The critical temperature decreases with increasing ion fluence $\left(2.5 \times 10^{16} \mathrm{Na} / \mathrm{cm}^{2}\right.$ at $1073 \mathrm{~K}$ and $5.0 \times 10^{16} \mathrm{Na} / \mathrm{cm}^{2}$ at $\left.1023 \mathrm{~K}\right)$. On the other hand, the RBS-C results indicate that the quality of the recrystallized layer is better in the case of the formation of smaller surface structures. 


\section{Discussion}

\subsection{Topology of silica network}

Glass formation, structural transformations, amorphization, and reconstruction of the network are governed, among other things, by the topological properties [127].

In 1932, Zachariasen [128] was the first to postulate the topological aspects (Zachariasen's Rules) necessary to describe the structure of inorganic glasses. He proposed that the atoms in a glass are linked together by almost the same forces as those in the crystalline material. Also, the internal energy of the amorphous state should be only slightly higher than the crystalline state and consequently the structural arrangement of these two phases should show similarities. In order to obtain glass formation, the following four topological conditions have to be fulfilled:

1. an oxygen atom should not be linked to more than two network forming cations,

2. the co-ordination number of oxygen around the network-forming cations must be small (i.e. 3 or 4 ),

3. the polyhedra should share corners, the sharing of faces or edges is forbidden,

4. at least three corners of each polyhedron must be shared to form a three dimensional network.

The term "random network" was introduced by Warren to describe Zachariansen's concepts of the structure [129]. The author proposed rules how the alkali and earth alkaline ions (M) are incorporated in the network [130]:

1. the cations are located in the relatively large voids in the structure,

2. for each additional oxygen anion introduced, one M-O-M brigde is broken so that two non-brindging oxygens are created.

Gupta and Cooper [131] (1982) improved Zachariasen's criteria by additing some parameters, such as the structural freedom and the connectivity of the network.

Si-based covalent materials like $\mathrm{SiO}_{2}, \mathrm{SiC}$, and $\mathrm{Si}_{3} \mathrm{~N}_{4}$ in their various crystalline polymorphs and amorphous phases can be regarded as networks of atomic tetrahedra ([SiX $\left.\mathrm{Si}_{4}\right]$, 


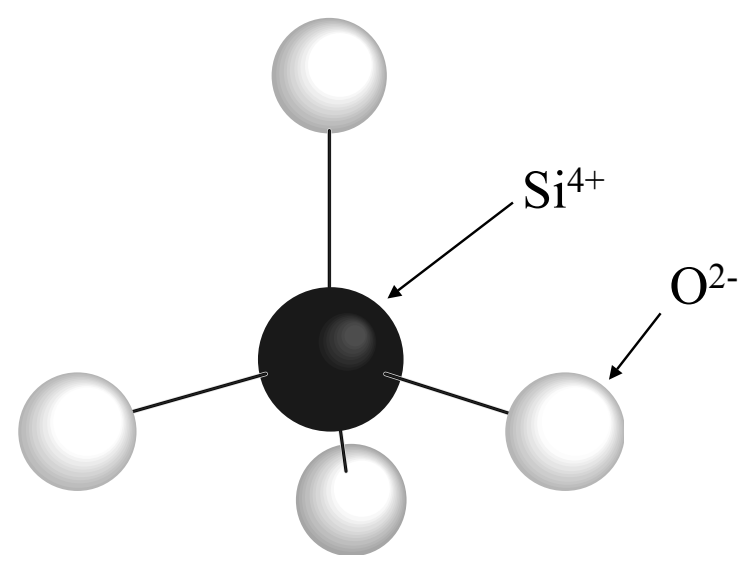

Figure 6.1: The basic unit of the $\mathrm{SiO}_{2}$ network - $\mathrm{SiO}_{4}$ tetrahedron.

where $\mathrm{X}=\mathrm{C}, \mathrm{N}, \mathrm{O}$ or $\mathrm{Si}$ ), called polytopes. In two dimensions polytopes are called polygons, in three dimensions polyhedra. X-ray absorption fine-structure spectroscopy (EXAFS [132]) measurements of ion implanted $\alpha$-quartz cleary confirmed that ion irradition leads to the formation of a fully connected disordered network and the chemical short range order in the $\left[\mathrm{SiO}_{4}\right]$-tetrahedra (see fig.6.1) is preserved [42].

Figure 6.2 (a) and (b) illustrate the typical two-dimensional representation of a network in the crystalline (the ordered phase) and in the amorphous (the disordered phase, in which there is no long-range translational or orientational correlation between the structuring units [133]) state, respectively; (c) presents a two-dimensional sketch of the structure of a sodium silicate glass (the non-bridging oxygens are created by the presence of the sodium ions, thus reducing the network connectivity, see below); the black dots mark the silicon atoms in the centre of the tetrahedra, the white circles the bridging and the blue dots the non-bridging oxygen atoms; green represents the alkali ions.

The connectivity of a polyhedral network can be expressed by a set of two numbers $\{V, C\}$, where $V$ is the number of vertices of the elemental polytope and $C$ the relative proportion of corners, edges, and faces of the polytopes shared with one another. In the case of quartz, each $\left[\mathrm{SiO}_{4}\right]$ tetrahedron has four vertices and each of them is linked to a neighboring tetrahedron: $\{V, C\}=\{4,2\}$. According to Gupta and Cooper [131], the structural freedom, $f$, of each vertex refers to the difference between the number of degrees of freedom, $d$, and the number of constraints, $h$, which orginate from the surrounding structure:

$$
f=d-h=d-(C / V)[\delta V-\delta(\delta+1) / 2]
$$

where $\delta$ is called the dimensionality of the structuring polytope (for example, $\delta$ for polyhedrons $=3, \delta$ for polygons $=2$ ). For $\mathrm{SiO}_{2}, d=3 ; \delta=3 ; V=4$, than $f=3-1.5 C=0$. From a topological point of view, this means that $\mathrm{SiO}_{2}$ forms a fully-connected network. 
a

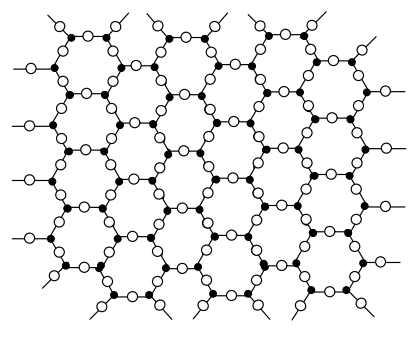

silicon

oxygen b

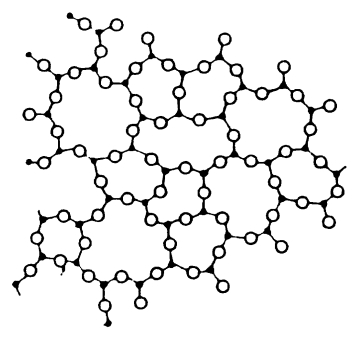

alkali ion

non-bridging oxygen

C

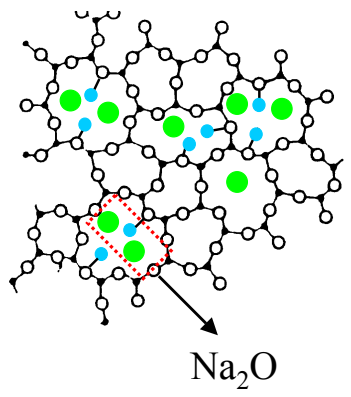

Figure 6.2: Two-dimensional representation of the periodic crystalline $\mathrm{SiO}_{2}$ network (a) and the Zachariasen [128] aperiodic amorphous network (b); (c) Warren's two-dimensional representation of a sodium silicate glass (after A. Szymański [91]).

Both the crystalline and amorphous $\mathrm{SiO}_{2}$-network is formed by silicon-oxygen tetrahedra $\left[\mathrm{SiO}_{4}\right]$. Each $\left[\mathrm{SiO}_{4}\right]$ tetrahedron is linked to the maximum number of neighbouring tetrahedra and there is no presence of non-connected tetrahedral units in the structure. By reducing the connectivity, $C<2$ or $f>0$, a change in topology occurs, which results in the creation of non-connected tetrahedral corners. However, in these terms, the topologically aperiodic $\mathrm{SiO}_{2}$-network shows high resistance to recrystallization.

Generally, if $f<0$, the number of constraints exceeds the degrees of freedom $(h>d)$, and the structure is constrained to its crystalline state. However, when $f>0(h<d)$, the structure is under-constrained, leading to the easy formation of aperiodic atomic arrangements. According to the argumentation of Hobbs et al. [135], the formation of disordered networks by ion irradiation strongly depends on the structural freedom $f$. Geologically, the irradiation-induced loss of crystallinity is expressed as "metamict" transformation [136] and in irradiation communities as "amorphization" [137]. The transformation between the periodic and aperiodic network occurred above a critical fluence [42].

Materials with $f<0$ would be unlikely to form topologically disordered structures under ion bombardment. On the other hand, crystals with $f>0$, have a high susceptibility to amorphization and subsequently, due to the larger value of $d$, should also be recrystallized easily, with minimal thermal activation even at lower temperatures. In the case of $f$ 
$\approx 0$, the matrix is most likely to form an aperiodic network. Indeed, $\mathrm{SiO}_{2}$ and $\mathrm{Si}$ become amorphized by ion irradiation at rather low values of the deposited energy per atom of 7 eV/atom [138] and $11 \mathrm{eV} /$ atom [139], as compared to $\mathrm{SiC}$ (26 eV/atom) [140] or $\mathrm{Si}_{3} \mathrm{~N}_{4}$ (> $700 \mathrm{eV} /$ atom) [141].

In the light of the topological approach, the average connectivity also affects the recrystallizability. The disordered network of $\left[\mathrm{SiO}_{4}\right]$ tetrahedra is strongly resistant to returning to the crystalline state. To start with, the epitaxial recrystallization of the amorphous $\mathrm{SiO}_{2}$-network requires a crystalline interface [142]. At the a/c interface, the breaking and rebonding of the original bonds takes place. However, this process takes the structure further away from the ordered state than towards it and the recrystallization would not be expected to occur $[3,143]$. The rebonding would usually produce a "wrong" pair of bonds in the matrix [3] and thus would be one step further from the ordered state.

The recovery of the disordered $\mathrm{SiO}_{2}$ network can be understood also in terms of the glass physics. After cooling a liquid-melt of oxide glass or silicate, two processes can be observed, namely, recrystallization or glass formation [37]. The glass can be formed if firstly, the final temperature is so low that the atoms rearrange too slowly into the stable crystalline state; secondly, the cooling rate is so high, that crystallization does not take place. On the other hand, the crystallization starts almost instantaneously below the melting temperature. Consequently, the energy barrier of nucleation for epitaxial recrystallization is essentially zero [97].

Macroscopically, the recrystallization rate is highly affected by the viscosity, which is connected to the atomic rearrangement required for crystallization from the melt. The relationship between the crystallization rate, $v$, and the viscosity, $\eta$, can be be expressed by the following equation [97]:

$$
v=\frac{\Delta H_{f}\left(T_{m}-T\right)}{3 \pi \lambda^{2} \eta T_{m}}
$$

where $\Delta H_{f}$ is the heat of fusion at the melting point, $\mathrm{T}_{m}$ the melting point, and $\lambda$ the atomic jump distance. The variation of the heat of fusion for different materials is not as high as that of the viscosity for example, $\Delta H_{f}^{\mathrm{H}_{2} \mathrm{O}}=1.44 \mathrm{kcal} / \mathrm{mol}$ and $\Delta \mathrm{H}_{f}^{\mathrm{SiO}_{2}}=3.4$ $\mathrm{kcal} / \mathrm{mol}$; but $\eta^{\mathrm{H}_{2} \mathrm{O}}=0.18$ poise and $\eta^{\mathrm{SiO}_{2}}=1 \times 10^{8}$ poise at their melting points (as $\eta$ is temperature dependent, $\mathrm{T}_{m}$ is used as the reference point). The small viscosity increases the probability of crystallization [97]. $\mathrm{As}^{\mathrm{SiO}_{2}}$ has the highest viscosity (due to strong SiO bonds) [144], the susceptibility of the structure to form into the ordered state is rather unlikely.

The compositional species in glass structures can be divided into two main groups: network formers and network modifiers. Network formers can form a glass without any additional components (i.e. $\mathrm{SiO}_{2}, \mathrm{~B}_{2} \mathrm{O}_{3}, \mathrm{GeO}_{2}$ ). On the other hand, network modifiers such as alkali elements ( $\mathrm{Li}, \mathrm{Na}, \mathrm{K}, \mathrm{Rb}, \mathrm{Cs})$, cannot produce a glass independently. As already noticed previously, fused silica, without any modifiers, forms a continuous random network of $\left[\mathrm{SiO}_{4}\right]$-tetrahedra linked together at the corners by "bridging" oxygen. Adding alkali modifiers to $\mathrm{SiO}_{2}$ glass breaks the continuity of the network through the creation of 
non-bridging sites. The alkali ions are located around the negatively charged non-bridging oxygens and provide the local charge neutrality [145]. The oxygen atom is linked to the alkali ions by a mainly ionic bond, which is much weaker than the strongly covalent Si-O bond [37].

In the sodium silicate glasses, an increased alkali concentration creates more non-bringing oxygens, resulting in an increase in the thermal expansion coefficient, $\alpha$, and a decrease in viscosity. In the $\mathrm{Na}_{2} \mathrm{O}-\mathrm{SiO}_{2}$ system, an almost linear dependence of the thermal expansion has been found (with increasing mol\% $\mathrm{Na}_{2} \mathrm{O}$ ), from $5 \times 10^{-7 \circ} \mathrm{C}^{-1}$ (silica glass) to $200 \times 10^{-7 \circ} \mathrm{C}^{-1}$ (45 mol\% Na $2 \mathrm{O}$ ) [146]. Therefore, increasing the alkali content always decreases the glass transition temperature, $\mathrm{T}_{g}$. For example, for the same composition range, $\mathrm{T}_{g}$ changes from $1200^{\circ} \mathrm{C}$ to $350^{\circ} \mathrm{C}$. As to the viscosity, the smaller the radius of the monovalent alkali cation, the further the value of $\eta$ decreased [144]. This can be explained by the bond strength alkali-oxygen (O-Li: $3.45 \mathrm{eV}$; O-Na and O-Rb: $2.65 \mathrm{eV}$; O-Cs: $3.06 \mathrm{eV}$ [10]).

According to the topological approach, by increasing the alkali concentration, more nonbridging oxygen sites are created, which reduce the connectivity of the tetrahedral network (i.e. $C<2$ or $\mathrm{f}>0$ ), similar to alkali glass silicates.

\subsection{Alkali diffusion in silica}

Diffusion of alkali-ions in quartz, a-SiO ${ }_{2}$, and various silicate glasses and the role of defect structures related to impurities or the chemical environment have been investigated in much detail over several decades and have been reviewed, among others, in [104, 107, $112,147,148,149,150,151,152,153,154,155]$. Although little is known about Rb diffusion in these materials, as most studies refer to Na diffusion $[112,147,148,150$, $151,152,153,154,155]$, here some results will be presented.

For Na-diffusion in quartz $(673-1273 \mathrm{~K}), \mathrm{E}_{a}^{N a}=1.06 \mathrm{eV}$ [122] was found. In $\mathrm{SiO}_{2}$ $\mathrm{Na}_{2} \mathrm{O}$ glass [123], two different activation energies were obtained, $0.74 \mathrm{eV}$ and $1.20 \mathrm{eV}$, below and above the glass transition temperature, respectively. Heinemann et al. [124] found that the sodium self-diffusion in $\alpha-\mathrm{Na}_{2} \mathrm{Si}_{2} \mathrm{O}_{5}$ single crystals was very anisotropic: $D^{*} \mathrm{Na}$ along the $\mathrm{c}$-axis (open channels) was about 2 orders of magnitude higher than $D^{*} \mathrm{Na}$ along the $a$-axis (perpendicular to the channels). The diffusion in the direction of the $b$ axis was not detectable (too slow). In glassy $\mathrm{Na}_{2} \mathrm{Si}_{2} \mathrm{O}_{5}$ which has a lower density than crystalline, $\mathrm{Na}$ diffusion was about one order of magnitude higher than in the crystal. However, it must be noted that almost the same activation energies were calculated for diffusion along the a or $\mathrm{c}$ axis and in glass (of the same composition). Systematic Na outdiffusion studies under vacuum after implantations in several metals [162], silicon [163], and silicon dioxide [165] provided evidence that half the implanted fluence escaped the matrix at $58-70 \%$ of the melting temperature, depending on the lattice structure in the crystalline matrices. 
The molecular dynamics (MD) simulations of $\mathrm{Na}^{+}$-diffusion in silicate glasses, $\mathrm{Na}_{2} \mathrm{O}$ $\mathrm{nSiO}_{2}$ with $\mathrm{n}=2,3,4$, is a field of great interest $[151,152,158,159,160,161]$ as the nature of alkali ion diffusion inside the glassy network is still a matter of debate. The nonDebye behaviour observed in the electric response of silica and its diffusion data has led to the motion of local ions based on a "forward-backward hopping mechanism" or a hopping processes over random potential barriers [151, 152]. Cooperative effects $[156,157]$ as well as "preferential pathways" [147, 148] governing the dynamics on a large scale were proposed.

- Na diffusion was much faster than $\mathrm{Si}$ or O diffusion, its diffusion constant being larger by around two orders of magnitude for $\mathrm{T} \leq 2500 \mathrm{~K}$. The $\mathrm{SiO}_{2}$ matrix can thus be considered as frozen with respect to the movement of sodium. The atoms of the network do not show any significant structural relaxation on the time scale of many ns [159].

- At temperatures below $3000 \mathrm{~K}$, Na diffusion proceeds along "preferential path ways" or "channels with pockets" as suggested by Ingram [147]. This means that even after diffusion times of several ns, large fractions of the $\mathrm{SiO}_{2}$ matrix have not been "visited" by migrating alkali-ions and the diffusion trajectories do not fill the space uniformly. These regions form a percolating structure around a channel network. The characteristic distance between these channels is of the order of 0.66 $\mathrm{nm}[159,160,161]$.

- The MD calculations by Horbach, Kob, and Binder $[159,160,161]$ indicate uncorrelated Na diffusion within the channels and do not support the cooperative motion proposed by Greaves $[156,157]$. There are preferred sites for the sodium ions inside the channels associated with dangling bonds. The fast $\mathrm{Na}$ diffusion within the channels and the rearrangement of the channel network within $\mathrm{SiO}_{2}$ - although proceeding on very different time scales - are intimately related to each other.

- The activation energy for $\mathrm{Na}$ diffusion strongly increased by decreasing the alkali concentration, from about $1.2 \mathrm{eV}$ (low alkali content) to about $0.6 \mathrm{eV}$ (15 mol\% of alkali oxide). Above this concentration, only a small change in $\mathrm{E}_{a}$ was observed [164]. The Na diffusion was always found to be assisted by non-bridging oxygen atoms (NBO). In the low alkali content regime, Na migration is associated with the breaking of $\mathrm{Si}-\mathrm{O}$ bonds giving rise to non-bridging oxygen atoms, therefore requiring a larger activation energy. By increasing the $\mathrm{Na}_{2} \mathrm{O}$ concentration (up to about $10 \%$ ) enhancement of the NBO was observed. Above this alkali content, microchannels were formed and the Na migrated through them. As the non-bridging oxygen atoms always existed in these regions, the energetical barrier was much lower and therefore diffusion much easier. 


\subsection{The SPEG mechanism}

Solid phase epitaxy of quartz after alkali ion implantation and annealing in air/oxygen has been studied previously in the case of Cs-, Na-, and Li-implantations [54, 57, 59]. The main stages of this process are recrystallization of the amorphous matrix (via a planar movement of the a/c interface towards the surface), out-diffusion of the alkali ions and oxygen exchange between the amorphous layer and the annealing gas.

It is clear from the above results that the epitaxy of $\mathrm{Rb}$-amorphized $\alpha$-quartz follows this scenario and is controlled by the annealing temperature and the $\mathrm{Rb}$-fluence in the presence of external oxygen. The oxygen exchange process facilitates the diffusion of $\mathrm{Rb}$, which in turn provides the topological freedom for the $\mathrm{SiO}_{2}$ network and leads to complete recrystallization at a critical temperature. Chemically guided epitaxy after Rb-irradiation thus appears to follow the mechanism discussed e.g. by Hobbs and collaborators [127, 134, 135], Gupta and Cooper [131], and Roccaforte et al. [52, 53, 54, 55, 56, 57, 58, 59, 60].

The isotope exchange between the network $\left({ }^{16} \mathrm{O}\right)$ and the gas phase $\left({ }^{18} \mathrm{O}\right)$ in crystalline non-irradiated $\alpha$-quartz was studied by Roccaforte et al. [57] using nuclear reaction analysis. Below $1073 \mathrm{~K}$ hardly any ${ }^{18} \mathrm{O}$ in-diffusion was detected. At $1173 \mathrm{~K}$ only a very small amount of oxygen was observed to migrate to the crystalline substrate and was limited to the first $35 \mathrm{~nm}$ of the material. This higher oxygen exchange at the surface was explained by an enhanced amount of Si-O broken bonds [9]. Defects could be introduced during the manufacturing of the samples due to grinding and polishing the surface [58]. The molecular dynamics simulation by Garofalini et al. [113] showed that the diffusion constants for $\mathrm{Si}$ and $\mathrm{O}$ ions at the surface of vitreous silica are about one order of magnitude higher than those in the bulk. The higher mobilities of the species in the surface region may be due to the lower density in this zone or to the loss of the neighbors on one side of the surface atoms.

Also, oxygen tracer diffusion was extensively investigated in crystalline $[9,116,117,118]$ and amorphous [9,116] silica, both theoretically [116, 117, 118] and experimentally $[9,114,118]$. Oxygen is generally believed to diffuse in a molecular $\mathrm{O}_{2}$ state, and gas transport experiments give a large scatter of activation energies in the range $1.04 \mathrm{eV}$ [114] to $1.35 \mathrm{eV}$ [116]. These values are very close to the activation energies, $0.88-1.25 \mathrm{eV}$ [9], calculated for the process determined by the isotope exchange between the network $\mathrm{O}$ and the gas phase $\mathrm{O}_{2}$. There are the following possibilities for the oxygen transport mechanisms in crystalline and amorphous silica [9], schematically shown in fig.6.3:

1. Diffusion of oxygen in the molecular state through internal channels;

2. Exchange between network oxygen and network vacancy;

3. Interstitial diffusion, which occurs by internal exchange between dissolved molecular oxygen ("interstitial defect"') and network oxygen. This mechanism can take place in the internal channels or at an external surface. 


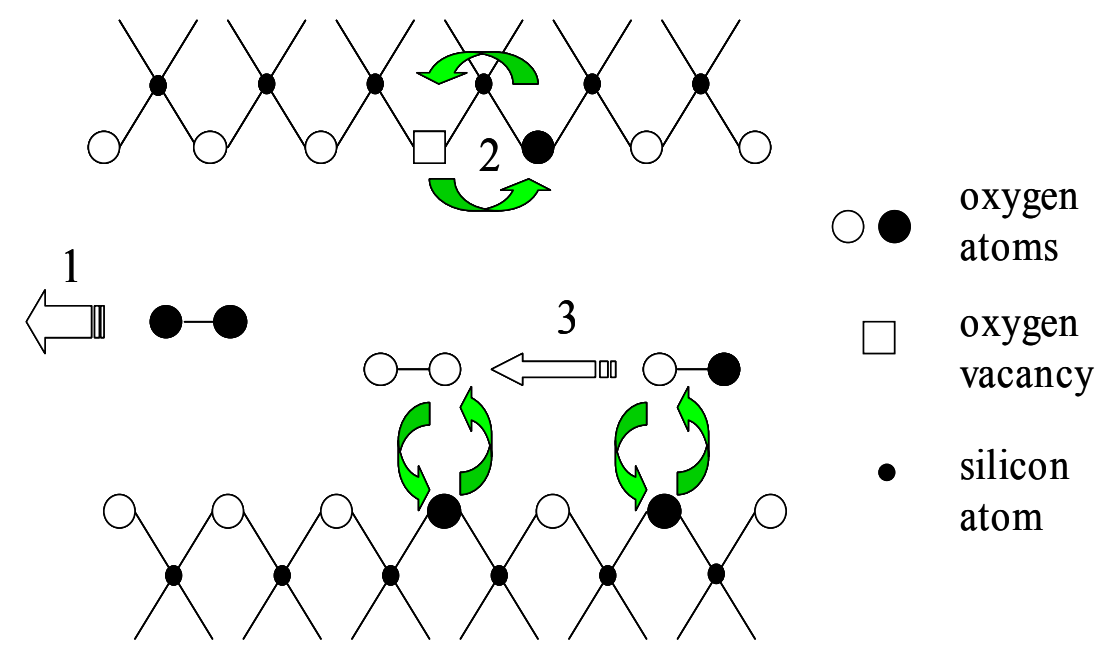

Figure 6.3: A schematic illustration of the transport mechanisms of oxygen in silica. (1) Molecular migration of oxygen through the structural channel. (2) Exchange between network oxygen and network vacancy. (3) Interstitial diffusion, exchange between dissolved molecular oxygen and network oxygen.

For the isotope exchange, the third mechanism can be applied and is given by the following equation [117]:

$$
\left(\mathrm{Si}-{ }^{16} \mathrm{O}-\mathrm{Si}\right)_{\text {quartz }}+{ }^{18} \mathrm{O}_{2} \longrightarrow\left(\mathrm{Si}-{ }^{18} \mathrm{O}-\mathrm{Si}\right)_{\text {quartz }}+{ }^{16} \mathrm{O}^{18} \mathrm{O} .
$$

After alkali ion implantation (which act as network modifiers [127, 131, 134, 135]) into the $\mathrm{SiO}_{2}$ matrix, a topologically disordered network is formed. The $\mathrm{Rb}$-ions are usually considered not to be integrated into the network structure itself, but to occupy interstices [131], as is the case in alkali-glass silicates (schematically shown in fig.6.4). In these silicates [131, 134], oxygen ions of the alkaline oxide introduce non-bridging bonds into the coordination shell of $\mathrm{Si}$, which form complicated chain-like and sheet-like structures of tetrahedral units with bridging oxygen (BO) and non-bridging oxygen (NBO). One oxygen atom is required for the charge balance and is obtained from the annealing atmosphere via oxygen exchange.

According to the scenario for SPEG in $\alpha$-quartz $[54,59]$ proposed by Roccaforte and collaborators, during the annealing process in the presence of external oxygen, $\mathrm{Rb}$ ions interact with the bridging oxygen (BO) and form non-connected tetrahedral corners, which weaken the Si-O bond of the inter-tetrahedral connections [166]. Evidently, the combination of alkali ions and oxygen opens up the network at the position of the bridging oxygen 
$\mathrm{a}$

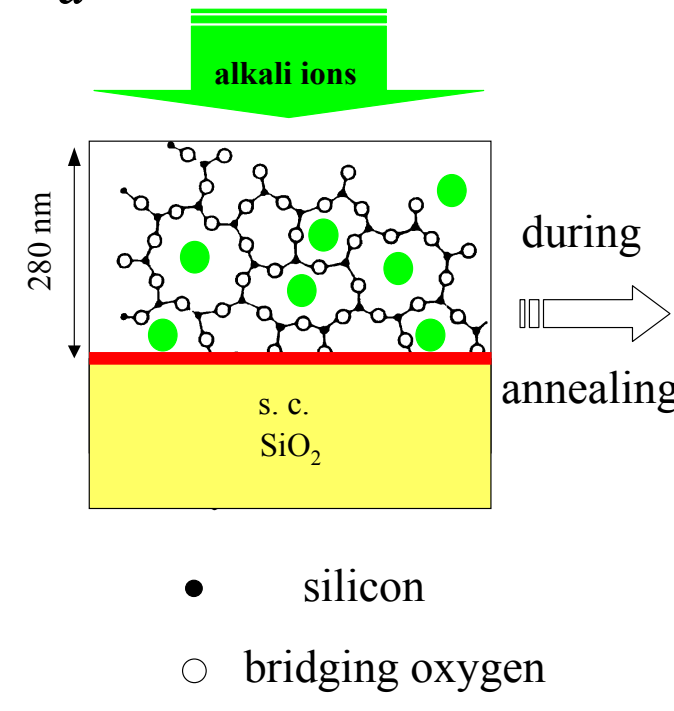

$\mathrm{b}$

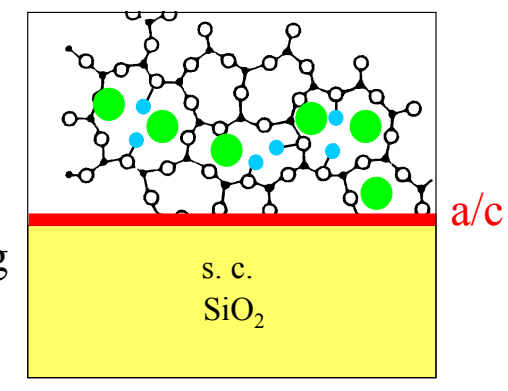

alkali ion

non-bridging oxygen

Figure 6.4: (a) Two-dimensional scheme of the $\mathrm{SiO}_{2}$ network after $\mathrm{Rb}$-implantation, like in the case of an alkali-glass silicate, where the alkali ions occupied the interstices. (b) The formation of the non-connected oxygen tetrahedral corners (non-bridging oxygens) during the annealing treatment.

and, in comparison to the fully connected network, the tetrahedrons can move and reorient much more easily. It is important to note that the non-bridging oxygen atoms have weaker bond strengths with alkali ions (O-Rb and O-Na: $2.65 \mathrm{eV}$; O-Cs: $3.06 \mathrm{eV}$; O-Li: $3.45 \mathrm{eV} \mathrm{[10])} \mathrm{than} \mathrm{with} \mathrm{a} \mathrm{Si} \mathrm{atom} \mathrm{at} \mathrm{the} \mathrm{center} \mathrm{of} \mathrm{the} \mathrm{tetrahedron} \mathrm{(O-Si,} 4.57 \mathrm{eV} \mathrm{[9]).} \mathrm{The}$ more weakly bonded oxygen ions therefore become free more easily under appropriate thermal activation and the oxygen exchange is favoured. This should increase the recrystallizability of the material according to the argumentation of Hobbs et al. [134].

The incorporation of $\mathrm{Rb}$ into the network and its diffusion can be described by the following equation:

$$
\left(O_{3}\right) \equiv S i-O-S i \equiv\left(O_{3}\right)+2 R b+O^{*} \Rightarrow\left(O_{3}\right) \equiv S i-O-R b R b-O^{*}-S i \equiv\left(O_{3}\right)
$$

where $\mathrm{O}^{*}$ represents the external oxygen $\left({ }^{18} \mathrm{O}\right)$.

Subsequently, during annealing the oxygen diffuses into the $\mathrm{Rb}$-implanted $\alpha$-quartz and the implanted $\mathrm{Rb}$ atoms are oxidized and dissolved into the disordered $\mathrm{SiO}_{2}$-network in the form of $\mathrm{Rb}_{2}^{+} \mathrm{O}^{-2}$, i.e. by forming an alkali glass, in which the bridging oxygen (BO) of the fully connected network are replaced by non-bridging oxygen (NBO). Increasing the $\mathrm{Rb}$ fluence increases the number of weak, non-connected tetrahedral corners, thus reducing the average connectivity of the network and enhancing its topological freedom [131]. 


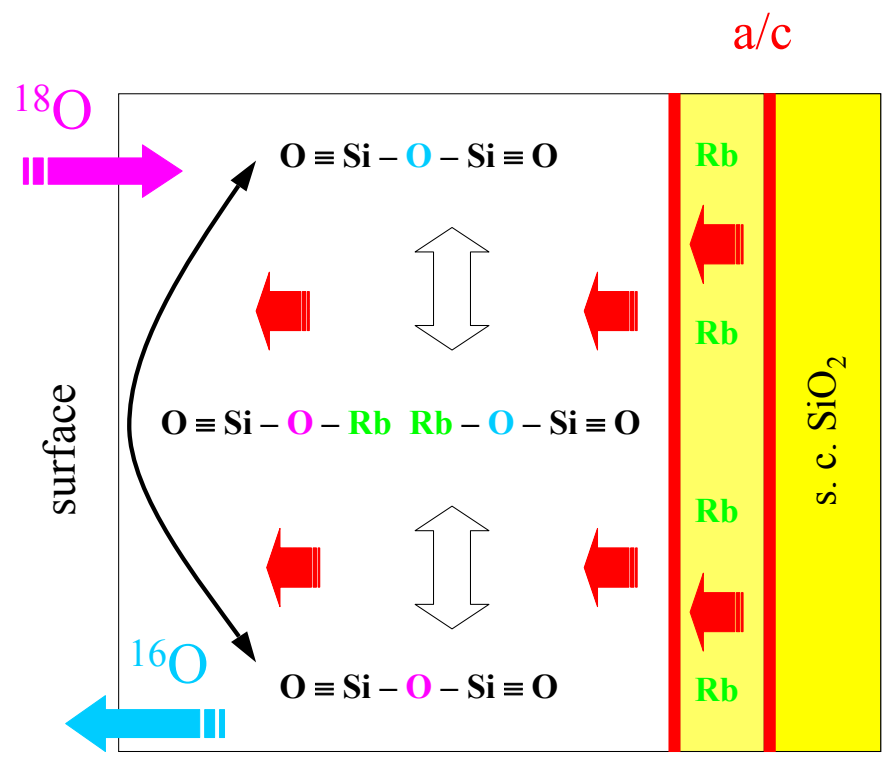

Figure 6.5: Schematically presented correlation between the migration of $\mathrm{Rb}$ and oxygen. The regrowth process took place when the tetrahedra opened up at the a/c interface and they were able to epitaxially align along the energetically more favorable crystalline structure.

As a result, the viscosity of the matrix decreases and the probability of recrystallization increases [44, 97].

In all the alkali-ion irradiated samples subject to annealing in ${ }^{18} \mathrm{O}_{2}$, oxygen in-diffusion and exchange between the matrix and annealing gas indeed confirmed. A strong correlation between the overall out-diffusion of $\mathrm{Rb}$ and ${ }^{18} \mathrm{O}$ migration through the amorphous matrix was found. The enhancement of the oxygen migration manifests itself by the experimentally observed ${ }^{16} \mathrm{O} \Leftrightarrow{ }^{18} \mathrm{O}$ exchange along "preferred diffusion pathways" [147, 148] of the $\mathrm{SiO}_{2}$ matrix, which occurs at the broken inter-tetrahedral linkages. The experimental values of the activation energy for epitaxial regrowth is in all cases much lower than the Si-O bond energy, $4.57 \mathrm{eV}$ [9], again showing that the presence of alkali ions and oxygen has a strong influence on the recrystallization. The correlation between the diffusion of $\mathrm{Rb}$ and the ${ }^{18} \mathrm{O}$ suggests that each oxygen isotope exchange was accompanied by a "jump" of $\mathrm{Rb}$ from one linkage to another. The formation of an alkali-glass silicate (see eq. 5.1) was correlated with the migration process and can be given by:

$\left(O_{3}\right) \equiv S i-O-R b R b-O^{*}-S i \equiv\left(O_{3}\right) \Rightarrow\left(O_{3}\right) \equiv S i-O^{*}-S i \equiv\left(O_{3}\right)+\left(R b_{2}^{+} O^{*-2}\right)_{j u m p}$

During this diffusion process from one non-bridging site to a new bridging site, the recovery of defects takes place. If the topological freedom of the individual tetrahedra at the $\mathrm{a} / \mathrm{c}$ interface has enough flexibility to reorient, then SPEG starts to take place along the energetically more favorable crystalline structure and accelerates with increasing temperature. 
In fact, this starts at around $1070 \mathrm{~K}$ in the case of air annealing and at around $970 \mathrm{~K}$ during ${ }^{18} \mathrm{O}_{2}$ annealing. During the layer-by-layer recrystallization process, $\mathrm{Rb}$ was pushed into the amorphous layer and the $\mathrm{a} / \mathrm{c}$ front moved towards the surface. The complete regrowth took place at $1170 \mathrm{~K}$ (air annealing) or at $1130 \mathrm{~K}\left({ }^{18} \mathrm{O}_{2}\right.$ annealing). Similar behaviour was observed in the samples irradiated at different fluences. Indeed, the regrowth rate increased with increasing implanted fluences. This process is illustrated schematically in fig.6.5.

On the basis of this schematic scenario, the amount of oxygen migration in the Rb implanted amorphous layer during thermal annealing can be estimated from a simple model suggested by Roccaforte et al. [57]. In the case of ${ }^{18} \mathrm{O}_{2}$ annealing, the migration of Rbions and in-diffusion of ${ }^{18} \mathrm{O}$ in the $\mathrm{SiO}_{2}$ layer start at about $773 \mathrm{~K}$. At about $973 \mathrm{~K}$, both $\mathrm{Rb}$ and ${ }^{18} \mathrm{O}$ have migrated to the a/c interface. In this model, it is assumed that each indiffusing oxygen atom, i.e. each isotope exchange, is accompanied by a "jump" of $\mathrm{Rb}$ from one inter-tetrahedral linkage to another. If we consider the average jump distance, $v$, of the $\mathrm{Rb}$ atom as equal to the lattice parameter of $\mathrm{SiO}_{2}$ along the $\mathrm{c}$ axis, i.e. $0.54 \mathrm{~nm}$, the average number of diffusion steps, $\mathrm{N}_{\text {step }}$, can be estimated from the relation:

$$
N_{\text {step }}=\lambda / \mathrm{v}
$$

where $\lambda$ is the diffusion length of the Rb-ion.

At $973 \mathrm{~K}$, the $\mathrm{Rb}$ diffusion front at half maximum has migrated $140 \mathrm{~nm}$ towards the c/a interface and $40 \mathrm{~nm}$ towards the surface, with respect to the initial Gaussian shaped profile. Hence one can calculate an average $\mathrm{Rb}$ migration path of $\lambda=90 \mathrm{~nm}$. Therefore, the number of diffusion steps is then given by $\mathrm{N}_{\text {step }}=\lambda / \nu=166$. Since the isotope exchange of one oxygen atom is accompanied by the movement of two $\mathrm{Rb}$ ions, the total number of oxygen atoms $\mathrm{N}_{o}$ is then given by:

$$
N_{o}=0.5 N_{\text {step }} N_{R b}
$$

where $\mathrm{N}_{R b}$ is the total number of $\mathrm{Rb}$ atoms in the network.

Using the experimental value of the $\mathrm{Rb}$ content in the sample annealed at $973 \mathrm{~K}$ obtained from RBS and ERDA analysis, $\mathrm{N}_{R b}=1 \times 10^{15} \mathrm{Rb} / \mathrm{cm}^{2}$, the total amount of the exchanged oxygen is $82 \times 10^{15}$ atoms $/ \mathrm{cm}^{2}$. This value is quite close to the experimentally integrated ${ }^{18} \mathrm{O}$ content of $84 \times 10^{15}$ atoms $/ \mathrm{cm}^{2}$ obtained from the ERDA analysis.

The interpretation of the results presented here can be summarized as follows:

- Complete epitaxial recrystallization of the $\mathrm{Rb}$ amorphized layers was observed after a 1-h annealing in air (at $1170 \mathrm{~K}$ ) or in an ${ }^{18} \mathrm{O}_{2}$ atmosphere (at $1130 \mathrm{~K}$ ).

- The recrystallization rate in air follows a two-step Arrhenius process with activation energies of $2.7 \pm 0.4 \mathrm{eV}$ and $0.6 \pm 0.2 \mathrm{eV}$ above and below an annealing temperature of $1070 \mathrm{~K}$, respectively. 
- Three processes, namely planar recrystallization of the amorphized $\alpha-\mathrm{SiO}_{2}$ layer, alkali ion out-diffusion, and ${ }^{16} \mathrm{O} \Leftrightarrow{ }^{18} \mathrm{O}$ exchange are highly correlated. This correlation was discussed with the help of the concept of the $\mathrm{SiO}_{2}$ network topology.

- Like in the previously studied cases of $\mathrm{Li}, \mathrm{Na}$, and $\mathrm{Cs}$ [59], the epitaxy in quartz is a consequence of the dissolution of the alkali network modifiers which increase the structural freedom by the formation of non-connected tetrahedron corners.

- The recrystallization rate increased with increasing ion fluence, due to the higher number of non-bridging oxygens (reduced network connectivity). 


\section{Outlook}

Due to the importance of $\mathrm{SiO}_{2}$ as an optoelectronic or photonic material, numerous studies have been undertaken to construct light-emitting devices by doping $\mathrm{SiO}_{2}$ with semiconductor and metal elements using various processing techniques [172, 173, 174, 175, $176,177]$. The optically active centers inside the insulating crystalline matrix $\left(\alpha-\mathrm{SiO}_{2}\right)$ offer interesting and promising technological applications in the design of optical devices. Both amorphous and crystalline $\mathrm{SiO}_{2}$ show only weak intrinsic luminescence in the visible range. The implantation and annealing conditions indeed strongly influence the intensity and spectral shape of the luminescent light output.

\subsection{Epitaxy after alkali ion implantation}

In the present investigation of $\mathrm{Na}$ - and $\mathrm{Rb}$-ion induced damage and recrystallization of $\alpha$-quartz, the dependence of the epitaxy on the ion fluence and the parameters of the annealing gas (type: air or ${ }^{18} \mathrm{O}_{2}$, temperature, time) was studied in detail. Full or partial epitaxy of the matrix was achieved under properly chosen implantation and annealing conditions. With respect to the results of previous studies after $\mathrm{Li}, \mathrm{Na}$ or $\mathrm{Cs}$ implantation $[58,59,106]$ some of the similarities and differences can be summarized as follows:

1) After irradiation, a continuous amorphous layer grew, which decreased in thickness by a planar movement of the $\mathbf{a} / \mathbf{c}$ interface to the surface during epitaxy. The AFM measurements gave evidence of a swelling of the $\mathrm{SiO}_{2}$ matrix during implantation and recompaction during epitaxy.

2) Epitaxial recrystallization occurs above a critical temperature, ion fluence, and probably oxygen pressure. The critical temperature for achieving full SPEG decreases for increasing alkali fluence and with decreasing alkali mass. The recrystallization rate increased with increasing alkali concentration and temperature; however it depends also weakly on the ${ }^{18} \mathrm{O}_{2}$ pressure.

3) Two main conditions must be fulfilled in order to achieve full epitaxy: the presence of alkali ions and oxygen. A minimum amount of alkali and oxygen concentration is required to achieve complete recovery of the amorphous layer. The epitaxy 


\begin{tabular}{ccccccccc}
\hline Type & $\begin{array}{c}\text { Energy } \\
(\mathrm{keV})\end{array}$ & $\begin{array}{c}\text { Fluence } \\
\left(10^{16} / \mathrm{cm}^{2}\right)\end{array}$ & $\begin{array}{c}\text { Anneal. } \\
\mathrm{Gas}\end{array}$ & $\begin{array}{c}\mathrm{T}_{1 / 2} \\
(\mathrm{~K})\end{array}$ & $\begin{array}{c}\mathrm{T}_{x} \\
(\mathrm{~K})\end{array}$ & $\begin{array}{c}\mathrm{E}_{a x} \\
(\mathrm{eV})\end{array}$ & $\begin{array}{c}\mathrm{E}_{a} \\
(\mathrm{eV})\end{array}$ & Ref. \\
\hline $\mathrm{H}$ & 20 & 5 & air & $820(50)$ & $-{ }^{1}$ & - & $0.86(13)$ & {$[59]$} \\
\hline $\mathrm{Li}$ & 15 & 2.5 & ${ }^{18} \mathrm{O}_{2}$ & $880(60)$ & $970^{2}$ & - & $0.45(09)$ & {$[59]$} \\
\hline $\mathrm{Na}$ & 50 & 2.5 & air & - & $1070^{2}$ & - & - & {$[106]$} \\
\hline $\mathrm{Na}$ & 50 & 5 & air & - & $1020^{2}$ & - & - & {$[59]$} \\
\hline $\mathrm{Na}$ & 50 & 2.5 & ${ }^{18} \mathrm{O}_{2}$ & $830(50)$ & 970 & - & - & \\
\hline $\mathrm{Na}$ & 50 & 5 & ${ }^{18} \mathrm{O}_{2}$ & $830(50)$ & 1020 & - & - & \\
\hline $\mathrm{Rb}$ & 175 & 2.5 & air & $1130(60)$ & 1170 & $0.6(2), 2.7(4)$ & $1.5(3)$ & \\
\hline $\mathrm{Rb}$ & 175 & 2.5 & ${ }^{18} \mathrm{O}_{2}$ & $870(45)$ & 1130 & $1.3(2)$ & $0.7(1)$ & \\
\hline $\mathrm{Cs}$ & 250 & 2.5 & air & $1065(50)$ & 1150 & $2.8(2)$ & $0.98(01)$ & {$[59]$} \\
\hline
\end{tabular}

Table 7.1: Processing parameters of chemically guided SPEG in quartz after alkali-ion implantation, where $T_{1 / 2}$ is the critical temperature, at which one half of the initial alkali content diffused out of the sample; $\mathrm{T}_{x}$ is the temperature at which complete SPEG was achieved; $\mathrm{E}_{a x}$ denotes activation energy of the recrystallization, and $\mathrm{E}_{a}$ the activation energy of the out-diffusion of the implanted species.

${ }^{1}$ No epitaxy, ${ }^{2}$ No complete epitaxy.

is thought to be a consequence of the dissolution of alkali-oxide (network modifiers), which increases the structural freedom of the network due to the formation of non-connected $\left[\mathrm{SiO}_{4}\right]$-tetrahedron corners, stabilized by nearby alkali ions. The observed correlation between the migration of alkali ions and oxygen is used to explain the rearrangement process of the $\mathrm{SiO}_{2}$ network.

4) Concerning the quality of the epitaxially grown layer, $\mathrm{Na}$ and $\mathrm{Rb}$ implantation turned out to be as profitable as Cs implantation, and definitely much better than Li or hydrogen implantation, for which partial or no epitaxy at all were found [59].

5) For the typical fluence of $2.5 \times 10^{16} / \mathrm{cm}^{2}$, full epitaxy was achieved at similar temperatures in air: $1070 \mathrm{~K}$ (Na, but no complete SPEG), $1170 \mathrm{~K}(\mathrm{Rb})$, and $1150 \mathrm{~K}$ (Cs). The corresponding temperatures after ${ }^{18} \mathrm{O}_{2}$ annealing were $970 \mathrm{~K}(\mathrm{Na})$ and $1130 \mathrm{~K}(\mathrm{Rb})$. For details see table 7.1. Evidently, after ${ }^{18} \mathrm{O}_{2}$ annealing the induced damage recovers at a lower temperature than in air annealing experiments.

6) After Rb-implantation, we observed a two-step epitaxy (Arrhenius-type) in air and a single-step epitaxy in an ${ }^{18} \mathrm{O}_{2}$ atmosphere. For air-annealed samples, below 1070 $\mathrm{K}$ the deduced activation energy was $E_{a x}^{L}=0.6 \pm 0.2 \mathrm{eV}$. Above $1070 \mathrm{~K}$, it was $E_{a x}^{H}$ $=2.7 \pm 0.4 \mathrm{eV}$. The regrowth rate in ${ }^{18} \mathrm{O}_{2}$ could be fitted with a single exponent, having an activation energy of $E_{a x}^{H}=1.3 \pm 0.2 \mathrm{eV}$. In the case of Cs implantation, the recrystallization speed was parametrized by a single activation energy of $2.8 \pm 0.2$ 
$\mathrm{eV}$ [59], which was very close to the high-temperature value after Rb implantation in air.

7) Another similarity occurs for the out-diffusion of the alkali ions from the matrix to its surface. As shown in table 7.1, the typical temperature at which half of the implanted alkali ion content has left the quartz samples extends from $820 \mathrm{~K}$ for hydrogen $\left(\Phi=5 \times 10^{16} \mathrm{H}\right.$-ions $\left./ \mathrm{cm}^{2}\right)$ [59] to $1130 \mathrm{~K}$ for Rb, and $1065 \mathrm{~K}$ for Cs [59], (air annealing). In the case of ${ }^{18} \mathrm{O}_{2}$ annealing, the corresponding temperatures are $\mathrm{Li}-880 \mathrm{~K}$ [59], $\mathrm{Na}-830 \mathrm{~K}$, and $\mathrm{Rb}-870 \mathrm{~K}$. It thus appears that out-diffusion is less dependent on the ion mass than on the annealing atmosphere.

8) For the first time, the surface topography of the samples before irradiation and during the complete process of chemically guided epitaxy was examined. These results nicely complement the results obtained via RBS-C analysis. However, the interpretation of surface structures requires further study.

9) The results of the present investigation are an important step towards achieving epitaxial regrowth of quartz after ion implantation, as shown in our recent luminescence studies on quartz irradiated with $\mathrm{Ba}$ and $\mathrm{Ge}$ ions $[51,178]$.

\subsection{Cathodoluminescence after $\mathrm{Rb}$ ion irradiation}

The cathodoluminescence (CL) measurements allow a better explanation of the changes in the quantity and quality of the lattice defects and impurity elements after amorphization and during the recrystallization process. Based on our recent results concerning the generation of luminescence after $\mathrm{Ba}$ and Ge-implantation $[51,178]$, the CL study was also applied to investigate the optical properties of the $\mathrm{Rb}$ damaged and recrystallized $\alpha$ quartz.

The typical room-temperature CL spectra of $\mathrm{Rb}$ implanted samples $\left(2.5 \times 10^{16} \mathrm{Rb} / \mathrm{cm}^{2}\right)$ taken as a function of the annealing temperature along with the spectra taken from a pure single-crystal (virgin) quartz and from an as-implanted sample recorded in the wavelength range (200 - $700 \mathrm{~nm}$ ) are presented in fig.7.1. Figure 7.1 (a) illustrates CL results obtained after air annealing; in fig.7.1 (b) the results after ${ }^{18} \mathrm{O}_{2}$ annealing are displayed.

Evidently, the CL spectra exhibited dramatic changes in the optical spectra that depend on the annealing atmosphere. The spectra (fig.7.1) were de-convoluted with Gaussianshaped subpeaks corresponding to different emission bands. The integrated intensities of the prominent bands are plotted as a function of the annealing temperature in figs.7.2 (a) and (b), after air and ${ }^{18} \mathrm{O}_{2}$ treatment respectively. The virgin sample shows a broad peak at $620 \mathrm{~nm}$ and $510 \mathrm{~nm}$, corresponding to the red $(2.0 \mathrm{eV}, \mathrm{R}-\mathrm{red})$ and the green band $(2.4 \mathrm{eV}$, $\mathrm{G}$ - green), respectively. It is commonly believed that the red peak is associated with either non-bridging oxygen-hole centers (NBOHC, $\equiv \mathrm{Si}-\mathrm{O} \cdot)$, three-coordinated silicon with 


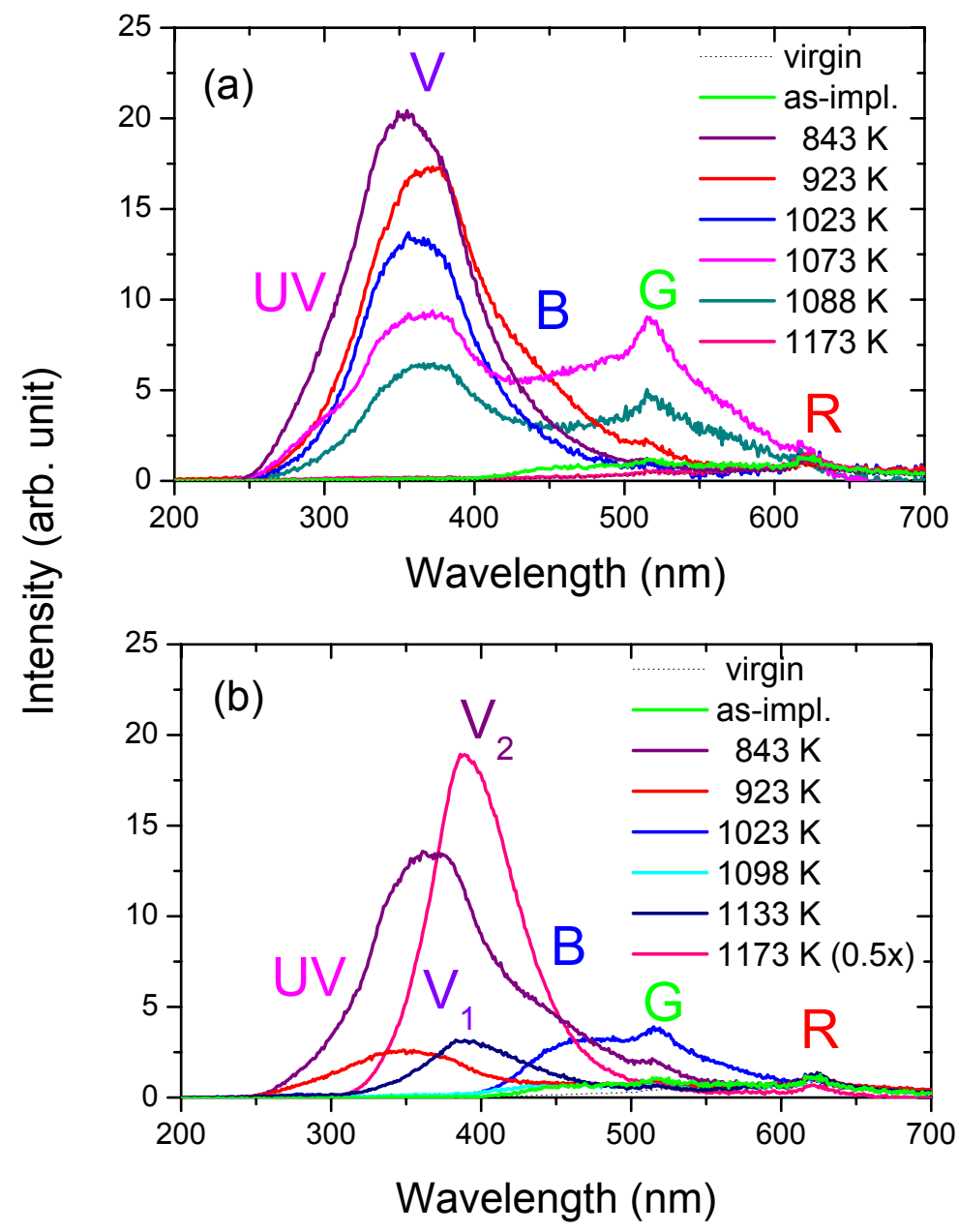

Figure 7.1: Room temperature cathodoluminescence spectra taken before and after $\mathrm{Rb}$ implantation at a fluence of $2.5 \times 10^{16} \mathrm{Rb} / \mathrm{cm}^{2}$ and annealed at different temperatures for $1 \mathrm{~h}$ in air (a) or ${ }^{18} \mathrm{O}_{2}$ (b) atmosphere.

a trapped electron ( $\equiv \mathrm{Si} \cdot)$ or with other associated precursors $[13,18,169,170]$. Figure 7.2 (a) also clearly shows that the intensity of this peak is insensitive to the presence of $\mathrm{Rb}$ ions and to the annealing temperature. The green peak at $2.4 \mathrm{eV}$ may be connected to oxygen vacancy-interstitial pairs $\left(\mathrm{V}_{o} ;\left(\mathrm{O}_{2} \mathrm{C}\right) \mathrm{i}\right)[18,26]$, or may be due to irradiationinduced self-trapped excitons (STE) within the $\alpha-\mathrm{SiO}_{2}$ outgrowth at the top of the quartz crystal containing a large amount of peroxy linkages (三Si-O-O-Si $\equiv$ ) [13]. After Rb implantation and annealing in air or in an ${ }^{18} \mathrm{O}_{2}$ atmosphere at various temperatures up to $1173 \mathrm{~K}$, besides those two peaks (red and green) the CL spectra exhibit more prominent peaks at $290 \mathrm{~nm}(4.3 \mathrm{eV}, \mathrm{UV}) ; 360 \mathrm{~nm}\left(3.4 \mathrm{eV}\right.$, violet $\left.-\mathrm{V}_{1}\right), 380 \mathrm{~nm}\left(3.25 \mathrm{eV}\right.$, violet $-\mathrm{V}_{2}$, only after ${ }^{18} \mathrm{O}_{2}$ annealing), and $445 \mathrm{~nm}(2.8 \mathrm{eV}$, blue - B). As shown in fig.7.2 (a) all these 


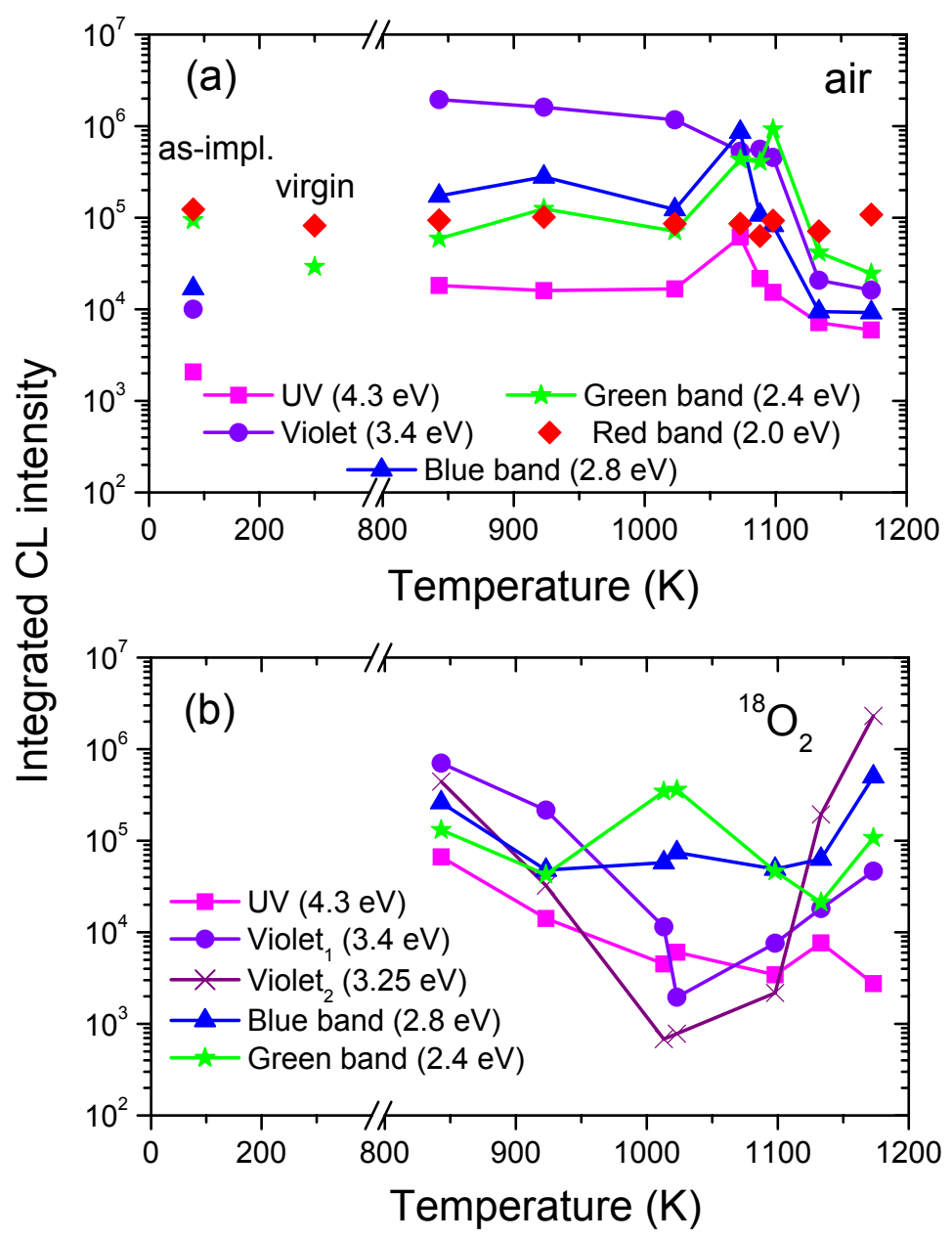

Figure 7.2: Temperature dependence of the integrated intensities of the extracted subpeaks for air (a) and ${ }^{18} \mathrm{O}_{2}$ (b) experiments. CL temperature $=300 \mathrm{~K}$.

peaks, except the $\mathrm{V}_{2}$ one, were also observed in the as-implanted sample. The blue and UV peaks are associated with oxygen deficiency centers (ODC, $\equiv \mathrm{Si}-\mathrm{Si} \equiv$ ) or with their precursors produced during ion-irradiation $[13,18,169,170]$. The violet peak $\left(\mathrm{V}_{2}\right)$ at $380 \mathrm{~nm}(3.25 \mathrm{eV})$ can be connected to the alkali-(or hydrogen) compensated $\left[\mathrm{Al}^{3+} / \mathrm{M}^{+}\right]$ (where $\mathrm{M}^{+}=\mathrm{H}^{+}$or alkali ion) center [31] or associated with impurities incorporated during growth [171]. Furthermore, a violet peak $\left(\mathrm{V}_{1}\right)$ observed at $360 \mathrm{~nm}(3.4 \mathrm{eV})$ can probably be attributed to $\mathrm{Rb}$-related defect luminescence. The results are summarized in tab.7.2.

The cathodoluminescence spectra are highly correlated with the structural transformations of the matrix during chemically induced epitaxy. This correlation provides the possibility to distinguish between various color centers related to either quartz, ion-beam amophized 


\begin{tabular}{cccc}
\hline $\begin{array}{c}\text { CL band } \\
(\mathrm{eV})\end{array}$ & $\begin{array}{c}\text { Wavelength } \\
(\mathrm{nm})\end{array}$ & Identification & Ref. \\
\hline $2.00 \pm 0.02$ & 620, red & NBOHC center, $\equiv$ Si $\cdot$ & {$[13,18,169,170]$} \\
\hline $2.40 \pm 0.03$ & 510, green & oxygen vacancy interstitial pairs, STE & {$[13,18,26]$} \\
\hline $2.80 \pm 0.04$ & 455, blue & ODC center & {$[13,18,169,170]$} \\
\hline $3.25 \pm 0.05$ & 380, violet-1 & alkali compensated $\left[\mathrm{Al}^{3+} / \mathrm{M}^{+}\right]$center & {$[31]$} \\
\hline $3.40 \pm 0.04$ & 360, violet- 2 & Rb related defect center & \\
\hline $4.30 \pm 0.03$ & $290, \mathrm{UV}$ & ODC center & {$[13,18,169,170]$} \\
\hline
\end{tabular}

Table 7.2: The cathodoluminescence emission bands observed at RT after Rb-ion irradiated $\alpha$-quartz (80 - $1173 \mathrm{~K}$ ).

silica or the implanted Rb-ions themselves.

For the samples annealed in air atmosphere, the transition from the damaged region (recrystallization started at $1070 \mathrm{~K}$ ) to the recovered one (complete SPEG at $1170 \mathrm{~K}$ ) was accompanied by a strong increase in the various bands in the CL spectra (see fig.7.2 (a)). The intensity variation of the green band was similar to that of the blue and UV one. The violet band $\left(\mathrm{V}_{1}\right)$ at $360 \mathrm{~nm}$ decreased in intensity with increasing annealing temperature. Probably, this is due to out-diffusion of $\mathrm{Rb}$ ions after thermal annealing. This fact suggests that $\mathrm{V}_{1}$ can be associated with Rb-related defects in the $\mathrm{SiO}_{2}$ network.

A completely different behaviour of the intensity variation of the bands was found after ${ }^{18} \mathrm{O}_{2}$ annealing. Only the green peak followed the dependence observed in air-annealed samples. In the case of the violets bands $\mathrm{V}_{1}$ and $\mathrm{V}_{2}$, whose intensity during the transformation process $(920-1130 \mathrm{~K})$ showed opposite effects as compared to air experiments, at first, the intensity of the $\mathrm{V}_{1}$ and $\mathrm{V}_{2}$ bands decreased and then increased with annealing temperature. The UV peak subsequently decreased with increasing temperature. The blue peak intensity seemed to be almost insensitive to the temperature during the transition process. This result suggests some interaction of the defects with a dissociated or mobile oxygen tracer $\left({ }^{18} \mathrm{O}\right)$.

The results presented here constitute the successful attempt to combine the chemically guided epitaxy of quartz after $\mathrm{Rb}$ ion irradiation and the luminescence study.

Future detailed CL studies of alkali implanted $\alpha$-quartz should help to answer some of the fundamental questions concerning the origin and thermal behaviour of luminescence centers in $\mathrm{SiO}_{2}$. Also further investigations are required, especially with regard to TEM measurements, in order to understand the luminescence mechanisms and the local environment of the implanted species.

The successful doping of $\alpha$-quartz via dynamic Ba ion implantation [51] should also work for other elements and should open up new possibilities to produce photoactive layers of quartz containing very small semiconductor, rare-earth or metal clusters and nanostructures. Their properties appear to be exciting for both fundamental studies and photonic applications. On the other hand, the double implantation (alkali ions plus $\mathrm{Ba}$ and $\mathrm{Ge}$ 
ions) should be applied in order to achieve complete epitaxy for larger $\mathrm{Ba}$, Ge ions fluences $[51,178]$.

\subsection{Laser-induced epitaxy}

Another possibility to achieve the recovery of the damage induced during ion-beam irradiation can be the application of a high-power pulsed laser (nanosecond order) [179]. The phase transformation behaviour of quartz under laser-induced shock compression of very short duration is an issue of considerable interest for two reasons. Firstly, the destruction of samples is reduced (which makes their recovery easier). Secondly, a progressive decrease in pressure with increasing distance from the irradiated surface allows for the effects of a range of shock pressures at each pulse. 


\section{Bibliography}

[1] Th. Demuth, Y. Jeanvoine, J. Hafner, and J. G. Ángyán, J. Phys. Condens. Matter 11, 3833 (1999).

[2] V. Dmitriev, V. Torgashev, P. Tolédano, and E. K. Salje, Europhys. Lett., 37, 553 (1997).

[3] C. S. Marians and L. W. Hobbs, J. Non-Cryst. Solids 124, 242 (1990).

[4] L. W. Hobbs, C. E. Jesurum, V. Pulim, and B. Berger, Phil. Mag. A, 78, 679 (1998).

[5] G. E. Walrafen and A. G. Revesz (ed.), Structure and Bonding in Noncrystalline Solids (Plenum Press, New York and London, 1986).

[6] L. Douillard, F. Jollet, J. P. Duraud, R. A. B. Devine, and E. Dooryhee, Radiation Effects and Defects in Solids 124, 351 (1992).

[7] A. E. Goresy, L. Dubrovinsky, T. G. Sharp, S. K. Saxena, and M. Chen, Science, 288, 1632 (2000).

[8] F. Harbsmeier and W. Bolse, J. Appl. Phys. 83, 4049 (1998).

[9] M. Lamkin, F. Riley, and R. Fordham, J. Eur. Ceram. Soc. 10, 347 (1992).

[10] CRC Handbook of Chemistry and Physics, ed by David R. Lide (CRC Press, Boca Raton, New York, 1997-1998).

[11] X. D. Fan, J. L. Peng, and L. A. Bursill, Modern Phys. Lett. B 12, 541 (1998).

[12] J. P. Duraud, F. Jollet, Y. Langevin, and E. Dooryhee, Nucl. Instr. and Meth. B 32, 248 (1988).

[13] M. A. Stevens-Kalceff and M. R. Philips, Phys. Rev. B 52, 3122 (1995).

[14] P. Kofstad, High Temperature Corrosion (Elsevier, London and New York, 1988).

[15] E. P. O’Reilly and J. Robertson, Phys. Rev. B 27, 3780 (1983).

[16] S. Dannefaer, T. Bretagnon, and D. Kerr, J. Appl. Phys. 74, 884 (1993). 
[17] D. L. Griscom, Phys. Rev. B 22, 4192 (1980).

[18] M. A. Stevens-Kalceff, Phys. Rev. Lett. 84, 3137 (2000).

[19] Z. Y. Lu, C. J. Nicklaw, D. M. Fleetwood, R. D. Schrimpf, and S. T. Pantelides, Phys. Rev. Lett. 89, 285505-1 (2002).

[20] J. Song, L. R. Corrales, G. Kresse, and H. Jonsson, Phys. Rev. B 64, 134102-1 (2001).

[21] T. Uchino, M. Takahashi, and T. Yoko, Phys. Rev. Lett. 86, 5522 (2001).

[22] A. H. Edwards and W. B. Fowler, Phys. Rev. B 26, 6649 (1982).

[23] S. Dannefaer, T. Bretagnon, and D. Craigen, J. Appl. Phys. 86, 190 (1999).

[24] M. A. Stevens Kalceff, G. J. Thorogood, and K. T. Short, J. Appl. Phys. 86, 205 (1999).

[25] H. Koyama, J. Appl. Phys. 51, 2228 (1980).

[26] M. Yoshikawa, K. Matsuda, Y. Yamaguchi, T. Matsunobe, Y. Nagasawa, H. Fujino, and T. Yamane, J. Appl. Phys. 92, 7153 (2002).

[27] M. G. Jani, L. E. Halliburton, and E. E. Kohnke, J. Appl. Phys. 54, 6321 (1983).

[28] D. L. Griscom, M. E. Gingerich, and E. J. Friebele, Phys. Rev. Lett. 71, 1019 (1993).

[29] K. Awazu and H. Kawazoe, J. Non-Cryst. Solids 179, 214 (1994).

[30] C. Fiori and R. A. B. Devine, Phys. Rev. Lett. 52, 2081 (1984).

[31] J. Götze and W. Zimmerle, Quartz and silica as guide to provenance in sediments and sedimentary rocks, Contribution to Sedimentary Geology, 21 (E. Schweizerbart'sche Verlagsbuchhandlung, Nägele u. Obermiller, Stuttgart 2000).

[32] D. L. Griscom, Phys. Rev. B 40, 4224 (1989).

[33] D. L. Griscom, J. Non-Cryst. Solids 73, 51 (1985).

[34] F. J. Feigl, W. B. Fowler, and K. L. Yip, Solid State Commun. 14, 225 (1974).

[35] K. L. Yip and W. B. Fowler, Phys. Rev. B 11, 2327 (1975).

[36] D. L. Griscom and F. Friebele, Phys. Rev. B 34, 7524 (1986).

[37] G. W. Arnold and P. Mazzoldi, in Ion Beam Modification of Insulators ed. by P. Mazzoldi and G. W. Arnold (Elsevier, Amsterdam, 1987), p. 195.

[38] M. Toulemonde, E. Balanzat, S. Bouffard, J. J. Grob, M. Hage-Ali, and J. P. Stoquert, Nucl. Instr. and Meth. B 46, 64 (1990). 
[39] R. G. Macaulay-Newcombe, D. A. Thompson, J. A. Davies, and D. V. Stevanovic, Nucl. Instr. and Meth. B 46, 180 (1990).

[40] L. Douillard and J. P. Duraud, J. Phys. III (France) 6, 1677 (1996).

[41] W. Bolse, Nucl. Instr. and Meth. B 141, 133 (1998).

[42] W. Bolse, Nucl. Instr. and Meth. B 148, 83 (1999).

[43] F. Piao, W. G. Oldham, and E. E. Haller, J. Non-Cryst. Solids 276, 61 (2000).

[44] K. P. Lieb, in "Encyclopedia of Nanoscience and Nanotechnology", N. Malva, in press.

[45] H. Fischer, G. Götz, and H. Karge, phys. stat. sol.(a) 76, 249 (1983).

[46] H. Fischer, G. Götz, and H. Karge, phys. stat. sol.(a) 76, 493 (1983).

[47] G. Devaud, C. Hayzelden, M. J. Aziz, and D. Turnbull, J. Non-Cryst. Solids 134, 129 (1991).

[48] G. W. Arnold and P. S. Peercy, J. Non-Cryst. Solids 41, 359 (1980).

[49] F. Harbsmeier, W. Bolse, M. R. da Silva, M. F. da Silva, and J. C. Soares, Nucl. Instr. and Meth. B 136/138, 263 (1998)

[50] S. Dhar, W. Bolse, and K. P. Lieb, J. Appl. Phys. 85, 3120 (1999).

[51] S. Dhar, S. Ga̧siorek, P. K. Sahoo, V. N. Kulkarni, and K. P. Lieb, J. Appl. Phys., submitted.

[52] F. Roccaforte, W. Bolse, and K. P. Lieb, Appl. Phys. Lett. 73, 1349 (1998).

[53] F. Roccaforte, W. Bolse, and K. P. Lieb, Appl. Phys. Lett. 74, 1922 (1999).

[54] F. Roccaforte, S. Dhar, F. Harbsmeier, and K. P. Lieb, Appl. Phys. Lett. 75, 2903 (1999).

[55] F. Roccaforte, W. Bolse, and K. P. Lieb, Nucl. Instr. and Meth. B 148, 692 (1999).

[56] F. Roccaforte, M. Gustafsson, W. Bolse, J. Keinonen, and K. P. Lieb, Nucl. Instr. and Meth. B 166/167, 148 (2000).

[57] F. Roccaforte, F. Harbsmeier, S. Dhar, and K. P. Lieb, Appl. Phys. Lett. 76, 3709 (2000).

[58] M. Gustafsson, F. Roccaforte, J. Keinonen, W. Bolse, L. Ziegler, and K. P. Lieb, Phys. Rev. B 61, 3327 (2000).

[59] F. Roccaforte, W. Bolse, and K. P. Lieb, J. Appl. Phys. 89, 3611 (2001). 
[60] F. Roccaforte, F. Harbsmeier, S. Dhar, and K. P. Lieb, Nucl. Instr. and Meth. B 178, 237 (2001)

[61] L. Royer, Bull. Soc. Fr. Mineralog. Cristallogr. 51, 7 (1928).

[62] M. Gebhardt, Epitaxy, in: Crystal Growth: an Introduction, ed. by P. Hartman (North-Holland, Amsterdam 1973).

[63] M. A. Hermann, W. Richter, and H. Sitter, Epitaxy Physical Foundation and Technical Implementation, Materials Science 62 (Springer 2003).

[64] G. L. Olson and J. A. Roth, Mat. Sci. Rep. 3, 1 (1988).

[65] G. L. Olson and J. A. Roth, Solid Phase Epitaxy, in Handbook of Crystal Growth, vol. 3, chap.7, ed. by D. T. J. Hurle (Elsevier Science B. V. 1994).

[66] A. Lietoila, A. Wakita, T. W. Sigmon, and J. F. Gibbons, J. Appl. Phys. 53, 4399 (1982).

[67] P. J. Chandler, F. L. Lama, P. D. Townsend, and L. Zhang, Appl. Phys. Lett. 53, 89 (1988).

[68] P. J. Chandler, L. Zhang, and P. D. Townsend, Nucl. Instr. and Meth. B 46, 69 (1990).

[69] P. D. Townsend, Nucl. Instr. and Meth. B 65, 243 (1992).

[70] W. L. Gong, L. M. Wang, and R. C. Ewing, J. Appl. Phys. 84, 4204 (1998).

[71] Y. Ikuta, K. Kajihara, M. Hirano, S. Kikugawa, and H. Hosono, Appl. Phys. Lett. 80, 3916 (2002).

[72] K. Kajihara, L. Skuja, M. Hirano, and H. Hosono, Phys. Rev. Lett. 89, 135507-1 (2002).

[73] K. Kajihara, Y. Ikuta, M. Hirano, and H. Hosono, Appl. Phys. Lett. 81, 3164 (2002).

[74] J. Kushibiki, M. Ohtagawa, and I. Takanaga, J. Appl. Phys. 94, 295 (2003).

[75] M. Uhrmacher, K. Pampus, F. J. Bergmeister, D. Purschke, and K. P. Lieb, Nucl. Instr. and Meth. B 9, 234 (1985).

[76] F. Harbsmeier, Diploma thesis, Universität Göttingen, Germany, (1996).

[77] M. Schwieckert, Diploma thesis, Universität Göttingen, Germany, (1998).

[78] J. F. Ziegler, J. P. Biersack, and U. Littmark, in: The Stopping and Range of Ions in Solids, Vol. 1 (Pergamon Press, New York, 1985).

[79] W. -K. Chu, J. W. Mayer, and M. -A. Nicolet, Backscattering Spectrometry (Academic Press, Orlando, 1978). 
[80] J. R. Tesmer and M. Nastasi (ed.), Handbook of Modern Ion Beam Materials Analysis, Materials Research Society (Pittsburgh USA, 1995).

[81] J. F. Ziegler, Helium Stopping Powers and Ranges in All Elemental Matter (Pergamon Press, New York, 1977).

[82] W. H. Bragg and R. Kleeman, Philo. Mag. 10, 318 (1905).

[83] K. P. Lieb, Contemporary Physics 40, 385 (1999).

[84] N. Bohr, Mat. Fys. Medd. Dan. Vid. Selsk. 18, 8 (1948).

[85] L. R. Doolittle, Nucl. Instr. and Meth. B 15, 227 (1986).

[86] J. Conrad, Ph. D. thesis, Universität Göttingen, (1996).

[87] R. S. Walker and D. A. Thompson, Nucl. Instr. and Meth. B 135, 489 (1976).

[88] J. Jokinen, J. Keinonen, P. Tikkanen, A. Kuronen, T. Ahlgren, and K. Nordlund, Nucl. Instr. and Meth. B 119, 533 (1996).

[89] D. R. Vij (ed.), Luminescence of Solids (Plenum Press, New York and London, 1998).

[90] A. S. Marfunin, Advanced Mineralogy, Vol.2 - Methods and instrumentations: Results and recent developments (Springer, Berlin Heidelberg New York, 1995).

[91] A. Szymański, Mineralogia techniczna (Wydawnictwo Naukowe PWN, Warszawa 1997).

[92] M. R. Krbetschek, J. Götze, A. Dietrich, and T. Trautmann, Spectral information from minerals relevant for luminescence dating, Radiat. Meas. 27/5, 6, (1997).

[93] G. Binnig, C. Quate, and C. Gerber, Phys. Rev. Lett. 56, 930 (1986).

[94] D. C. Jacobson, J. M. Poate, and G. L. Olson, Appl. Phys. Lett. 48, 118 (1986).

[95] E. Nygren, M. J. Aziz, D. Turnbull, J. M. Poate, D. C. Jacobson, and R. Hull, Appl. Phys. Lett. 47, 105 (1985).

[96] V. J. Fratello, J. F. Hays, F. Spaepen, and D. Turnbull, J. Appl. Phys. 51, 6160 (1980).

[97] S. X. Wang, L. M. Wang, R. C. Erwing, and R. H. Doremus, J. Non-Cryst. Solids 238, 198 (1998).

[98] V. J. Fratello, J. F. Hays, and D. Turnbull, J. Appl. Phys. 51, 4718 (1980).

[99] E. Nygren, M. J. Aziz, and D. Turnbull, Appl. Phys. Lett. 47, 232 (1985).

[100] T. Fuss, C. S. Ray, N. Kitamura, M. Makihara, and D. E. Day, J. Non-Cryst. Solids 318, 157 (2003). 
[101] Ch. Meade, R. J. Hemley, and H. K. Mao, Phys. Rev. Lett. 69, 1387, (1992).

[102] R. Kirchheim, J. Non-Cryst. Solids 55, 243 (1983).

[103] G. W. Arnold, G. Battaglin, A. Boscolo-Boscoletto, F. Caccavale, G. De Marchi, P. Mazzoldi, and A. Miotello, Nucl. Instr. and Meth. B 65, 387 (1992).

[104] B. J. Fishbein and J. D. Plummer, Appl. Phys. Lett. 50, 1200 (1987).

[105] S. Dhar, S. Ga̧siorek, M. Lang, K. P. Lieb, J. Keinonen, and T. Sajavaara, Surf. and Coat. Technol., 158-159(C), 436 (2002).

[106] F. Roccaforte, doctoral thesis, Universität Göttingen, (1999).

[107] S. J. Rothmann, T. L. M. Marcuso, L. J. Nowicki, P. M. Baldo, and A. W. McCormick, J. Am. Ceram. Soc., 65, 578 (1982).

[108] O. L. Anderson and D. A. Stuart, J. Am. Ceram. Soc., 37, 573 (1954).

[109] G. H. Frischat, Phys. Chem. Glasses 11, 25 (1970).

[110] G. H. Frischat, Glastech. Ber. 43, 174 (1970).

[111] G. H. Frischat, in Amorphous Material, R. W. Douglas and B. Ellis (eds.) (WileyInterscience, London, New York, Sydney, 1972), p. 235.

[112] G. H. Frischat, Phys. Chem. Glasses 25, 110 (1984).

[113] S. H. Garofalini and S. Conover, J. Non-Cryst. Solids 74, 171 (1985).

[114] H. A. Schaeffer, J. Non-Cryst. Solids 38-39, 545 (1980).

[115] G. Battaglin, G. W. Arnold, G. Mattei, P. Mazzoldi, J. C. Dran, J. Appl. Phys. 85, 8040 (1999).

[116] D. R. Hamann, Phys. Rev. Lett. 81, 3447 (1998).

[117] J. R. Chelikowsky, Phys. Rev. B 64, R2251 (2000).

[118] M. I. Heggie, R. Jones, C. D. Latham, S. C. P. Maynard, and P. Tole, Phil. Mag. B 65, 463 (1992).

[119] W. Bolse, J. Conrad, F. Harbsmeier, M. Borowski, and T. Roedle, Mater. Sci. Forum 248/249, 319 (1997).

[120] M. Meier, V. Braetsch, and G. H. Frischat, J. Am. Ceram. Soc., 73, 2122 (1990).

[121] U. Schoo, C. Cramer, and H. Mehrer, Solid State Ionics 138, 105 (2000).

[122] L. Rybach and F. Laves, Geoch. et Cosmochim. Acta, 31, 539 (1967).

[123] C. Kaps, J. Solids State Phys., 65, 189 (1984). 
[124] I. Heinemann and G. H. Frischat, J. Am. Ceram. Soc., 73, 3712 (1990).

[125] H. Cabane, D. Laporte, and A. Provost, Contrib. Mineral. Petrol. 142, 361 (2001).

[126] C. Bonafos, B. Colomneau, A. Altibelli, M. Carrada, G. Ben Assayag, B. Garrido, M. López, A. Pérez-Rodríguez, J. R. Morante, and A. Claverie, Nucl. Instr. and Meth. B 178, 17 (2001).

[127] L. W. Hobbs, J. Non-Cryst. Solids 192/193, 79 (1995).

[128] W. H. Zachariasen, J. Am. Ceram. Soc. 54, 3841 (1932).

[129] A. R. Cooper, J. Non-Cryst. Solids 49, 1 (1982).

[130] B. E. Warren, J. Am. Ceram. Soc. 24, 256 (1941).

[131] P. K. Gupta and A. R. Cooper, J. Non-Cryst. Solids 123, 14 (1990).

[132] D. C. Koningsberger, R. Prins (Ed.), X-Ray Absorption: Principles, Applications and Techniques of EXAFS, SEXAFS and XANES (New York, 1988).

[133] C. E. Jesurum, V. Pulim, and L. W. Hobbs, Nucl. Instr. and Meth. B 141, 25 (1998).

[134] L. W. Hobbs, Nucl. Instr. and Meth. B 91, 30 (1994).

[135] L. W. Hobbs, A. N. Sreeram, C. E. Jesurum and B. A. Berger, Nucl. Instr. and Meth. B 116, 18 (1996).

[136] R. C. Ewing, Nucl. Instr. and Meth. B 91, 22 (1994).

[137] F. F. Morehead, Jr. and B. L. Crowder, Radiat. Eff. 6, 27 (1970).

[138] R. K. Eby, R. C. Ewing, R. C. Birtcher, J. Mater. Res. 7, 3080 (1992).

[139] J. K. N. Linder, R. Zuschlag, E. H. te Kaat, Nucl. Instr. and Meth. B 62, 314 (1992).

[140] D. F. Mullica, H. O. Perkins, D. A. Grossie, L. A. Boatner, B. C. Sales, J. Solid State Chem. 62, 371 (1986).

[141] S. J. Zinkle, Nucl. Instr. and Meth. B 91, 234 (1994).

[142] J. Rankin, L. W. Hobbs, L. A. Boatner, and C. W. White, Nucl. Instr. and Meth. B 32, 28 (1988).

[143] A. R. Cooper, Phys. Chem. Glasses 19, 60 (1978).

[144] H. Scholze and N. J. Kreidl, in Glass: Science and Technology, Vol. 3 Technological Aspects of Viscosity, ed. by D. R. Uhlmann and N. J. Kreidl (Academic Press, New York, 1986), p. 233.

[145] Ch. Huang and A. N. Cormak, J. Chem. Phys. 93, 8180 (1990). 
[146] H. Rawson, in Materials Science and Technology - A Comprehensive Treatment, Vol. 9 Glass Formation in Oxide Systems, J. Zarzycki (Vol. ed.); ed. by R. W. Cahn, P. Haasen, E. J. Kramer (Weinheim, Wiley-VCH, 1991), p.280.

[147] M. D. Ingram, Phys. Chem. Glasses 28, 215 (1987).

[148] M. D. Ingram, Phil. Mag. B 60, 739 (1989).

[149] D. E. Day, J. Non-Cryst. Solids 21, 343 (1976).

[150] W. Beier and G. H. Frischat, J. Non-Cryst. Solids 73, 113 (1985).

[151] P. Jund and R. Jullien, Phil. Mag. A 79, 223 (1999).

[152] P. Jund, W. Kob, and R. Jullien, Phys. Rev. B 64, 134303 (2001).

[153] H. Jain, Phys. Stat. Sol. A 80, K15 (1983).

[154] N. G. Stenina, L. Sh. Bazarov, M. Ya. Shcherbakova, and R. I. Mashkovtsev, Phys. Chem. Min. 10, 180 (1984).

[155] K. B. Hitt and J. J. Martin, J. Appl. Phys. 54, 5030 (1983).

[156] G. N. Greaves, J. Non-Cryst. Solids 71, 203 (1985).

[157] G. N. Greaves, Miner. Mag. 64, 441 (2000).

[158] P. Maass, A. Bunde, and M. D. Ingram, Phys. Rev. Lett. 68, 3064 (1992).

[159] J. Horbach and W. Kob, Phil. Mag. B 79, 1981 (1999).

[160] J. Horbach, W. Kob, and K. Binder, Chem. Geol. 174, 87 (2001).

[161] J. Horbach, W. Kob, and K. Binder, Phys. Rev. Lett. 88, 125502 (2002).

[162] M. Uhrmacher and K. P. Lieb, Nucl. Instr. and Meth. B 68, 175 (1992).

[163] V. Milman, M. C. Payne, V. Heine, R. J. Needs, J. S. Lin, and M. H. Lee, Phys. Rev. Lett. 70, 2928 (1993).

[164] J. Oviedo and J. F. Sanz, Phys. Rev. B 58, 9047, (1998).

[165] M. Schwickert, K. P. Lieb, W. Bolse, M. Gustafsson, and J. Keinonen, Nucl. Instr. and Meth. B 147, 238 (1999).

[166] S. M. Allen, E. L. Thomas, The structure of materials (Wiley, Boston, 1999).

[167] R. B. Iverson and R. Reif, J. Appl. Phys. 62, 1675 (1987).

[168] J. -F. Poggemann, G. Heide, and G. H. Frischat, J. Non-Cryst. Solids 326/327, 15 (2003). 
[169] H. S. Bae, T. G. Kim, C. N. Whang, S. Im, J. S. Yun, and J. H. Song, J. Appl. Phys. 91, 4078 (2002).

[170] L. Skuja, B. Güttler, D. Schiel, and A. R. Silin, Phys. Rev. B 58, 14296 (1998).

[171] B. J. Luff and P. D. Townsend, J. Phys.: Condens. Matter 2, 8089 (1990).

[172] H. Hosono, J. Non-Cryst. Solids 187, 457 (1995).

[173] L. Rebohle, J. Von Borany, R. A. Yankov, W. Skorupa, I. E. Tyschenko, H. Förb, and K. Leo, Appl. Phys. Lett. 71, 2809 (1997).

[174] Y. Q. Wang, G. L. Kong, W. D. Chen, H. W. Diao, C. Y. Chen, S. B. Zhang, and X. B. Liao, Appl. Phys. Lett. 81, 4174 (2002).

[175] L. Rebohle, J. Von Borany, W. Skorupa, H. Förb, and S. Niedermeier, Appl. Phys. Lett. 77, 969 (2000).

[176] A. V. Kabashin and M. Meunier, Appl. Phys. Lett. 82, 1619 (2003).

[177] H. Yang, X. Wang, H. Shi, S. Xie, F. Wang, X. Gu, and X. Yao, Appl. Phys. Lett. 81,5144 (2002).

[178] P. K. Sahoo, S. Dhar, S. Ga̧siorek, and K. P. Lieb, Nucl. Instr. and Meth. B in press.

[179] T. de Resseguier, P. Berterretche, M. Hallouin, and J. P. Petitet, J. Appl. Phys. 94, 2123 (2003). 



\section{Acknowledgements}

Beim meinem Doktorvater, Herrn Prof. Dr. Klaus Peter Lieb, möchte ich mich an dieser Stelle ganz besonders für die Möglichkeit bedanken, in Göttingen meine Doktorarbeit anfertigen zu dürfen. Ohne seine kompetenten Betreung der Arbeit und seine ständige Bereitschaft für die zahlreichen, fruchtbaren Diskussionen wäre diese Arbeit in der vorliegenden Form nicht entstanden.

I am deeply grateful to Prof. Jan Styczen for giving me the possibility to work in the IFJ and the opportunity to study in Göttingen. I thank him for this continuous interest and encouragement.

I would like to offer my sincere thanks to Dr. Sankar Dhar, who introduced me to RBS and experimental work, for the numerous discussions about the results and his continuous suggestions to support this topic.

Dr. Bogusław Rajchel help and support during my stay at the IFJ are gratefully acknowledged.

I am very grateful to Timo Sajavaara and Prof. Juhani Keinonen from the University of Helsinki for carrying out the TOF-ERDA and AFM measurements, the fruitful collaboration and the discussions about the recrystallization, and the nice time I spent in Helsinki.

Prof. Hans Hofsäss und Uli Vetter bin ich in besonderem Masse zu Dank verpflichtet für dem unkomplizierten Zugang zur CL Anlage.

Bei Herrn Dr. Lüder Ziegler bedanke ich mich für die Vorbereitung der ${ }^{18} \mathrm{O}_{2}$-Ampullen und für die vielen netten Gespräche zwischendurch.

Herrn Uwe Ronsöhr ist für das Blasen der Quarz-Ampullen zu danken.

Mein grosser Dank geht an Marius Hausmann für seine Einführung und seine ständige Hilfsbereitschaft beim Praktikum/PC ("meine 5 Min"), für die Lösung meiner zahlreichen kleinen und grossen Probleme, wenn die wieder sofort erledigt werden mussten:) und für alle sprachlichen Korrekturen:). Was wäre das Leben ohne "Kinder Überraschungen" gewesen?:)

Frau Kulinska:) danke ich dafür, dass die mir während der gesamten Promotionszeit immer mit Rat zur Seite stand. 
I address my special thanks to the members of my "Kraków-group: wysoko wykwalifikowanej kadry": Kasi Mitury and Adama Adamskiego for their pleasant cooperation in the experimental work and for the excellent atmosphere within the group.

I thank Alexander Müller und Velia Milinović for the relaxed atmosphere during our "Wednesday-activities".

Helge Kröger danke ich für die zahlreichen Gefallen!

I am in debed to Pratap Sahoo for introducing me to the CL and very fruitful discussions.

Bei Emily Hooker und Lucie Hamdi möchte ich mich sehr herzlich bedanken für das genaue und schnelle Durchlesen dieser Arbeit.

Detlef Purschke und Andreas König gilt grosser Dank für das "Fahren" des IONAS und die angenehme Atmosphäre bei vielen Stunden Strahlzeit.

Andreas danke ich für "Stasieńka", zahlreiche Gespräche und moralische Unterstützung und Aufmeksamkeit.

I am grateful to all former members of the "Diplomandenzimmer": Kun Zhang, Ratnesh Gupta, Meng Han, and other colleagues for creating the friendly relationship and positive atmosphere for scientific work.

Ich bedanke mich sehr herzlich bei Frau Wohlfahrt, für ihre unermündliche und unkomplizierte Hilfe.

Den Werkstätten danke ich für die jederzeit schnelle Umsetzung meiner Wünsche in die Realität.

Allen Mitgliedern der AG-Lieb, Kern und Festkörperphysikern, und allen Mitarbeitern am II. Physikalischen Institut an dieser Stelle ein grosses Dankeschön für die freundliche Aufnahme, das tolle und offene Arbeitsklima und die netten Ablenkungen des Alltags (z.B. Erholungspausen am Kicker).

Allen meinen Freunden, insbesondere Renata, Magda, Agnieszka, Ania und Peter, Joanna, Jan, danke ich für ihre Unterstützung in guten und schlechten Zeiten und für die vielen schönen Erinnerungen.

An letzter aber an wichtigster Stelle möchte ich meinen Eltern, Michał, Czesław, Agatka und Dominiczka danken für die vielfältige und umfassende Unterstüzung während meiner Promotionszeit. 


\section{Lebenslauf}

\section{Persönliche Daten}

Name: Stanisława Ga̧siorek

Geburtsdatum: 2. Mai 1973

Geburtsort: Krakau, Polen

Nationalität: polnisch

Familienstand: ledig

\section{Ausbildung}

1980 - 1988 Grundschule Bȩbło/Polen

1988 - 1992 Gymnasium "Jan III Sobieski" in Krakau

1992 - 1997 Studium in der Fakultät für Stoffingenieurwesen und Keramik an der Stanisław

Staszic Akademie für Bergbau- und Hüttenwesen, Krakau, Polen

1998 - 2004 Promotionsstudium am H. Niewodniczański Institut für Kernphysik in Krakau/Polen

2000 - 2004 Promotionsstudium am II. Physikalischen Institut der Universität Göttingen

\section{Tätigkeiten}

1997 - 1998 Wissenschaftliche Mitarbeiterin am H. Niewodniczański Institut für Kernphysik in Krakau/Polen

2000 - 2004 Wissenschaftliche Mitarbeiterin am II. Physikalischen Institut der Universität Göttingen

\section{Auszeichnungen}

1995 und 1996 Auszeichnungen des Rektors der Akademie für Bergbau- und Hüttenwesen für sehr gute Studienleistungen

1996 Zusätzliches Studienstipendium aufgrund sehr guter Leistungen

1997 Stanisław Staszic Preis für herausragende Studienleistungen als beste Studentin der Fakultät 